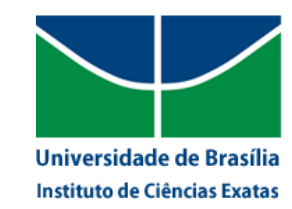

\author{
UNIVERSIDADE DE BRASÍLIA \\ Instituto DE Ciências Exatas \\ Departamento de Matemática
}

Grupos com restrições em classes de conjugação verbal

por

Agenor Freitas de Andrade 


\section{Grupos com restrições em classes de conjugação verbal}

por

\section{Agenor Freitas de Andrade}

Tese apresentada ao Programa de Pós-Graduação do Departamento de Matemática da Universidade de Brasília, como requisito parcial para obtenção do título de Doutor em Matemática.

Área de concentração: Álgebra.

Orientador: Prof. Dr. Pavel Shumyatsky 


\section{Agenor Freitas de Andrade}

Grupos com restrições em classes de conjugação verbal

Tese defendida no Programa de Pós-Graduação do Departamento de Matemática da Universidade de Brasília como requisito parcial para obtenção do título de Doutor em Matemática, aprovada em 07 de Julho de 2016, pela Banca Examinadora constituída pelos professores:

Prof. Dr. Pavel Shumyatsky

Universidade de Brasília - UnB

Presidente da Banca

Profa. Dr. ${ }^{a}$ Cristina Acciarri

Universidade de Brasília - UnB

Prof. Dr. ${ }^{\circ}$ Ricardo Nunes de Oliveira

Universidade Federal de Goiás - UFG

Prof. Dr. ${ }^{\circ}$ Norai Romeu Rocco

Universidade de Brasília - UnB

Prof. Dr. ${ }^{\circ}$ Jhone Caldeira Silva

Universidade Federal de Goiás - UFG 
Todos os direitos reservados. É proibida a reprodução total ou parcial do trabalho sem autorização da universidade, do autor e do orientador.

Agenor Freitas de Andrade 


\section{Dedicatória}

Para Jê, Aninha, Carol e Dudu. 


\section{Agradecimentos}

Agradeço a Deus, por me permitir mais esta conquista e por me conduzir todos os dias.

À minha esposa Jeisa Fernandes Marcondes, pelo carinho, amor, companheirismo, pelos filhos, por acreditar em mim, por se sacrificar em prol de minha realização pessoal e profissional, enfim, por abrir mão de toda uma vida e me acompanhar neste louco sonho, que finalmente está se realizando. Jê, sem você e seu apoio eu não teria conseguido. Te amo.

Aos meus filhos, Ana Júlia, Maria Carolina e Eduardo, vocês são a minha razão de existir, o meu viver. Tudo que faço é para ou por vocês. O simples fato de existirem me motiva a levantar todos os dias e buscar o melhor para nossa família.

Aos meus pais, Eduardo e Wanderly, obrigado por toda uma vida de carinho e amor; pela excelente criação que tive - graças aos esforços contínuos de vocês dois nunca me faltou nada, muito pelo contrário. Hoje reconheço com muito valor todo o esforço que tiveram que fazer para poderem me proporcionar o estudo e conforto que vocês não tiveram ou que tiveram que abrir mão por minha causa. Obrigado também pela compreensão na distância em que nos separa e, por todo o apoio em minha jornada, desde o momento em que mudei de Cuiabá para Goiânia e de lá para Luziânia. Não há palavras que servem de agradecimento por tudo que fizeram nesta vida por mim. Obrigado, eu amo vocês.

Ao meu irmão Duh, obrigado pelo carinho e pela atenção que sempre teve comigo e, principalmente com meus filhos.

Ao professor Pavel Shumyatsky, meus sinceros agradecimentos. Não apenas por suas orientações, não só por acreditar em mim, nem apenas pelas sugestões ou muito menos pelo enorme aprendizado que me proporcionou. Obrigado principalmente pela dedicação e enorme empenho, pelo profissionalismo e pela maneira como direcionou as orientações, que tive durante todo o curso de doutorado, e por esta tese. Obrigado por se dispor a me recepcionar e a resolver os problemas que este desafio impõe. São poucos, realmente muito poucos, os que possuem tanta capacidade e disponibilidade para, não só orientar, mas principalmente conduzir uma tese (e seu orientando) com tanta maestria, como você o faz. Muito obrigado. 
Ao meu amigo Tannery Postal (in memoriam) pela nossa eterna amizade. Sinto sua falta cara.

Ao professor Ricardo Nunes de Oliveira, meu orientador de mestrado e, quem me ajudou abrir as portas para o doutorado.

Aos meus amigos Adriano, Alex Teló, Bruno, Caíke, Danilo Sanção Douglas, Emerson e ao meu compadre Benedito Leandro Neto, obrigado pelas ajudas durante o doutorado (mestrado também, para vários de vocês), discussões sobre listas de exercícios, dicas em provas, pelas risadas e conversas inúteis no banco em frente ao departamento e, principalmente pelos churrascos e cervejas que já tomamos juntos.

Ao meu amigo Silvio, que me acompanha nesta jornada desde 2004 na UFMT, onde superamos juntos, a graduação, a casa do Estudante na UFG, o mestrado, o concurso para o Instituto Federal de Goiás e, agora por fim o doutorado. Obrigado pelas dicas tanto no estudo quanto no trabalho, pelas diversas horas de estudo e discussão. Seu apoio foi muito importante.

Aos meus amigos de Cuiabá (a Galera do BH), amigos que fiz durante a vida, amizade sincera que nasceu na infância, ainda com peladas e trucos com tereré e que perdurará (creio eu) durante toda minha vida. Eu não poderia deixar de me lembrar de vocês nesse momento especial: Eduardo Cabeça, Eduardo Valderrama, Du Barba, Henrique, João Vitor, Luh Perri, Otávio Valderrama Jr, Paulinho e Pedro Perri.

Aos meus amigos desde o tempo de graduação na UFMT em 2004, amigos que ainda guardo no peito e possuo o prazer de reencontrar, ainda que por breves momentos Fabrício, Marquinhos e Wilson Gaúcho.

À família de minha esposa: Bibi, Bruna, Cleonice, João Francisco, Joelson e Tio Sandro, obrigado pela vida e criação com muito amor e carinho que proporcionaram à Jeisa e que proporcionam aos meus filhos.

Aos colegas de departamento Alex Paraíba, Cleilton, Enio, Keidna, Lais, Otto, Raimundo e Yerko, obrigado pelas inúmeras ajudas.

Aos professores José Carlos Barros Silva e Oneida Cristina Gomes Barcelos Irigon, obrigado pela amizade e, principalmente por me ajudarem no processo de licença para poder realizar este doutorado.

Aos professores e amigos de IFG, Gesiel, João Guilherme, Thiago Bolseiro e Ulisses, obrigado pelas caronas e por podermos conversar e passar o tempo, compartilhando perspectivas, sonhos e esperanças de sucesso durante nossa (longa) jornada de Luziânia à Brasília-UnB.

À todos os demais colegas, professores e servidores administrativos do MAT/UnB que de alguma forma contribuíram para este trabalho, obrigado.

À FAPEG/CAPES pelo suporte financeiro. 


\section{Epígrafe}

"...ela demonstrou tanto prazer

de estar em minha companhia que eu experimentei uma sensação que até então não conhecia de ser querer bem de se querer quem se tem e ela me faz tão bem ela me faz tão bem que eu também quero fazer isso por ela..." (Tão Bem. Lulu Santos)

"Best remain silent and be thought a fool, that open your mouth and remove the doubt". (Abraham Lincoln)

"Uma razão por que a matemática goza de especial estima sobre todas as demais ciências, é que suas leis são absolutamente certas e indiscutíveis, enquanto que as das outras são, até certo ponto, debatíveis e com o perigo constante de serem derrotadas por fatos recém descobertos". 


\section{Resumo}

de Andrade, Agenor Freitas. Grupos com restrições em classes de conjugação verbal. Brasília, 2016. 80p. Tese de Doutorado. Departamento de Matemática, Universidade de Brasília.

O presente trabalho contém dois resultados principais. O primeiro trata da seguinte situação. Dada uma palavra $w$ e um grupo $G$, denotaremos por $G_{w}$ o conjunto de todos os $w$-valores em $G$ e por $w(G)$ o correspondente subgrupo verbal. Mostraremos que se $w=\gamma_{n}$ ou $w=\delta_{n}$ e se $G$ for um grupo tal que para todo $g \in G$ exista um número finito de subgrupos de Chernikov $C_{1}, \ldots, C_{k}$ tais que $g^{G_{w}} \subseteq \bigcup_{i=1}^{k} C_{i}$, então o subgrupo $\left\langle g^{w(G)}\right\rangle$ é de Chernikov.

O segundo resultado principal desta tese aborda o conceito de comutadores coprimos generalizados introduzido por Shumyatsky em [37]. Sobre esse assunto consideraremos a seguinte situação. Suponha que $G$ seja um grupo finito e $X$ o conjunto de todos os $\gamma_{n}^{*}$-comutadores ou $\delta_{n}^{*}$-comutadores em $G$. Mostraremos que se $\left|g^{X}\right| \leq m$ para todo $g \in G$, então a ordem do $n$-ésimo termo da série inferior de Fitting de $G$ é $(m, n)$-limitada.

\section{Palavras-chave}

classes de conjugação; comutadores coprimos; grupos de Chernikov; residual nilpotente; subgrupos verbais 


\section{Abstract}

de Andrade, Agenor Freitas. Groups with restrictions in verbal conjugacy classes. Brasília, 2016. 80p. PhD. Thesis. Departamento de Matemática, Universidade de Brasília.

This work has two main results. The first concerns the following situation. Given a word $w$ and a group $G$, we denote by $G_{w}$ the set of all $w$-values in $G$ and by $w(G)$ the corresponding verbal subgroup. We show that if $w=\gamma_{n}$ or $w=\delta_{n}$ and $G$ is a group in which for every $g \in G$ there exist finitely many Chernikov subgroups $C_{1}, \ldots, C_{k}$ such that $g^{G_{w}} \subseteq \bigcup_{i=1}^{k} C_{i}$, then the subgroup $\left\langle g^{w(G)}\right\rangle$ is Chernikov.

The second main result of this thesis addresses the concept of generalized coprime commutators introduced by Shumyatsky in [37]. Suppose that $G$ is finite group and $X$ is either the set of all $\gamma_{n}^{*}$-commutators or the set of all $\delta_{n}^{*}$-commutators in $G$. We show that if $\left|g^{X}\right| \leq m$ for all $g \in G$, then the order of the $n$th term of the lower Fitting series of $G$ is $(m, n)$-bounded.

\section{Keywords}

Chernikov groups; conjugacy classes; coprime commutators; nilpotent residual; verbal subgroups 


\section{Lista de símbolos}

$G, H, X, Y, \ldots \quad$ grupos, conjuntos, etc

$k, l, m, n, \ldots \quad$ inteiros positivos

$\pi$

um conjunto de números primos

$x, y, g, h, \ldots \quad$ elementos de um grupo/conjunto

1

$x^{y}$

$x^{G}$

$X^{G}$

w

elemento identidade de um grupo ou o grupo trivial $\{1\}$

$y^{-1} x y$

classe de conjugação de $x$ em $G$

$\left\{x^{g} ; x \in X, g \in G\right\}$

palavra de grupo

$G_{w}$

$x^{G_{w}}$

$[x, y]$

conjunto dos $w$-valores de $G$

classe de conjugação verbal de $x$ em $G$

$\left[x_{1}, \ldots, x_{n}\right]$

$x^{-1} y^{-1} x y$

$[g, \alpha]$

$\left[\left[x_{1}, \ldots, x_{n-1}\right], x_{n}\right]$

$H \leq G$

$g^{-1} g^{\alpha}, \alpha$ um automorfismo de $G$

$H<G$

$H$ é um subgrupo de $G$

$H \unlhd G$

$H$ é um subgrupo próprio de $G$

$\langle X\rangle$

$H$ é um subgrupo normal de $G$

$\left\langle X_{\lambda} ; \lambda \in \Lambda\right\rangle$

subgrupo gerado pelo subconjunto $X$

$|x|$

subgrupo gerado pelos subconjuntos $X_{\lambda}$

$|X|$

$|G: H|$

ordem do elemento $x$

ordem (cardinalidade) do conjunto $X$

$Z(G)$

índice de $H$ em $G$

$C_{G}(x)$

o centro de um grupo $G$

$C_{G}(H)$

centralizador do elemento $x$ em $G$

$N_{G}(H)$

centralizador de $H$ em $G$

$\left\langle X^{G}\right\rangle$

normalizador de $H$ em $G$

$[H, K]$

fecho normal de $X$ em $G$

$\left[H,{ }_{n} K\right]$

subgrupo comutador

$[[H, \underbrace{K, \ldots, K}_{n-1}], K]$ 


$\begin{array}{ll}G^{\prime}=[G, G] & \text { subgrupo derivado de } G \\ {[G, \alpha]} & \langle[g, \alpha] ; g \in G\rangle \\ \text { Aut }(G) & \text { grupo dos automorfismos de } G \\ w(G) & \text { subgrupo verbal associado à } w \text { em } G \\ \gamma_{n}(G) & n \text {-ésimo termo da série central inferior de } G \\ \gamma_{\infty}(G) & \text { o residual nilpotente de um grupo } G \\ G^{(n)} & n \text {-ésimo subgrupo derivado de } G \\ Z_{\alpha}(G) & \alpha \text {-ésimo centro de } G \\ Z_{\infty}(G) & \text { hipercentro de } G \\ F_{i}(G) & i \text {-ésimo termo da série superior de Fitting } \\ D_{i}(G) & i \text {-ésimo termo da série inferior de Fitting } \\ G^{0} & \text { parte radicável de um grupo de Chernikov } \\ \text { tam }(G) & \text { tamanho de um grupo de Chernikov } \\ \operatorname{Res}_{f}(G) & \text { residual finito de } G \\ C_{p^{\infty}} & \text { o } p \text {-grupo quase-cíclico (Prüfer), } p \text { primo } \\ O_{\pi}(G) & \pi \text {-subgrupo normal maximal de } G \\ \delta_{k}^{*}(G) & \text { subgrupo gerado pelos } \delta_{k}^{*} \text {-comutadores de } G \\ \gamma_{k}^{*}(G) & \text { subgrupo gerado pelos } \gamma_{k}^{*} \text {-comutadores de } G\end{array}$




\section{Sumário}

$\begin{array}{ll}\text { Epígrafe } & 7\end{array}$

$\begin{array}{ll}\text { Lista de símbolos } & \mathbf{1 0}\end{array}$

$\begin{array}{ll}\text { Introdução } & 13\end{array}$

1 Preliminares $\quad \mathbf{1 8}$

1.0.1 Subgrupos de Hall 23

1.1 Subgrupos verbais 23

1.2 Grupos localmente finitos 25

$\begin{array}{ll}1.3 & \text { Coberturas para grupos } \\ 1.4 & 27\end{array}$

$\begin{array}{lll}1.4 & \text { FC-grupos } & 28\end{array}$

1.4.1 $\mathrm{FC}(w)$-grupos 29

1.5 Grupos hipercentrais 31

1.6 Grupos de Chernikov 32

1.6.1 Grupos de automorfismos de grupos de Chernikov 40

2 Um critério para um subgrupo normal ser de Chernikov 43

2.1 Resultados obtidos 43

2.2 A prova do Teorema 2.3

3 Grupos com classes de conjugação verbal limitadas $\quad 48$

3.1 Resultados obtidos 48

3.2 Resultados auxiliares 49

3.3 A prova do Teorema $3.2 \quad 51$

3.3.1 O caso $w=\delta_{n} \quad 51$

$\begin{array}{lll}\text { 3.3.2 } \mathrm{O} \text { caso } w=\gamma_{n} & 57\end{array}$

4 Limitando a ordem do residual nilpotente de um grupo finito $\quad \mathbf{6 0}$

4.1 Comutadores coprimos em grupos finitos 60

4.2 Resultados obtidos 63

4.3 A prova da Proposição $4.18 \quad 65$

$\begin{array}{lll}\text { 4.4 A prova da Proposição } 4.16 & 71\end{array}$

4.5 A prova dos Teoremas 4.20 e $4.21 \quad 73$

$\begin{array}{ll}\text { Referências Bibliográficas } & \mathbf{7 6}\end{array}$

$\begin{array}{ll}\text { Índice Remissivo } & 79\end{array}$ 


\section{Introdução}

Sejam $X, Y$ subconjuntos de um grupo $G$. Denotaremos por $X^{Y}$ o conjunto $\left\{x^{y} ; x \in X, y \in Y\right\}$, onde $x^{y}=y^{-1} x y$ é chamado o conjugado de $x$ por $y$. No caso onde $X=\{x\}$, denotaremos $X^{Y}$ por $x^{Y}$. Se $x \in G$ o conjunto $x^{G}$ é chamado a classe de conjugação de $x$ em $G$.

Um grupo $G$ é chamado um $F C$-grupo se $g^{G}$ for finito para todo $g \in G$. Além disso, $G$ é chamado um BFC-grupo se $g^{G}$ for finito para todo $g \in G$ e se o número de elementos em $g^{G}$ for limitado por uma constante que não dependa da escolha do elemento $g \in G$.

Uma palavra de grupo, ou simplesmente uma palavra é um elemento não trivial do grupo livre $F=F(X)$ onde $X$ é um conjunto de geradores livres $\left\{x_{1}, x_{2}, \ldots\right\}$.

Dada uma palavra $w=w\left(x_{1}, \ldots, x_{s}\right)$, um elemento $h$ de um grupo $G$ é chamado um $w$-valor se existirem $g_{1}, \ldots, g_{s} \in G$ tais que $h=w\left(g_{1}, \ldots, g_{s}\right)$. Denotaremos por $G_{w}$ o conjunto de todos os $w$-valores de $G$ e por $w(G)$ o subgrupo gerado por $G_{w}$, chamado o subgrupo verbal associado à palavra $w$. Para cada $x \in G$ o conjunto $x^{G_{w}}$ chama-se de a classe de conjugação verbal de $x$ em $G$.

Em [11] Franciosi, de Giovanni e Shumyatsky introduziram uma generalização 'verbal' de FC-grupos. Mais precisamente, consideraram a seguinte situação. Dada uma palavra $w$, um grupo $G$ é dito um $F C(w)$-grupo se $x^{G_{w}}$ for finito para todo $x \in G$. Posteriormente Brazil, Krasilnikov e Shumyatsky introduziram em [5] a noção de $\operatorname{BFC}(w)$-grupos. Um grupo $G$ é chamado um $B F C(w)$-grupo se $x^{G_{w}}$ for finito para todo $x \in G$ e se o número de elementos em $x^{G_{w}}$ for limitado por uma constante que não dependa da escolha do elemento $x$.

Um subgrupo $H$ de um grupo $G$ é dito $F C$-imerso em $G$ se $x^{H}$ for finito para todo $x \in G$ e $H$ é dito $B F C$-imerso em $G$ se o número de elementos em $x^{H}$ for limitado por uma constante que não dependa da escolha do elemento $x$. O principal resultado de [11], caracteriza os $\mathrm{FC}(w)$-grupos em termos do subgrupo verbal, desde que a palavra $w$ seja concisa.

Teorema 1.33 [[11], Teorema A.] Sejam w uma palavra concisa e G um FC(w)grupo. Então o subgrupo verbal w $(G)$ é $F C$-imerso em $G$. 
Recorde que uma palavra $w$ é dita concisa se sempre que o conjunto dos $w$ valores for finito para um grupo $G$ então isso acarrete a finitude do subgrupo verbal $w(G)$.

Tendo em vista os resultados anteriores, Muñoz-Escolano e Shumyatsky em [24] consideraram a seguinte questão. Dada uma palavra concisa $w$ e um grupo $G$, assuma que para todo $x \in G$ o subgrupo $\left\langle x^{G_{w}}\right\rangle$ satisfaça à determinada condição de finitude. É verdade que uma condição similar é também satisfeita por $\left\langle x^{w(G)}\right\rangle$ para todo $x \in G$ ?

O comutador de dois elementos de $x$ e $y$ é definido da seguinte maneira $x^{-1} y^{-1} x y$ e será denotado por $[x, y]$. Lembremos que dados um grupo livre $F=F(X)$ e um inteiro positivo $k$, a $k$-ésima palavra central inferior é definida indutivamente da seguinte forma.

$$
\gamma_{1}\left(x_{1}\right)=x_{1}, \quad \gamma_{k}\left(x_{1}, \ldots, x_{k}\right)=\left[\gamma_{k-1}\left(x_{1}, \ldots, x_{k-1}\right), x_{k}\right]
$$

onde $x_{i} \in X$ para todo $i$.

Já a $k$-ésima palavra derivada $\delta_{k}$, é definida indutivamente, da seguinte forma:

$$
\delta_{0}\left(x_{1}\right)=x_{1}, \quad \delta_{k}\left(x_{1}, \ldots, x_{2^{k}}\right)=\left[\delta_{k-1}\left(x_{1}, \ldots, x_{2^{k-1}}\right), \delta_{k-1}\left(x_{2^{k-1}+1}, \ldots, x_{2^{k}}\right)\right],
$$

onde $x_{i} \in X$ para todo $i$. Os subgrupos verbais de um grupo $G$ associados às palavras $\gamma_{k}$ e $\delta_{k}$ serão denotados respectivamente por $\gamma_{k}(G)$ e $G^{(k)}$.

O principal resultado apresentado em [24] foi o seguinte teorema.

Teorema 3.1 [[24], Teorema 1.1] Sejam $n$ um inteiro positivo e w a n-ésima palavra central inferior $\gamma_{n}$ ou a n-ésima palavra derivada $\boldsymbol{\delta}_{n}$. Suponha que $G$ seja um grupo tal que $\left\langle g^{G_{w}}\right\rangle$ seja de Chernikov para todo $g \in G$. Então $\left\langle g^{w(G)}\right\rangle$ é de Chernikov para todo $g \in G$.

Recorde que um grupo $G$ é dito de Chernikov se possuir um subgrupo de índice finito que seja um produto direto de um número finito de grupos do tipo $C_{p^{\infty}}$, para vários primos $p$. Por um resultado obtido independentemente por Shunkov [39] e por Kegel e Wehrfritz [18] grupos de Chernikov são precisamente os grupos localmente finitos que satisfazem a condição minimal sobre seus subgrupos, isto é, grupos no qual qualquer subconjunto não vazio de subgrupos possui um subgrupo minimal.

Nesta tese consideramos a seguinte situação. Sejam $n$ um inteiro positivo e $w$ a palavra $\delta_{n}$ ou $\gamma_{n}$. Suponha que $G$ seja um grupo tal que para todo $g \in G$ exista um número finito de subgrupos de Chernikov cuja união contenha a classe de 
conjugação verbal $g^{G_{w}}$. Sob estas hipóteses mostramos que $\left\langle g^{w(G)}\right\rangle$ é de Chernikov para todo $g \in G$.

Teorema 3.2 Sejam $n$ um inteiro positivo e $w$ a palavra central inferior $\gamma_{n}$ ou a palavra derivada $\delta_{n}$. Suponha que $G$ seja um grupo tal que, para cada elemento $g \in G$ exista um número finito de subgrupos de Chernikov cuja união contenha $g^{G_{w}}$. Então $\left\langle g^{w(G)}\right\rangle$ é de Chernikov para todo $g \in G$.

Uma família de subgrupos $\left\{H_{i}\right\}_{i \in I}$ de um grupo $G$ é chamada uma cobertura para $G$ se

$$
G=\bigcup_{i \in I} H_{i}
$$

É natural nos perguntarmos quais informações sobre $G$ podem ser deduzidas à partir de propriedades dos subgrupos $H_{i}$.

Em [32], Rogério e Shumyatsky consideraram a situação onde um grupo $G$ é tal que o conjunto de todos os $\boldsymbol{\delta}_{k}$-comutadores (respectivamente, $\boldsymbol{\gamma}_{k}$-comutadores) estivesse contido em uma união de um número finito de subgrupos de Chernikov e, obtiveram os seguintes resultados.

Teorema 2.1 [[32], Teorema 1.] Sejam $k$ um inteiro positivo e $G$ um grupo tal que o conjunto de todos os $\boldsymbol{\delta}_{k}$-comutadores esteja contido em uma união de um número finito de subgrupos de Chernikov. Então $G^{(k)}$ é de Chernikov.

Teorema 2.2 [[32], Teorema 2.] Sejam $k$ um inteiro positivo e $G$ um grupo tal que o conjunto de todos os $\gamma_{k}$-comutadores esteja contido em uma união de um número finito de subgrupos de Chernikov. Então $\gamma_{k}(G)$ é de Chernikov.

No decorrer da demonstração do Teorema 3.2, baseando-nos nas técnicas utilizadas por Rogério e Shumyatsky em [32], consideramos a situação onde subconjuntos normais de um grupo dado estivessem contidos em uma união de um número finito de subgrupos de Chernikov e obtivemos o seguinte resultado que generaliza os Teoremas 2.1 e 2.2 .

Teorema 2.3 Seja X um subconjunto normal de um grupo G. Suponha que exista um número finito de subgrupos de Chernikov tais que $X$ esteja contido na união desses subgrupos. Então $\langle X\rangle$ é de Chernikov.

Como consquência do Teorema 2.3 obtemos o seguinte resultado.

Corolário 2.9 Sejam w uma palavra de grupo e G um grupo. Suponha que o conjunto de todos os $w$-valores de $G$ esteja contido em uma união de um número finito de subgrupos de Chernikov. Então o subgrupo verbal w $(G)$ é de Chernikov.

Outro foco de nosso trabalho é o estudo dos comutadores coprimos generalizados $\gamma_{k}^{*}$ e $\delta_{k}^{*}$, introduzido por Shumyatsky em [37], como uma ferramenta para 
estudar propriedades de grupos finitos que possam ser expressas em termos dos comutadores de elementos de ordens coprimas.

Todo elemento de um grupo finito $G$ é um $\gamma_{1}^{*}$-comutador. Sejam $k \geq 2$ e $X$ o conjunto de todos os elementos de $G$ que sejam potências de $\gamma_{k-1}^{*}$-comutadores. Um elemento $x \in G$ é chamado um $\gamma_{k}^{*}$-comutador se existirem $a \in X$ e $b \in G$ tais que $x=[a, b]$ e $(|a|,|b|)=1$. O subgrupo de $G$ gerado por todos os $\gamma_{k}^{*}$-comutadores será denotado por $\gamma_{k}^{*}(G)$.

Similarmente os $\delta_{k}^{*}$-comutadores são definidos como segue. Todo elemento de um grupo finito $G$ é um $\delta_{0}^{*}$-comutador. Sejam $k \geq 1$ e $Y$ o conjunto de todos os elementos de $G$ que sejam potências de $\delta_{k-1}^{*}$-comutadores. Um elemento $x \in G$ é chamado um $\delta_{k}^{*}$-comutador se existirem $a, b \in Y$ tais que $x=[a, b]$ e $(|a|,|b|)=1$. O subgrupo de $G$ gerado por todos os $\delta_{k}^{*}$-comutadores será denotado por $\delta_{k}^{*}(G)$.

O último termo da série central inferior de um grupo finito $G$ é chamado o residual nilpotente de $G$ e, é usualmente denotado por $\gamma_{\infty}(G)$. A série inferior de Fitting de um grupo $G$ é definida recursivamente por

$$
D_{0}(G)=G \text { e } D_{i+1}(G)=\gamma_{\infty}\left(D_{i}(G)\right)
$$

para $i=0,1,2, \ldots$ Em [37], Shumyatsky mostrou que se $k \geq 2$ então o conjunto dos $\gamma_{k}^{*}$-comutadores geram $\gamma_{\infty}(G)$ e se $k \geq 1$ então o conjunto dos $\delta_{k}^{*}$-comutadores geram o subgrupo $D_{k}(G)$.

Observe que os comutadores coprimos $\gamma_{k}^{*}$ e $\delta_{k}^{*}$ não são palavras, porém em várias situações se comportam como palavras.

Com as notações apresentadas anteriormente provamos os seguintes teoremas que limitam a ordem do residual nilpotente de um grupo finito.

Teorema 4.20 Sejam $k \geq 2$ um inteiro e $G$ um grupo finito. Denote por $X$ o conjunto de todos os $\gamma_{k}^{*}$-comutadores de $G$. Suponha que $\left|g^{X}\right| \leq m$ para todo $g \in G$. Então $\left|\gamma_{k}^{*}(G)\right|$ é $(m, k)$-limitado.

Recorde que se $k \geq 1$ os subgrupos $D_{k}(G)$ e $\delta_{k}^{*}(G)$ coincidem.

Teorema 4.21 Sejam $k \geq 1$ um inteiro e $G$ um grupo finito. Denote por $X$ o conjunto de todos os $\delta_{k}^{*}$-comutadores de $G$. Suponha que $\left|g^{X}\right| \leq m$ para todo $g \in G$. Então $\left|D_{k}(G)\right|$ é $(m, k)$-limitado.

O Capítulo 1, é introdutório com resultados já conhecidos a respeito da teoria de grupos e serve de base conceitual para o desenvolvimento desta tese. Nesse capítulo, abordaremos assuntos como palavras de grupos, comutadores, grupos localmente finitos, grupos radicáveis, grupos de Chernikov e de algumas de suas propriedades, que serão muito úteis nos Capítulos 2 e 3. O Capítulo 2, destina-se à demonstração do Teorema 2.3 (e seu corolário). O objetivo central do Capítulo 3, é 
provar o Teorema 3.2. O Capítulo 4 aborda os comutadores coprimos $\delta_{k}^{*}$ e $\gamma_{k}^{*}$. Nesse capítulo faremos uma apresentação do tema expondo alguns dos principais resultados já apresentados sobre os comutadores coprimos generalizados, entre outros. Por fim, o objetivo principal do Capítulo 4 é provar os Teoremas 4.20 e 4.21. Os principais resultados obtidos nesta tese foram publicados em [3] e [38]. 


\section{Preliminares}

O objetivo deste capítulo é estabelecer notações, definições e resultados preliminares que serão utilizados nos demais capítulos desta tese. Essencialmente, os resultados e notações apresentados aqui podem ser encontrados em [14, 15, 29, 30, 31, 33], entre outras referências clássicas. Entretanto, para facilitar a leitura, faremos alguns breves comentários sobre temas como: palavras de grupos, grupos localmente finitos, FC-grupos, grupos radicáveis e grupos de Chernikov, entre outros.

Ao longo desta tese a expressão " $\{m, n, \ldots\}$-limitado" significa "limitado por uma função que depende apenas dos parâmetros $m, n, \ldots$. .

Usaremos o símbolo $H \leq G$ para dizer que $H$ é um subgrupo de um grupo $G$. Já o símbolo $N \unlhd G$ denota que $N$ é um subgrupo normal em $G$.

Dado um subconjunto $X$ de um grupo $G$, definimos o subgrupo gerado por $X$, o qual denotaremos por $\langle X\rangle$, como o menor subgrupo de $G$ que contém o subconjunto $X$.

Seja $H$ um subgrupo de um grupo $G$. Para cada $x \in G$ o conjunto $H x=$ $\{h x ; h \in H\}$ é chamado uma classe lateral (à direita) de $H$. Podemos selecionar um elemento de cada classe lateral de $H$ (usando o axioma da escolha) e denotar por $T$ o conjunto resultante dos representantes das classes laterais (à direita). Então $G$ é a união disjunta

$$
G=\bigcup_{t \in T} H t
$$

e assim cada elemento de $G$ pode ser escrito (de maneira única) na forma $h t$ onde $h \in H$ e $t \in T$. O conjunto $T$ é chamado um transversal (à direita) de $H$ em $G$. Note que $|T|$ é igual à cardinalidade do conjunto das classes laterais de $H$. A cardinalidade do conjunto de classes laterais de $H$ em $G$ é chamado o índice de $H$ em $G$ e será denotado por $|G: H|$.

Sejam $X, Y$ subconjuntos de um grupo. Escreveremos $X^{Y}$ para denotarmos o conjunto $\left\{x^{y} ; x \in X, y \in Y\right\}$, onde $x^{y}=y^{-1} x y$ é chamado o conjugado de $x$ por $y$. Em particular, dado um grupo $G$ e um elemento $x \in G$ o conjunto $x^{G}$, de todos os conjugados de $x$ em $G$ é chamado a classe de conjugação de $x$ em $G$. Se $X$ 
for um subconjunto não vazio de $G$ então o fecho normal de $X$ em $G$ é o menor subgrupo normal de $G$ que contenha $X$. Denotaremos o fecho normal de $X$ em $G$ por $\left\langle X^{G}\right\rangle$. É fácil verificar que $\left\langle X^{G}\right\rangle=\left\langle g^{-1} X g ; g \in G\right\rangle$. Note que se $H \leq G$ então $\left\langle H^{G}\right\rangle=\left\langle H^{g} ; g \in G\right\rangle$.

Um subconjunto $X$ é dito normal em $G$ se para todo $x \in X$ e para qualquer $g \in G$ o elemento $x^{g}$ for novamente um elemento de $X$.

Um homomorfismo de um grupo $G$ em um grupo $H$ é uma aplicação $\alpha: G \rightarrow H$ tal que $(x y)^{\alpha}=(x)^{\alpha}(y)^{\alpha}$, para quaisquer $x, y \in G$. Chamamos $\alpha$ de um isomorfismo de $G$ em $H$ se $\alpha$ for um homomorfismo bijetor. Em particular, um automorfismo de $G$ é um isomorfismo de $G$ em $G$. O conjunto de todos os automorfismos de $G$ será denotado por $\operatorname{Aut}(G)$. É um resultado bem conhecido que $\operatorname{Aut}(G)$ é um grupo com a operação de composição de aplicações. Seja $g \in G$ e considere a aplicação $\alpha_{g}: G \rightarrow G$ dada por $x^{\alpha_{g}}=x^{g}$. Então para cada $g \in G$ a aplicação $\alpha_{g}$ é um isomorfismo de $G$. Chamamos $\alpha_{g}$ o automorfismo interno de $G$ induzido por $g$ e denotaremos por $\operatorname{Inn}(G)$ o conjunto de todos os automorfismos internos de $G$. É claro que $\operatorname{Inn}(G) \unlhd A u t(G)$.

Os seguintes subgrupos de um grupo $G$ serão considerados no decorrer desta tese.

- $Z(G)=\{x \in G ; x g=g x$, para todo $g \in G\}$ é chamado o centro de $G$.

- Para cada $x \in G$ o subgrupo $C_{G}(x)=\{g \in G ; g x=x g\}$ é denomiado o centralizador de $x$ em $G$.

- Se $H \leq G$ então o subgrupo $C_{G}(H)=\{g \in G ; g h=h g$, para todo $h \in H\}$ é dito o centralizador de $H$ em $G$.

- Se $H \leq G$ então o subgrupo $N_{G}(H)=\left\{g \in G ; h^{g} \in H\right.$, para todo $\left.h \in H\right\}$ é chamado o normalizador de $H$ em $G$.

Lema 1.1 (Robinson, [29]). Para um grupo G valem os seguintes resultados.

1. $Z(G) \unlhd G$ e $G / Z(G) \cong \operatorname{Inn}(G)$.

2. Se $x \in G$ então $\left|x^{G}\right|=\left|G: C_{G}(x)\right|$.

3. Se $H \leq G$ então $C_{G}(H) \unlhd N_{G}(H)$ e $N_{G}(H) / C_{G}(H)$ é isomorfo à um subgrupo de $\operatorname{Aut}(H)$.

Sejam $x, y$ elementos de um grupo $G$. O elemento $x^{-1} y^{-1} x y$ é chamado o comutador de $x$ e $y$ e será denotado por $[x, y]$. O subgrupo de $G$ gerado por todos os comutadores $[x, y]$, onde $x, y \in G$ é chamado o subgrupo derivado de $G$ e será denotado 
por $G^{\prime}$. Sejam $k \geq 3$ e $g_{1}, \ldots, g_{k}$ elementos em $G$. Então o comutador de peso $k$ de $g_{1}, \ldots, g_{k}$ é definido indutivamente como

$$
\left[g_{1}, g_{2}, \ldots, g_{k}\right]=\left[\left[g_{1}, \ldots, g_{k-1}\right], g_{k}\right]
$$

O próximo lema descreve algumas propriedades de comutadores em um grupo.

Lema 1.2 ([29], 5.1.5, p. 123). Sejam x,y,z elementos de um grupo G. Então:

1. $[x, y]=[y, x]^{-1}$.

2. $[x y, z]=[x, z]^{y}[y, z]=[x, z][x, z, y][y, z]$.

3. $[x, y z]=[x, z][x, y]^{z}=[x, z][x, y][x, y, z]$.

O seguinte resultado é bem conhecido e sua demonstração pode ser obtida em [14].

Lema 1.3 ([14], Lema 2.2.2, p.19). Sejam $n$ um inteiro positivo e $G$ um grupo. Suponha que $x$ e y sejam elementos de $G$ tais que $[x, y, y]=1$. Então $[x, y]^{n}=\left[x, y^{n}\right]$.

Dados dois subconjuntos não vazios $X$ e $Y$ de um grupo $G$, denotaremos por $[X, Y]$ o subgrupo gerado pelo conjunto

$$
\{[x, y] ; x \in X, y \in Y\}
$$

Em particular, se $H, K$ forem dois subgrupos de $G$ então

$$
[H, K]=\langle[h, k] ; h \in H, k \in K\rangle \text {. }
$$

Se $n$ for um inteiro positivo, definimos recursivamente os subgrupos $\left[H,_{0} K\right]=H$ e para $n \geq 1$

$$
\left[H,{ }_{n} K\right]=\left[\left[H,{ }_{n-1} K\right], K\right]
$$

Lema 1.4 ([15], Lema 4.1). Se $H$ e $K$ são subgrupos de um grupo então

$$
[H, K] \unlhd\langle H, K\rangle .
$$

Lema 1.5 ([29], 5.1.6, p.124). Sejam X um subconjunto e $K$ um subgrupo de um grupo. Então:

1. $\left\langle X^{K}\right\rangle=\langle X,[X, K]\rangle$.

2. $\left\langle[X, K]^{K}\right\rangle=[X, K]$. 
3. Se $K=\langle Y\rangle$ então $[X, K]=\left\langle[X, Y]^{K}\right\rangle$.

Se $\alpha$ for um automorfismo de um grupo $G$ então denotaremos o elemento $g^{-1} g^{\alpha}$ por $[g, \alpha]$. Assim, podemos definir o subgrupo

$$
[G, \alpha]=\langle[g, \alpha] ; g \in G\rangle
$$

Se $A \leq A u t(G)$ então $A$ é chamado um grupo de automorfismos de $G$. Para um grupo de automorfismos $A$ de um grupo $G$, os seguintes subgrupos de $G$ serão considerados nessa tese.

- O comutador de $G$ e A,

$$
[G, A]=\langle[G, \alpha] ; \alpha \in A\rangle
$$

- O grupo dos pontos fixos de A (também conhecido como o centralizador de A em $G)$,

$$
C_{G}(A)=\left\langle g \in G ; g^{\alpha}=g, \text { para todo } \alpha \in A\right\rangle
$$

Lema 1.6 ([15], Lema 4.28). Seja A um grupo de automorfismos de um grupo finito $G$ e suponha que $(|G|,|A|)=1$. Então

$$
G=C_{G}(A)[G, A]
$$

Uma $a c ̧ \tilde{a} o$ de um grupo $G$ em um grupo $H$ é um homomorfismo de $G$ em $\operatorname{Aut}(H)$. Uma ação $\theta$ de $G$ em $H$ é dita fiel se seu núcleo for trivial. Note que quando um grupo $G$ age fielmente sobre um grupo $H$ então claramente $G$ pode ser visto como um grupo de automorfismos de $H$. Por fim, uma ação de $G$ em $H$ é chamada trivial se ela fixar todo elemento de $\boldsymbol{H}$.

Lema 1.7 ([15], Lema 4.29). Seja A um grupo finito agindo sobre um grupo finito $G$ e suponha que $(|G|,|A|)=1$. Então $[G, A, A]=[G, A]$.

Lema 1.8 ([36], Lema 2.2). Seja A um grupo de automorfismos de um grupo finito $G$ com $(|A|,|G|)=1$. Suponha que $B$ seja um subconjunto normal de $A$ tal que $A=\langle B\rangle$. Seja $i \geq 1$ um inteiro. Então $[G, A]$ é gerado por subgrupos da forma $\left[G, b_{1}, \ldots, b_{i}\right]$, onde $b_{1}, \ldots, b_{i} \in B$.

O próximo resultado é conhecido como o Lema dos Três Subgrupos.

Lema 1.9 ([29], 5.1.10, p.126). Sejam $H, K, L$ subgrupos de um grupo $G$. Suponha que $[H, K, L]=1=[K, L, H]$. Então $[L, H, K]=1$. 
Lema 1.10 ([6], Lema 1.6). Sejam $N, H_{1}, \ldots, H_{l}$ subgrupos de um grupo $G$. Suponha que $N \unlhd G$. Se $K=\left\langle H_{1}, \ldots, H_{l}\right\rangle$ então

$$
[N, K]=\left[N, H_{1}\right] \ldots\left[N, H_{l}\right]
$$

Demonstração. Observe que $[N, K]=\langle[x, k] ; x \in N, k \in K\rangle$. Como $K=\left\langle H_{1}, \ldots, H_{l}\right\rangle$, temos que dado $k \in K$ então $k=h_{i_{1}} \ldots h_{i_{s}}$, com $h_{i_{j}} \in H_{i_{j}}$ para todo $j=1, \ldots, s$, onde $1 \leq i_{1}, \ldots, i_{s} \leq l$. Sendo $N \unlhd G$, dado $x \in N$ segue que

$$
\left[x, h_{i_{1}} \ldots h_{i_{s}}\right] \in \prod_{j=1}^{s}\left[N, H_{i_{j}}\right] .
$$

Portanto concluímos que $[N, K] \leq\left[N, H_{1}\right] \ldots\left[N, H_{l}\right]$. A outra inclusão é imediata. O lema está provado.

Um grupo finito $P$ é dito ser um $p$-grupo se $|P|=p^{n}$, para algum primo $p$ e para algum inteiro positivo $n$.

Teorema 1.11 ([14], Teorema 1.2.14, p.8). Um p-grupo abeliano finito $P$ é o produto direto de subgrupos cíclicos $H_{i}, 1 \leq i \leq n$. Além disso, o inteiro $n$ e as ordens $\left|H_{i}\right|$ são unicamente determinados.

Nas condições do Teorema 1.11 se $\left|H_{i}\right|=p^{e_{i}}$, diremos que $P$ é do tipo $\left(p^{e_{1}}, p^{e_{2}}, \ldots, p^{e_{n}}\right)$. Em particular, um grupo do tipo $(p, p, \ldots, p)$, é chamado de $p$ grupo abeliano elementar.

Dado um $p$-grupo finito $P$ ( $p$ primo), para cada $i \geq 1$ defina o seguinte subgrupo

$$
\Omega_{i}(P)=\left\{x \in P ; x^{p^{i}}=1\right\}
$$

Decorre do Teorema 1.11 que se $P$ for abeliano então o subgrupo $\Omega_{1}(P)$ é abeliano elementar .

Teorema 1.12 ([14], Teorema 2.1.6, p. 18). Se P for um p-grupo abeliano finito então o subgrupo $\Omega_{i}(P)$ é característico em $P$ para todo $i$.

Teorema 1.13 ([14], Teorema 5.2.4, p. 178). Seja A um $p^{\prime}$-grupo de automorfismos de um p-grupo abeliano $P$. Suponha que A age trivialmente sobre $\Omega_{1}(P)$. Então $A=1$.

Teorema 1.14 ([14], Teorema 5.2.3, p.177). Seja A um p'-grupo de automorfismos de um p-grupo abeliano P. Então

$$
P=C_{P}(A) \times[P, A]
$$




\subsubsection{Subgrupos de Hall}

Seja $\pi$ um conjunto não vazio de números primos. Um inteiro positivo $n$ é dito um $\pi$-número se todo divisor primo de $n$ pertence a $\pi$. Um elemento $x$ de um grupo finito é chamado um $\pi$-elemento, se a ordem de $x$ for um $\pi$-número. Por fim, um grupo finito $G$ é chamado um $\pi$-grupo, se todo elemento de $G$ for um $\pi$-elemento. O complementar do conjunto $\pi$ (isto é, os números primos que não pertencem à $\pi$ ) será denotado por $\pi^{\prime}$.

Um subgrupo $H$ de um grupo finito $G$ é chamado um $\pi$-subgrupo de Hall de $G$ se, $H$ for um $\pi$-grupo e se $|G: H|$ for um $\pi^{\prime}$-número. Note que, se $H$ for um $\pi$-subgrupo de Hall de $G$ então

$$
(|H|,|G: H|)=1
$$

Os $\pi$-subgrupos normais de um grupo $G$ possuem um comportamento interessante. De fato, suponha que $H$ e $K$ sejam $\pi$-subgrupos com $K \unlhd G$. Então $H \cap K$ e $H K / K$ são $\pi$-grupos, de modo que, podemos concluir que $H K$ é um $\pi$-grupo. Consequentemente, o subgrupo gerado por todos os $\pi$-subgrupos normais de $G$ é um $\pi$-grupo. Esse é o único $\pi$-subgrupo normal maximal de $G$ o qual denotaremos por $O_{\pi}(G)$.

\subsection{Subgrupos verbais}

Uma palavra de grupo, ou simplesmente uma palavra é um elemento não trivial do grupo livre $F=F(X)$ onde $X$ é um conjunto de geradores livres $\left\{x_{1}, x_{2}, \ldots\right\}$. Considere $w=w\left(x_{1}, \ldots, x_{s}\right)$ uma palavra. Podemos escrever

$$
w=x_{i_{1}}^{n_{1}} \ldots x_{i_{k}}^{n_{k}},
$$

onde $n_{j}$ é um inteiro e $i_{j} \in\{1, \ldots, s\}, j=1, \ldots, k$. Nesta tese, consideraremos todas as palavras em sua forma reduzida. Para uma referência mais detalhada sobre o assunto consultar Robinson [29, Capítulo 2] ou Johnson [17, Capítulo 1].

Uma palavra $w=w\left(x_{1}, \ldots, x_{s}\right)$ pode ser sempre vista como um função definida em qualquer grupo. Um elemento $g$ de um grupo $G$ é chamado um $w$ valor de $G$ se existirem $g_{1}, \ldots, g_{s} \in G$ tais que $g=w\left(g_{1}, \ldots, g_{s}\right)$. Denotaremos por $G_{w}$ o conjunto de todos os $w$-valores de $G$, isto é,

$$
G_{w}=\left\{w\left(g_{1}, \ldots, g_{s}\right) ; g_{i} \in G\right\}
$$


O subgrupo verbal associado à palavra $w$, o qual denotaremos por $w(G)$, é o subgrupo gerado pelo conjunto $G_{w}$, isto é,

$$
w(G)=\left\langle w\left(g_{1}, \ldots, g_{s}\right) ; g_{i} \in G\right\rangle
$$

Dado um homomorfismo de grupos $\alpha: G \rightarrow H$ e uma palavra $w$, então para $g_{1}, \ldots, g_{s} \in G$ vale que $w\left(g_{1}, \ldots, g_{s}\right)^{\alpha}=w\left(g_{1}^{\alpha}, \ldots, g_{1}^{\alpha}\right)$. Consequentemente, $w(G)^{\alpha} \leq$ $w(H)$. Em particular, todo subgrupo verbal de um grupo $G$ é normal.

A seguir apresentamos alguns exemplos de palavras.

Exemplo 1.15. Sejam $F=F(X)$ um grupo livre e $X$ um conjunto de geradores livres. São palavras:

1. O comutador (de peso 2) $w=\left[x_{i}, x_{j}\right]$, nos geradores $x_{i}, x_{j}, i \neq j$;

2. Para $k \geq 1$, a $k$-ésima palavra central inferior $\gamma_{k}$, é definida indutivamente, da seguinte forma:

$$
\gamma_{1}\left(x_{1}\right)=x_{1}, \quad \gamma_{k}\left(x_{1}, \ldots, x_{k}\right)=\left[\gamma_{k-1}\left(x_{1}, \ldots, x_{k-1}\right), x_{k}\right],
$$

onde $x_{i} \in X$ para todo $i$.

3. Para $k \geq 0$, a $k$-ésima palavra derivada $\boldsymbol{\delta}_{k}$, é definida indutivamente, $d a$ seguinte forma:

$$
\delta_{0}\left(x_{1}\right)=x_{1}, \quad \delta_{k}\left(x_{1}, \ldots, x_{2^{k}}\right)=\left[\delta_{k-1}\left(x_{1}, \ldots, x_{2^{k-1}}\right), \delta_{k-1}\left(x_{2^{k-1}+1}, \ldots, x_{2^{k}}\right)\right]
$$

com $x_{i} \in X$ para todo $i$.

Um elemento $g$ de um grupo $G$ é chamado um $\gamma_{k}$-comutador se existirem $g_{1}, \ldots, g_{k}$ elementos em $G$ tais que $g=\gamma_{k}\left(g_{1}, \ldots, g_{k}\right)$. Analogamente, um elemento

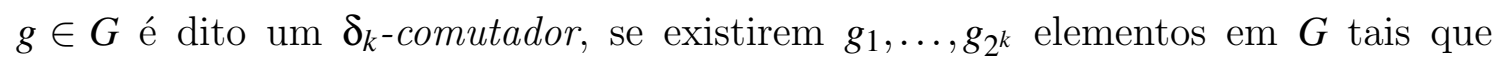
$g=\delta_{k}\left(g_{1}, \ldots, g_{2^{k}}\right)$.

Lema 1.16 ([24], Lema 2.6). Sejam $k \geq 0$ um inteiro, $G$ um grupo e $y \in G$ um elemento qualquer. Se $x_{1}, \ldots, x_{k}$ são $\delta_{k}$-comutadores então $\left[y, x_{1}, \ldots, x_{k}\right]$ é também um $\delta_{k}$-comutador.

Os seguintes subgrupos serão considerados no decorrer dessa tese.

$$
\begin{aligned}
\gamma_{k}(G) & =\left\langle\gamma_{k}\left(g_{1}, \ldots, g_{k}\right) ; g_{i} \in G\right\rangle . \\
G^{(k)} & =\left\langle\delta_{k}\left(g_{1}, \ldots, g_{2^{k}}\right) ; g_{i} \in G\right\rangle .
\end{aligned}
$$


O subgrupo $\gamma_{k}(G)$ é chamado o $k$-ésimo termo da série central inferior de $G$, enquanto o subgrupo $G^{(k)}$ é chamado o $k$-ésimo subgrupo derivado de $G$ (ou simplesmente, a $k$-ésima derivada de $G$ ). Um grupo $G$ é dito nilpotente (de classe $\leq k$ ) se $\gamma_{k+1}(G)=1$. Já $G$ é chamado um grupo solúvel (de comprimento derivado $\leq k)$ se $G^{(k)}=1$.

O seguinte teorema é conhecido como o Teorema de Fitting.

Teorema 1.17 ([29], 5.2.8, p.133). Sejam $H$ e $K$ dois subgrupos normais nilpotentes de um grupo. Suponha que $H$ possua classe de nilpotência $c_{1}$ e que $K$ possua classe de nilpotência $c_{2}$. Então $H K$ é nilpotente e possui classe de nilpotência no máximo $c_{1}+c_{2}$.

O subgrupo gerado por todos os subgrupos normais nilpotentes de um grupo $G$ é chamado o subgrupo de Fitting de $G$ e será denotado por $F(G)$. Se $G$ for finito então $F(G)$ é nilpotente.

Se $G$ for um grupo finito e $n$ um inteiro positivo, defina recursivamente, os seguintes subgrupos $F_{n}(G)$. Considere $F_{0}(G)=1$ e para cada $n \geq 1$, defina

$$
F_{n}(G) / F_{n-1}(G)=F\left(G / F_{n-1}(G)\right)
$$

Então

$$
1=F_{0}(G) \leq F(G)=F_{1}(G) \leq F_{2}(G) \leq \ldots,
$$

é chamada a série superior de Fitting. Um grupo (finito) $G$ é solúvel se, e somente se, $F_{n}(G)=G$ para algum inteiro $n$. O menor inteiro $n$ tal que $F_{n}(G)=G$ é chamado a altura de Fitting de $G$ (veja Robinson [29], 5.4.5, p. 149).

\subsection{Grupos localmente finitos}

Um conceito que utilizaremos e que será muito importante ao longo desta tese é o de grupos localmente finitos. Dedicamos essa seção a definir e apresentar algumas propriedades sobre tais grupos.

Seja $x$ um elemento de um grupo $G$. Diremos que $x$ possui ordem finita, digamos $n$, se o subgrupo cíclico $\langle x\rangle$ tiver ordem $n$. Se $\langle x\rangle$ for infinito então diremos que $x$ possui ordem infinita. Escreveremos $|x|$ para nos referirmos à ordem do elemento $x$.

Um grupo é dito periódico (ou de torção) se todos seus elementos possuem ordens finitas. Se as ordens dos elementos de um grupo são finitas e limitadas, então o grupo é dito de expoente finito. O expoente de um grupo é então o mínimo múltiplo 
comum entre as ordens de todos os elementos. Obviamente, um grupo finito possui expoente finito e grupos com expoente finito são grupos periódicos.

Lema 1.18 ([33], 195, p.75). A classe dos grupos periódicos é fechada a subgrupos, quocientes e extensões de seus membros.

O seguinte resultado é bem conhecido. Uma demonstração para tal fato pode ser deduzida dos resultados de Robinson [29, 4.2.9] e [29, 4.2.10], p.103.

Lema 1.19. Sejam $m$ e $n$ dois inteiros positivos. Suponha que $G$ seja um grupo abeliano m-gerado de expoente $n$. Então $|G| \leq m^{n}$.

Um grupo $G$ é chamado localmente finito se todo subgrupo finitamente gerado de $G$ for finito. Em particular, todo grupo localmente finito é periódico.

Não é difícil ver que a classe dos grupos localmente finitos é fechada com respeito a subgrupos e imagens homomórficas. O teorema a seguir (devido à Schmidt [35]) garante que a classe dos grupos localmente finitos é fechada a extensões.

Teorema 1.20 ([30], Teorema 1.45). Se $N$ for um subgrupo normal de um grupo $G$ tal que $N$ e $G / N$ sejam localmente finitos, então $G$ é localmente finito.

O próximo resultado é bem conhecido.

Lema 1.21 ([33], 455, p.195). Um grupo solúvel e periódico é localmente finito.

Lema 1.22 ([24], Lema 2.9). Seja X um conjunto normal em um grupo localmente finito $G$. Se a for um elemento de $G$ tal que o conjunto $a^{X}$ seja finito, então o conjunto $a^{\langle X\rangle}$ é também finito.

Demonstração. Sejam $x_{1}, \ldots, x_{n}$ elementos de $X$ tais que $a^{X}=\left\{a^{x_{1}}, \ldots, a^{x_{n}}\right\}$. Considere $Y=\left\langle x_{1}, \ldots, x_{n}\right\rangle$. Note que $Y$ é finito, pois $G$ é localmente finito. Consequentemente, a classe de conjugação $a^{Y}$ é também finita. Seja $N=\langle X\rangle$. Afirmamos que $a^{N}=a^{Y}$. De fato, seja $y \in N$. Logo $y$ pode ser escrito como um produto $y=y_{1} \ldots y_{m}$, onde $y_{i} \in X$, para todo $i \in\{1, \ldots, m\}$. É claro que $a^{Y} \subseteq a^{N}$. Assim, para concluirmos a demonstração do lema, é suficiente que mostremos que $a^{y} \in a^{Y}$. Se $m=1$ então $a^{y} \in\left\{a^{x_{1}}, \ldots, a^{x_{n}}\right\} \subseteq a^{Y}$. Assim, podemos assumir que $m \geq 2$ e utilizarmos indução sobre $m$. Suponha que $a^{y_{1}}=a^{x_{1}}$. Para cada $i=2, \ldots, m$, seja $z_{i}=x_{1} y_{i} x_{1}^{-1}$. Sendo $X$ um subconjunto normal em $G$, segue que $z_{i} \in X$, para todo índice $i$. Então

$$
\begin{aligned}
a^{y} & =a^{x_{1} y_{2} \ldots y_{m}} \\
& =a^{z_{2} \ldots z_{m} x_{1}}
\end{aligned}
$$

Por indução sobre $m$, segue que $a^{z_{2} \cdots z_{m}} \in a^{Y}$. Uma vez que $x_{1} \in Y$, segue que $\left(a^{z_{2} \ldots z_{m}}\right)^{x_{1}}=a^{y} \in a^{Y}$. O lema está provado. 
Observação 1.23. De forma mais geral podemos definir grupos localmente- $\mathcal{X}$, onde $\mathcal{X}$ é um propriedade de grupo. Seja $\mathcal{X}$ uma propriedade de grupo (por exemplo, finitude, nilpotência, etc). Um grupo $G$ é dito um localmente- $\mathcal{X}$ (ou localmente $\mathcal{X}$ grupo) se cada subgrupo finitamente gerado de $G$ for um $\mathcal{X}$-grupo.

\subsection{Grupos que possuem coberturas finitas}

Uma cobertura de um grupo $G$ é uma família $\left\{S_{i}\right\}_{i \in I}$ de subconjuntos de $G$ tais que $G=\bigcup_{i \in I} S_{i}$. Se $\left\{H_{i}\right\}_{i \in I}$ for um cobertura de $G$ por subgrupos, é natural indagarmos quais informações sobre $G$ podem ser deduzidas a partir de propriedades dos subgrupos $H_{i}$. Observe que todo grupo pode ser coberto por subgrupos cíclicos. De fato, $G=\bigcup_{x \in G}\langle x\rangle$. Assim, faz sentido que consideremos apenas coberturas por um número finito de subgrupos. No caso em que a cobertura é finita, muito pode ser dito sobre a estrutura do grupo $G$. O primeiro resultado nesta direção foi apresentado por Baer (veja Neumann [25]), onde ele provou que um grupo $G$ admite um cobertura por um número finito de subgrupos abelianos se, e somente se, $G$ for central-porfinito, isto é, se $|G: Z(G)|$ for finito. A parte não-trivial disso pode ser deduzida do seguinte resultado devido à B.H. Neumann [26].

Lema 1.24 ([30], Lema 4.17). Seja $G=\bigcup_{i=1}^{n} S_{i} g_{i}$, onde $S_{1}, \ldots, S_{n}$ são subgrupos de $G$ (não necessariamente distintos). Então podemos omitir desta união qualquer $S_{i} g_{i}$ para os quais o índice $\left|G: S_{i}\right|$ seja infinito.

Além disso, foi observado por Baer que se um grupo possui uma cobertura por um número finito de subgrupos cíclicos então esse grupo é cíclico ou finito (veja Robinson [30, p.123], corolário do Teorema 4.33). Mais recentemente, FernándezAlcober e Shumyatsky provaram em [10] que, se um grupo $G$ é tal que o conjunto de todos os comutadores está contido em uma união de um número finito de subgrupos cíclicos, então $G^{\prime}$ é finito ou cíclico. Isso sugere a questão sobre a estrutura de grupos para os quais o conjunto de todos os $\gamma_{k}$-comutadores (ou, todos os $\boldsymbol{\delta}_{k}$-comutadores, respectivamente) esteja contido em uma união de um número finito de subgrupos cíclicos. Em [7] Cutolo e Nicotera mostraram que se um grupo $G$ é tal que o conjunto de todos os $\gamma_{k}$-comutadores esteja contido em uma união de um número finito de subgrupos cíclicos então $\gamma_{k}(G)$ é finito-por-cíclico. Até o momento ainda não é conhecido um resultado similar para as palavras derivadas $\boldsymbol{\delta}_{k}$. 


\subsection{Grupos com classes de conjugação finitas}

Um elemento $g$ de um grupo $G$ é chamado um $F C$-elemento se $g$ possuir apenas um número finito de conjugados em $G$, isto é, se a classe de conjugação $g^{G}$ for finita ou, equivalentemente, se o índice $\left|G: C_{G}(g)\right|$ for finito. É um resultado bem conhecido que em um grupo $G$ os FC-elementos formam um subgrupo característico.

Lema 1.25 ([29], 14.5.5, p.441.). Em qualquer grupo o conjunto dos FC-elementos forma um subgrupo característico.

O conceito de FC-elemento pode ser visto como uma generalização de um elemento do centro de um grupo (é claro que tais elementos possuem apenas um conjugado). Por essa razão o subgrupo de todos os FC-elementos é chamado de $F C$-centro de $G$. Observe que o centro de $G$ está contido no FC-centro de $G$.

Um grupo é chamado um FC-grupo se ele coincide com seu FC-centro. Em outras palavras, um grupo $G$ é um FC-grupo se, $x^{G}$ for finito para todo $x \in G$. Em particular, os grupos abelianos e todos os grupos finitos são FC-grupos.

Não é difícil verificar que a classe dos FC-grupos é fechada com respeito à formação de subgrupos, imagens homomórficas e produtos diretos. O seguinte resultado é devido à Dietzmann, e sua demonstração pode ser obtida em Robinson [29, 14.5.7], p.442 (veja também Robinson [30, Corolário 2], p.45).

Lema 1.26 (Lema de Dietzmann). Seja X um subconjunto finito e normal de um grupo G. Suponha que todos os elementos de $X$ possuam ordens finitas. Então $\langle X\rangle$ é finito. Em particular, se $a \in G$ for um elemento de ordem finita, que possui apenas um número finito de conjugados então $\left\langle a^{G}\right\rangle$ é finito.

O próximo resultado é devido à Baer e sua demonstração pode ser obtida, por exemplo, em [29].

Lema 1.27 ([29], 14.5.6, p.442). Se G for um FC-grupo então $G / Z(G)$ é um grupo de torção residualmente finito.

Recorde que um grupo $G$ é residualmente finito se dado $g \neq 1$ em $G$ existir $N \unlhd G$ tal que $g \notin N$ e $G / N$ seja finito.

O seguinte resultado descreve a estrutura de FC-grupos.

Lema 1.28 ([30], Teorema 4.32). Seja G um FC-grupo. Então:

1. $G / Z(G)$ é localmente normal e finito.

2. Os elementos de ordem finita em $G$ formam um subgrupo localmente normal e finito que contém o subgrupo $G^{\prime}$. 
O seguinte resultado descreve os FC-grupos periódicos.

Lema 1.29 ([29], 14.5.8, p.443). Um grupo periódico G é um FC-grupo se, e somente se, cada subconjunto finito de $G$ estiver contido em um subgrupo normal e finito em $G$.

Um grupo $G$ é chamado um BFC-grupo se existir um inteiro positivo $m$ tal que $\left|x^{G}\right| \leq m$ para todo $x \in G$, ou seja, nenhum elemento em $G$ possui mais do que $m$ conjugados. É claro que todo BFC-grupo é um FC-grupo. O seguinte resultado de B.H. Neumann descreve os BFC-grupos, em termos de seus subgrupos derivados.

Lema 1.30 ([29], 14.5.11, p. 444). Um grupo G é um BFC-grupo se, e somente se, o subgrupo derivado $G^{\prime}$ for finito.

O próximo resultado é conhecido como Teorema de Schur.

Lema 1.31 ([30], Teorema 4.12). Seja $G$ um grupo tal que $|G: Z(G)|=n$. Então $G^{\prime}$ é finito e $\left(G^{\prime}\right)^{n}=1$.

Além disso, Wiegold [42] determinou um limitante para a ordem de $\left|G^{\prime}\right|$ em termos da ordem de $\left|x^{G}\right|$.

Teorema 1.32 ([42], Teorema 4.7). Se G for um BFC-grupo, tal que $\left|x^{G}\right| \leq n$ para todo $x \in G$. Então $G^{\prime}$ possui ordem n-limitada.

\subsection{1 $\quad \mathbf{F C}(w)$-grupos}

Uma noção importante que será considerada nessa tese é a de classe de conjugação verbal. Dada uma palavra $w$, para cada elemento $x$ de um grupo $G$ o conjunto $x^{G_{w}}$ é chamado a classe de conjugação verbal de $x$ em $G$.

Em [11] Franciosi, de Giovanni e Shumyatsky introduziram uma generalização 'verbal' de FC-grupos e apresentaram resultados importantes sobre grupos com restrições em classes de conjugação verbal. Mais precisamente, consideraram a seguinte situação. Dada uma palavra $w$, um grupo $G$ é chamado um $F C(w)$ grupo se $x^{G_{w}}$ for finito para todo $x \in G$. Por analogia, em [5] Brazil, Krassilnikov e Shumyatsky introduziram a noção de $\mathrm{BFC}(w)$-grupos. Assim, um grupo $G$ foi chamado um $B F C(w)$-grupo se $x^{G_{w}}$ for finito para todo $x \in G$ e, se o número de elementos em $x^{G_{w}}$ for limitado por uma constante que não dependa da escolha do elemento $x$. Em outras palavras, $G$ é um $\mathrm{BFC}(w)$-grupo se existe um inteiro positivo $m$ tal que $\left|x^{G_{w}}\right| \leq m$ para todo $x \in G$.

Uma palavra $w$ é dita concisa se sempre que o conjunto dos $w$-valores for finito para um grupo $G$ então isso acarrete a finitude do subgrupo verbal $w(G)$. 
Sejam $G$ um grupo e $w$ uma palavra. Na década de 1960, P. Hall questionou se toda palavra seria concisa, porém a resposta para esse problema é não. Em [16] Ivanov provou que este problema possui solução negativa, em sua forma geral (veja também Olshanskii [27, p.439]). Por outro lado, muitas palavras importantes são concisas. Por exemplo, Turner-Smith mostrou em [41] que as palavras $\gamma_{k}$ e $\delta_{k}$ eram concisas ([41, Proposição 6], p.175). Outros resultados sobre palavras concisas podem ser encontrados em Merzlyakov [23] e Wilson [43].

Um subgrupo $H$ de $G$ é dito $F C$-imerso em $G$ se $x^{H}$ for finito, para todo $x \in G$ e $H$ é dito ser $B F C$-imerso em $G$ se o número de elementos em $x^{H}$ for limitado por uma constante que não dependa da escolha do elemento $x$. Considere uma palavra $w$ e $G$ um grupo, tal que o subgrupo verbal $w(G)$ seja FC-imerso em $G$. Então $G$ é um $\mathrm{FC}(w)$-grupo. O principal resultado de [11], caracteriza os $\mathrm{FC}(w)$-grupos, em termos do subgrupo verbal, e garante que a recíproca desse fato é também verdadeira, desde que a palavra $w$ seja concisa.

Teorema 1.33 ([11], Teorema A.). Sejam $w$ uma palavra concisa e G um $F C(w)$ grupo. Então o subgrupo verbal w $(G)$ é FC-imerso em $G$.

O seguinte resultado é uma extensão do Lema 1.28, que garante que o grupo quociente $G / Z(G)$ é localmente finito, desde que $G$ seja um FC-grupo.

Proposição 1.34 ([11], Proposição 2.4). Sejam w uma palavra concisa e G um $F C(w)$-grupo. Então o grupo quociente $G / C_{G}(w(G))$ é localmente finito.

Como consquência da Proposição 1.34, temos o seguinte resultado.

Corolário 1.35 ([11], Corolário 2.5). Sejam w uma palavra concisa e G um $F C(w)$ grupo. Então o subgrupo $[G, w(G)]$ é localmente finito.

O seguinte resultado generaliza o Lema de Dietzmann (Lema 1.26).

Corolário 1.36 ([11], Corolário 2.6). Sejam $n$ um inteiro positivo, $w=\gamma_{n}$ a n-ésima palavra central inferior e $G$ um grupo. Se $x$ for um elemento de $G$ que possua ordem finita e se a classe de conjugação verbal $x^{G_{w}}$ for finita, então o subgrupo $\left\langle x^{G}\right\rangle$ é localmente finito.

Com as notações estabelecidas anteriormente, o seguinte resultado é imediato.

Lema 1.37. Seja $G$ um $F C(w)$-grupo periódico, onde $w=\delta_{k}$ ou $w=\gamma_{k}$. Então $G$ é localmente finito.

Demonstração. Primeiramente, considere $w=\delta_{k}$. Então $\left[G, G^{(k)}\right]$ é localmente finito (Corolário 1.35). Consequentemente, $G^{(k+1)}$ é localmente finito. Logo o quociente 
$G / G^{(k+1)}$ é um grupo solúvel e periódico e, portanto é localmente finito (Lema 1.21). Disto segue que $G$ é localmente finito (Teorema 1.20).

Seja $w=\gamma_{k}$, então $\gamma_{k+1}(G)=\left[G, \gamma_{k}(G)\right]$ é localmente finito (Corolário 1.35). Portanto, $G / \gamma_{k+1}(G)$ é um grupo periódico e nilpotente e portanto é localmente finito (Lema 1.21). O lema está provado.

Em [5] Brazil, Krassilnikov e Shumyatsky, apresentaram o seguinte resultado que caracteriza os $\mathrm{BFC}(w)$-grupos, em termos do subgrupo verbal $w(G)$, desde que a palavra $w$ seja concisa. Mais precisamente, provaram o seguinte resultado.

Teorema 1.38 ([5], Teorema 1.2). Seja w uma palavra concisa. Um grupo G é um $B F C(w)$-grupo se, e somente se, $w(G)$ for BFC-imerso em $G$.

\subsection{Grupos hipercentrais}

Seja $\alpha$ um ordinal. Podemos definir a série (transfinita e generalizada) central superior de um grupo $G$ como:

$$
\begin{gathered}
Z_{0}(G)=1, \\
Z_{\alpha+1}(G) / Z_{\alpha}(G)=Z\left(G / Z_{\alpha}(G)\right),
\end{gathered}
$$

juntamente com a seguinte condição de completude

$$
Z_{\lambda}(G)=\bigcup_{\alpha<\lambda} Z_{\alpha}(G)
$$

onde $\lambda$ é um ordinal limite. Uma vez que a cardinalidade de $G$ não pode ser excedida, existe um ordinal $\beta$ tal que $Z_{\beta}(G)=Z_{\beta+1}(G)=\ldots$, isto é, existe um subgrupo terminal, chamado o hipercentro de $G$. Por simplicidade, dado um grupo $G$, denotaremos o hipercentro de $G$ por $Z_{\infty}(G)$. É usual nos referirmos ao subgrupo $Z_{\alpha}(G)$ como o $\alpha$-ésimo centro de $G$. Um grupo $G$ é chamado de hipercentral se $G=Z_{\infty}(G)$.

Um subgrupo $H$ de um grupo $G$ é dito ascendente (em $G$ ) se existir uma série ascendente de $H$ em $G$, isto é, se existir

$$
H=H_{0} \unlhd H_{1} \unlhd \cdots H_{\beta}=G
$$

Combinando os resultados [29, 12.2.1] e [29, 12.2.4] de Robinson, concluímos que em grupos hipercentrais todo subgrupo é ascendente. Destacamos esse resultado na forma da seguinte proposição. 
Proposição 1.39. Todo subgrupo de um grupo hipercentral é ascendente.

\subsection{Grupos de Chernikov}

O objetivo dessa seção é introduzir os grupos de Chernikov, notações e algumas propriedades relacionadas a esses grupos, que terão um papel muito importante nos Capítulos 2 e 3, onde estudaremos propriedades de determinadas classes de conjugação verbal de um grupo que estejam contidas em uma união de um número finito de subgrupos de Chernikov. Além disso, abordaremos os grupos radicáveis que também serão muito importantes para os resultados obtidos nesta tese.

Começamos com a noção de grupos quase-cíclicos. Considere $p$ um número primo e para cada inteiro $i$, seja $C_{p^{i}}$ um grupo cíclico de ordem $p^{i}$. Existe uma maneira natural de vermos cada subgrupo $C_{p^{i}}$ como um subgrupo de $C_{p^{i+1}}$, de modo que podemos considerar que

$$
1<C_{p}<C_{p^{2}}<C_{p^{3}}<\ldots
$$

Defina

$$
C_{p^{\infty}}=\bigcup_{n=0}^{\infty} C_{p^{n}} .
$$

Para cada primo $p$, o grupo $C_{p^{\infty}}$ é chamado um $p$-grupo quase-cíclico (ou um $p$-grupo de Prüfer).

É bem conhecido que todo subgrupo próprio de $C_{p^{\infty}}$ é $C_{p^{n}}$ para algum inteiro $n$ e que $C_{p^{\infty}} / C_{p^{n}} \cong C_{p^{\infty}}$. Assim, $C_{p^{\infty}}$ é um grupo infinito no qual todo subgrupo próprio é cíclico finito e, tal que todo quociente próprio é isomorfo à $C_{p^{\infty}}$ (veja Rose [33], p.52).

Um grupo $G$ é chamado um grupo radicável (divisível) se todo elemento for uma $n$-ésima potência para todo inteiro positivo $n$. Assim, se $G$ for um grupo radicável segue que dado $g \in G$ e um inteiro positivo $n$, existe $g_{1} \in G$ tal que $g_{1}^{n}=g$. Em particular, note que para cada primo $p$, o grupo quase-cíclico $C_{p^{\infty}}$ é radicável.

O seguinte resultado é uma caracterização da estrutura de grupos abelianos radicáveis.

Teorema 1.40 ([29], 4.1.5, p.97). Um grupo abeliano $G$ é radicável se, e somente se, for um produto direto de cópias isomorfas de $\mathbb{Q}$ e de p-grupos quase-cíclicos, para vários primos $p$. 
Em particular, decorre do Teorema 1.40 que se $G$ for periódico então $G$ será um grupo abeliano e radicável se, e somente se, for um produto direto de grupos quase-cíclicos.

Corolário 1.41. Um grupo abeliano periódico é radicável se, e somente se, for um produto direto de p-grupos quase-cíclicos, para vários primos $p$.

Os seguintes resultados embora sejam elementares são importantes e serão úteis ao longo dessa tese.

Lema 1.42 ([33], 470(iv), p.202). Se G for um grupo abeliano radicável não-trivial então $G$ não pode ser finitamente gerado. Em particular, grupos abelianos radicáveis não triviais são infinitos.

Lema 1.43 ([12], Ex. 2(b), p.67). Se G for um grupo radicável não-trivial, então G não possui subgrupos próprios de índice finito.

Demonstração. É suficiente que mostremos que $G$ não possui subgrupos normais de índice finito. Seja $N$ um subgrupo normal de índice finito em $G$. Suponha que $|G: N|=k$. Logo $x^{k} \in N$ para todo $x \in G$. Seja $g \in G$. Uma vez que $G$ é radicável existe $z \in G$ tal que $g=z^{k}$. Consequentemente $g \in N$ e assim $G=N$. O lema está provado.

O seguinte resultado é uma consequencia direta do Lema 1.43.

Corolário 1.44. Sejam $A_{1}, \ldots, A_{n}$ subgrupos abelianos e radicáveis de um grupo $G$. Se $G=\left\langle A_{1}, \ldots, A_{n}\right\rangle$ então $G$ não possui subgrupos próprios de indice finito.

Demonstração. Seja $1 \neq H$ um subgrupo próprio de índice finito em $G$. Então $H \cap A_{i}$ possui índice finito em $A_{i}$ para todo $i=1, \ldots, n$ e assim pelo Lema 1.43 segue que $H \cap A_{i}=A_{i}$. Logo $A_{i} \leq H$, para todo índice $i=1, \ldots, n$. Como $G=\left\langle A_{1}, \ldots, A_{n}\right\rangle$ concluímos que $G \leq H$, uma contradição. O lema está provado.

O próximo resultado garante que, em particular, subgrupos quase-cíclicos de FC-grupos são centrais.

Teorema 1.45 ([40], Teorema 1.9). Seja $H$ um subgrupo de um FC-grupo G. Se $H$ não possui subgrupos próprios de índice finito então $H$ é um grupo abeliano radicável contido em $Z(G)$.

Observe que o grupo dos racionais (em relação à soma) é radicável, porém o subgrupo dos números inteiros (vistos como subgrupo de $\mathbb{Q}$ ) não é radicável. Assim, a classe dos grupos radicáveis não é fechada com respeito a subgrupos. O próximo resultado, cuja demonstração pode ser obtida na seção §23 ("Complete abelian groups") de Kurosh [21], garante que a classe dos grupos abelianos radicáveis é fechada a quocientes. 
Lema 1.46 ([21], p.163). Todo quociente de um grupo abeliano radicável é radicável.

O próximo resultado garante que grupos abelianos gerados por subgrupos radicáveis são radicáveis.

Lema 1.47 ([21], p.194). Um grupo abeliano gerado por subgrupos radicáveis é radicável.

Demonstração. Seja $I$ um conjunto de índices e suponha que $G=\left\langle A_{i}, i \in I\right\rangle$, onde $A_{i}$ é um subgrupo radicável para todo $i \in I$. Dados $g \in G$ e $n$ um inteiro positivo, devemos mostrar que existe $g_{1} \in G$ tal que $g_{1}^{n}=g$. Como $g \in G$ temos que $g=a_{i_{1}} \ldots a_{i_{r}}$, onde $a_{i_{j}} \in A_{i_{j}}$ com $i_{j} \in I$ para todo $j=1, \ldots, r$. Uma vez que $A_{i_{j}}$ é radicável existe $b_{j} \in A_{i_{j}}$ tal que $a_{i_{j}}=b_{j}^{n}$. Logo

$$
g=a_{i_{1}} \ldots a_{i_{r}}=\left(b_{1} \ldots b_{r}\right)^{n} .
$$

Portanto $g_{1}=b_{1} \ldots b_{r}$ é um elemento de $G$ tal que $g_{1}^{n}=g$. O lema está provado.

O Lema 1.47 vale de modo mais geral. De fato, podemos deduzir que um grupo gerado por subgrupos radicáveis que se centralizam é radicável.

Ainda sobre grupos radicáveis, apresentamos abaixo o seguinte resultado.

Lema 1.48 ([30], Lema 3.13). Seja $R$ um subgrupo normal, abeliano e radicável de um grupo $G$ e seja $H$ um subgrupo de $G$ tal que

$$
\left[R,{ }_{n} H\right]=[R, \underbrace{H, \ldots, H}_{n}]=1,
$$

para algum inteiro positivo $n$. Se $H / H^{\prime}$ for periódico então $[R, H]=1$.

Lema 1.49 ([6], Lema 1.33). Seja A um subgrupo periódico, abeliano e radicável de um grupo G. Se A for ascendente então $\left\langle A^{G}\right\rangle$ é abeliano e radicável.

Demonstração. Suponha que $A$ seja um subgrupo ascendente de $G$. Seja $A=$ $A_{0} \unlhd A_{1} \unlhd \cdots A_{\beta}=G$ uma série ascendente de $A$ em $G$. Para cada ordinal $\alpha<\beta$ defina $H_{\alpha}=\left\langle A^{A_{\alpha}}\right\rangle$. Então $H_{\alpha+1} \leq\left\langle A_{\alpha}^{A_{\alpha+1}}\right\rangle=A_{\alpha}$. Consequentemente, $H_{\alpha+1}$ normaliza $H_{\alpha}$. Portanto, para $1 \leq \alpha \leq \beta$ os subgrupos $H_{\alpha}$ são os termos de uma série ascendente de $A$ em $H_{\beta}=\left\langle A^{G}\right\rangle$. Suponha por contradição, que $\left\langle A^{G}\right\rangle$ não seja abeliano. Seja $\alpha$ o menor ordinal tal que $H_{\alpha}$ não seja abeliano. Então claramente, $1<\alpha$ não pode ser um ordinal limite, assim

$$
H_{\alpha}=\left\langle A^{A_{\alpha}}\right\rangle=\left\langle H_{\alpha-1}^{A_{\alpha}}\right\rangle .
$$

Seja $g \in A_{\alpha}$. Então os subgrupos abelianos $H_{\alpha-1}$ e $H_{\alpha-1}^{g}$ são ambos normais em $H_{\alpha}$. Consequentemente,

$$
\left[H_{\alpha-1}, H_{\alpha-1}^{g}, H_{\alpha-1}^{g}\right]=1
$$


Logo, $\left[H_{\alpha-1}, H_{\alpha-1}^{g}\right]=1$ (Lema 1.48). Isso mostra que $\left\langle A^{A_{\alpha}}\right\rangle=H_{\alpha}$ é abeliano, contrariando nossa escolha. Portanto, $\left\langle A^{G}\right\rangle$ é abeliano. Além disso, $\left\langle A^{G}\right\rangle$ é radicável (Lema 1.47). O lema está provado.

Os lemas que se seguem sobre grupos radicáveis desempenharão um papel muito importante na demonstração do principal resultado do Capítulo 3.

Lema 1.50 ([24], Corolário 2.2). Seja A um subgrupo abeliano e radicável de um grupo nilpotente e periódico $G$. Então A é central em $G$.

O próximo resultado decorre do Lema 1.50.

Lema 1.51. Sejam $R_{1}$ e $R_{2}$ dois subgrupos normais, periódicos, abelianos e radicáveis de um grupo. Então o produto $R_{1} R_{2}$ é abeliano.

Demonstração. Uma vez que $R_{1}$ e $R_{2}$ são normais, periódicos e abelianos segue que o produto $R_{1} R_{2}$ é nilpotente de classe menor que ou igual a 2 (Teorema 1.17). Sendo $R_{1}$ e $R_{2}$ radicáveis, segue que $R_{i} \leq Z\left(R_{1} R_{2}\right)$, para $i=1,2$ (Lema 1.50). Portanto, $R_{1} R_{2}$ é abeliano. O lema está provado.

O Lema 1.51 pode ser estendido, por indução para um número finito de tais subgrupos, isto é, se $R_{1}, \ldots, R_{l}$ forem subgrupos normais, periódicos, abelianos e radicáveis então o produto $R=R_{1} \ldots R_{l}$ é abeliano. Destacamos esse fato na forma do seguinte corolário.

Corolário 1.52. Sejam $R_{1}, \ldots, R_{l}$ subgrupos normais, periódicos, abelianos e radicáveis de um grupo $G$. Então o produto $R_{1} R_{2} \ldots R_{l}$ é abeliano.

Lema 1.53 ([24], Corolário 2.3). Seja A um grupo periódico agindo sobre um grupo periódico, abeliano e radicável $G$. Então $[G, A, A]=[G, A]$.

Lema 1.54 ([24], Lema 2.4). Seja A um grupo finito agindo sobre um grupo periódico, abeliano e radicável $G$. Então $[G, A]$ é radicável.

Demonstração. Uma vez que

$$
[G, A]=\prod_{a \in A}[G, a]
$$

para mostrarmos que $[G, A]$ é radicável é suficiente que provemos que $[G, a]$ é radicável para todo $a \in A$ (Lema 1.47).

Sejam $x \in[G, a]$ e $n$ um inteiro positivo. Então existe $g \in G$ tal que $x=[g, a]$. Sendo $G$ radicável, existe $g_{1} \in G$ tal que $g_{1}^{n}=g$. Por outro lado, como $G$ é abeliano, segue que

$$
\left[g_{1}, a\right]^{n}=\left[g_{1}^{n}, a\right]
$$


Assim $x_{1}=\left[g_{1}, a\right]$ é um elemento de $[G, a]$ tal que $x_{1}^{n}=[g, a]=x$ e, consequentemente $[G, a]$ é radicável. O lema está provado.

Diremos que um grupo $G$ satisfaz a condição minimal para subgrupos, ou simplesmente, que $G$ satisfaz min, se todo subconjunto não vazio $S$, constituído de subgrupos de $G$ e parcialmente ordenado pela relação de inclusão, possuir um elemento minimal, isto é, existir $H \subseteq S$ com a propriedade de que não exista $L \subseteq S$ tal que $L \subseteq H$.

Note que todos grupos finitos claramente satisfazem a condição minimal para subgrupos. Além disso, para cada primo $p$, o $p$-grupo quase-cíclico $C_{p^{\infty}}$ satisfaz min, uma vez que seus subgrupos próprios são finitos.

Diremos que um grupo $G$ satisfaz a condição de cadeia descendente para subgrupos se, toda sequência descendente de subgrupos $H_{1} \geq H_{2} \geq \ldots$, em $G$ se torna eventualmente estacionária, isto é, existe um inteiro positivo $n$ tal que $H_{n}=H_{n+1}=\ldots$

O seguinte resultado garante que um grupo satisfaz min se, e somente se, ele satisfaz a condição de cadeia descendente para subgrupos. O próximo resultado é bem conhecido. A versão que apresentamos para este resultado pode ser obtida na tese de doutorado de Enio [22, Teorema 1.7.5]

Lema 1.55. Um grupo $G$ satisfaz min se, e somente se, $G$ satisfaz a condição de cadeia descendente para subgrupos.

Definição 1.56. Diremos que um grupo $G$ é de Chernikov se $G$ for uma extensão finita de um grupo abeliano satisfazendo a condição minimal para subgrupos (min).

É devido a Kuroš um resultado bem conhecido, que afirma que um grupo abeliano satisfaz min se, e somente se, for um produto direto de um número finito de grupos quase-cíclicos e grupos cíclicos finitos de ordem potência de um primo, a demonstração desse fato pode ser obtida em Robinson [29, 4.2.11], p.104 (veja também Fuchs [12, Teorema 19.2], p. 65). Destacamos esse resultado na forma do seguinte teorema.

Teorema 1.57 (Kuroš). Seja $G$ um grupo abeliano. Então $G$ satisfaz min se, e somente se, $G$ for um produto direto de um número finito de p-grupos quase-cíclicos e grupos cíclicos de ordem potência de um número primo.

Observe que um grupo de Chernikov $G$ possui um (único) subgrupo de índice finito que é um produto direto de um número finito de grupos quase-cíclicos, o qual denotaremos por $G^{0}$. Chamaremos $G^{0}$ a parte radicável de $G$. Note que a parte radicável de um grupo de Chernikov $G$ é um subgrupo minimal de índice finito em $G$ e que, portanto é característico em $G$. 
Lema 1.58 (Robinson, [30], p.68). Seja G um grupo de Chernikov. Então:

1. $G$ é localmente finito.

2. G satisfaz min.

3. G possui expoente finito se, e somente se, for finito.

Os próximos dois lemas nos fornecem uma caracterização importante sobre a parte radicável de um grupo de Chernikov $G$. O residual finito de $G$, o qual denotaremos por $\operatorname{Res}_{f}(G)$, é a interseção de todos subgrupos normais $N$ em $G$ cujos quocientes $G / N$ sejam finitos. Observe que $\operatorname{Res}_{f}(G)$ é um subgrupo característico em $G$ e que o quociente $G / \operatorname{Res}_{f}(G)$ não precisa ser necessariamente finito. Porém, quando $G / \operatorname{Res}_{f}(G)$ é finito então $\operatorname{Res}_{f}(G)$ é o menor subgrupo normal de $G$ com quociente finito.

Lema 1.59 ([22], Lema 1.7.19). Se G for um grupo de Chernikov, então $G^{0}=$ $\operatorname{Res}_{f}(G)$.

Demonstração. Uma vez que $G$ satisfaz min segue que $G / \operatorname{Res}_{f}(G)$ é finito. Sendo $G^{0}$ um subgrupo normal em $G$ de índice finito, segue que $\operatorname{Res}_{f}(G) \leq G^{0}$. Considere o quociente $\bar{G}^{0}=G^{0} \operatorname{Res}_{f}(G) / \operatorname{Res}_{f}(G)$. Então $\bar{G}^{0}$ é um grupo abeliano e radicável (Lema 1.46). Além disso, $\bar{G}^{0}$ deve ser finito (uma vez que $G / \operatorname{Res}_{f}(G)$ é finito). Portanto $\bar{G}^{0}$ é trivial (Lema 1.42) e consequentemente $G^{0} \leq \operatorname{Res}_{f}(G)$. O lema está provado.

O próximo resultado é bem conhecido e, a demonstração aqui apresentada é uma consequência direta do Lema 1.59.

Lema 1.60. Seja $H$ um subgrupo de um grupo de Chernikov $G$. Então $H^{0} \leq G^{0}$.

Demonstração. O subgrupo $H^{0}$ é minimal de índice finito em $H$ (Lema 1.59). Seja $\bar{H}=H \cap G^{0}$. Como $G^{0}$ possui índice finito em $G$ segue que $\bar{H}$ possui índice finito em $H$. Como $\bar{H} \unlhd H$ segue que $H^{0}=\operatorname{Res}_{f}(H) \leq \bar{H} \leq G^{0}$. O lema está provado.

Não é difícil verificar que a classe dos grupos de Chernikov é fechada para subgrupos e quocientes. Porém, menos óbvio é o fato de que a classe dos grupos de Chernikov seja fechada a extensões. A seguinte proposição, garante que de fato a classe dos grupos de Chernikov é fechada para extensões.

Proposição 1.61 ([30], Corolário do Teorema 3.12, p.69). A classe dos grupos de Chernikov é fechada para subgrupos, quocientes e extensões. 
Por um resultado obtido por Shunkov [39] e independentemente também por Kegel e Wehrfritz [18, 19] temos que os grupos de Chernikov são exatamente os grupos localmente finitos que satisfazem a condição minimal para subgrupos. A versão que apresentamos a seguir pode ser encontrada em [19].

Teorema 1.62 ([19], Corolário 5.8). Para um grupo localmente finito G, as seguintes condições são equivalentes.

1. G é um grupo de Chernikov;

2. G satisfaz a condição minimal para subgrupos;

3. O centralizador de todo elemento não trivial de $G$ satisfaz a condição minimal para subgrupos;

4. Todo subgrupo abeliano de $G$ satisfaz min.

Seja $G^{0}$ a parte radicável de um grupo de Chernikov $G$. Suponha que $G^{0}$ possua índice $i$ em $G$ e que $G^{0}$ seja o produto de exatamente $j$ grupos do tipo $C_{p^{\infty}}$, para vários primos $p$. O par ordenado $(j, i)$ é chamado o tamanho de G. Quando necessário, representaremos o tamanho de um grupo de Chernikov $G$ por $\operatorname{tam}(G)$. O conjunto de todos os pares $(j, i)$ pode ser ordenado lexograficamente, isto é, dados dois pares $\left(j_{1}, i_{1}\right)$ e $\left(j_{2}, i_{2}\right)$ diremos que $\left(j_{1}, i_{1}\right)<\left(j_{2}, i_{2}\right)$ se, e somente se, $j_{1}<j_{2}$ ou se $j_{1}=j_{2}$ e $i_{1}<i_{2}$.

Lema 1.63 ([2], Lema 2.7). Seja $G$ um grupo de Chernikov.

1. Se $H$ for um subgrupo próprio de $G$ então o tamanho de $H$ é estritamente menor do que o tamanho de $G$.

2. Se $N$ for um subgrupo normal e infinito de $G$ então o tamanho de $G / N$ é estritamente menor do que o tamanho de $G$.

No item 2. do Lema 1.63 é importante que $N$ seja infinito. Por exemplo, se $p$ for um número primo então $G=C_{p^{\infty}}$ é um grupo de Chernikov. Note que para cada inteiro positivo $n$, o subgrupo $N=C_{p^{n}}$ é um subgrupo normal finito contido em $G$. Entretanto, $G / N \cong G$ e assim possuem o mesmo tamanho.

Um grupo $G$ tem camadas finitas (tradução do termo em inglês "finitelayer") se $G$ possuir apenas um número finito de elementos de qualquer ordem dada.

O próximo resultado pode ser encontrado em Robinson [29, Exercício 4.3.5], p. 113.

Lema 1.64. Seja $p$ um número primo. Um p-grupo abeliano satisfaz min se, e somente se, tem camadas finitas. 
Uma demonstração detalhada para o Lema 1.64 pode ser obtida em Garcia [13, Proposição 1.23].

O Teorema de Kuroš (Teorema 1.57) combinado com o Lema 1.64 nos fornece que se um grupo abeliano satisfaz min então esse grupo tem camadas finitas. Destacamos esse resultado na forma do seguinte corolário.

Corolário 1.65. Se $G$ for um grupo abeliano satisfazendo min então $G$ possui camadas finitas.

O próximo resultado é bem conhecido e a demonstração que apresentamos será deduzida do Corolário 1.65.

Lema 1.66. Seja $G$ um grupo de Chernikov. Se $G^{0} \leq Z(G)$ então $G$ tem camadas finitas.

Demonstração. Seja $\left\{d_{1}, \ldots, d_{n}\right\}$ um transversal de $G^{0}$ em $G$. Recorde que $G$ é localmente finito (Lema 1.58(1)). Suponha que $d_{i}$ possua ordem $m_{i}$ para todo $i=1, \ldots, n$. Consideraremos os elementos de $G$ que possuem ordem $m$. Se provarmos que cada classe lateral $d_{i} G^{0}$ que contém um elemento de ordem $m$ possui de fato somente um número finito de elementos desta ordem, então $G$ conterá também um número finito de elementos de ordem $m$. Seja $g \in d_{i} G^{0}$ e suponha que $g \in G$ possua ordem $m$. É claro que existe $z \in G^{0}$ tal que $g=d_{i} z$. Por hipótese $G^{0} \leq Z(G)$, donde obtemos que

$$
1=g^{m}=d_{i}^{m} z^{m} .
$$

Como $\left|d_{i}\right|=m_{i}$ segue que $z^{m m_{i}}=1$. Então o número de elementos de $d_{i} G^{0}$ que possuem ordem $m$ é limitado pelo número de elementos de $G^{0}$ que possuem ordem divisora de $m m_{i}$. Como $G^{0}$ é abeliano e satisfaz $\min$ (Lema 1.58(2)) segue do Corolário 1.65 que $G^{0}$ tem camadas finitas. Portanto apenas um número finito de elementos em $G^{0}$ possui ordem $m m_{i}$ e, consequentemente $G$ tem camadas finitas. O lema está provado.

Em particular, o Lema 1.66 garante que um grupo radicável e de Chernikov possui apenas um número finito de elementos de uma determinada ordem.

O próximo resultado é bem conhecido e garante que um grupo gerado por um número finito de subgrupos de Chernikov que se centralizam é de Chernikov.

Lema 1.67. Seja $G$ um grupo gerado por um número finito de subgrupos de Chernikov que se centralizam. Então $G$ é de Chernikov.

Demonstração. Sejam $C_{1}, \ldots, C_{n}$ subgrupos de Chernikov tais que $G=\left\langle C_{1}, \ldots, C_{n}\right\rangle$ $\operatorname{com}\left[C_{i}, C_{j}\right]=1, i \neq j \operatorname{com} i, j \in\{1, \ldots, n\}$. Provaremos o lema por indução sobre $n$. 
Se $n=1$ então é claro que $G$ é de Chernikov. Suponha $n \geq 2$ e, por indução sobre $n$ suponha o resultado verdadeiro para grupos gerados por no máximo $n-1$ subgrupos de Chernikov que comutem entre si. Seja $N=\left\langle C_{1}, \ldots, C_{n-1}\right\rangle$. Então $N$ é de Chernikov. Por hipótese, dados $i, j \in\{1, \ldots, n\}$ os subgrupos $C_{i}$ e $C_{j}$ se centralizam e, portanto, podemos concluir que $N$ é normal em $G$. Como $G / N$ está contido na imagem de $C_{n}$ em $G / N$ segue que $G / N$ é de Chernikov. Como $N$ e $G / N$ são de Chernikov segue pela Proposição 1.61 que $G$ é de Chernikov. O lema está provado.

Para um grupo de Chernikov $G$, denotaremos por $G^{*}$ o subgrupo $\left[G, G^{0}\right]$.

Lema 1.68 ([24], Lema 2.7). Seja G um grupo de Chernikov. Suponha que exista um inteiro positivo $m$ tal que $G$ possa ser gerado por elementos de ordem dividindo m. Se $G^{*}=1$ então $G$ é finito.

Demonstração. Como $G^{*}=1$, temos que $G^{0} \leq Z(G)$. Assim $G / Z(G)$ é finito e, consequentemente $G^{\prime}$ é finito (Lema 1.31). Como $G$ é gerado por elementos de ordem $m$, concluímos que $G$ possui expoente finito. De fato, sejam $x \in G$ e $\bar{x}$ sua imagem no grupo quociente $G / G^{\prime}$. Temos que $x=x_{1} \cdots x_{s}$, onde cada elemento $x_{i}$ possui ordem dividindo $m$. As imagens de $x_{i}$ em $G / G^{\prime} \operatorname{comutam}\left(G / G^{\prime}\right.$ é abeliano) e, assim $\bar{x}^{m}=1$. Portanto, o grupo quociente $G / G^{\prime}$ possui expoente finito. Sendo $G^{\prime}$ finito, concluímos que $G$ possui expoente finito (Lema 1.18) e, portanto é finito (Lema 1.58 (3)). O lema está provado.

Lema 1.69 ([24], Lema 2.8). Seja $G$ um grupo tal que $\left\langle x^{G}\right\rangle$ seja de Chernikov, para todo $x \in G$. Então todos os subgrupos abelianos e radicáveis de $G$ geram um subgrupo abeliano e radicável.

Um resultado útil que será utilizado no decorrer desta tese é o seguinte teorema acerca de grupos de Chernikov, cuja demonstração pode ser obtida em Robinson [30, Teorema 4.23], p.115 (veja também Polovickii [28]).

Teorema 1.70 (Polovickii). Seja $G$ um grupo tal que $G / Z(G)$ seja de Chernikov. Então $G^{\prime}$ é de Chernikov.

\subsubsection{Grupos de automorfismos de grupos de Chernikov}

Uma questão relevante sobre grupos de Chernikov é o estudo de seus grupos de automorfismos (veja por exemplo Robinson [30, Capítulo 3]). Em geral, se um grupo $G$ for de Chernikov então não é verdade que $A u t(G)$ seja de Chernikov. O seguinte resultado é devido a Baer [4]. 
Lema 1.71 ([30], Lema 3.28). Seja $G$ um produto direto de um número finito de grupos do tipo $C_{p^{\infty}}$ (para vários primos $p$ ) e seja $\alpha$ um automorfismo não-trivial de $G$ que fixe todo elemento de ordem $p$ e, quando $p=2$, fixe todo elemento de ordem 4. Então $\alpha$ possui ordem infinita.

Ainda nesse contexto, o próximo resultado de Baer nos apresenta uma condição para que grupos de automorfismos de grupos de Chernikov sejam de Chernikov.

Teorema 1.72 ([30], Teorema 3.29). Seja A um grupo de automorfismos de um grupo de Chernikov G. Se A for periódico, então A é de Chernikov.

Reciprocamente, em Schlette [34] ("The Main Theorem", p.403, item 4 (b)) foi provado que se $G$ for um grupo periódico, cujos grupos periódicos de automorfismos são de Chernikov, então $G$ é de fato um grupo de Chernikov. O seguinte resultado é devido a Baer [4] e sua demonstração pode ser obtida em Robinson.

Teorema 1.73 ([30], Teorema 3.39.2). Seja A um grupo periódico de automorfismos de um grupo de Chernikov $G$. Então $A / A \cap \operatorname{Inn}(G)$ é finito.

Corolário 1.74 ([30], Corolário do Teorema 3.29.2, p.85). Seja G um grupo de Chernikov. Se o centro de $G$ possui indice finito então qualquer subgrupo periódico dos automorfismos de $G$ é finito.

Lema 1.75 ([24], Lema 2.5). Seja A um grupo radicável e de Chernikov agindo sobre um grupo de Chernikov $B$. Então $[B, A, A]=1$.

Demonstração. Seja $B^{0}$ a parte radicável de $B$. Então $A / C_{A}\left(B^{0}\right)$ é finito (Teorema 1.73). Observe que $A$ não possui subgrupos de índice finito (Lema 1.43). Assim, segue que $C_{A}\left(B^{0}\right)=A$ e, portanto, $\left[A, B^{0}\right]=1$. Por outro lado, $B / B^{0}$ é finito e, consequentemente, segue que $A / C_{A}\left(B / B^{0}\right)$ é também finito. Novamente, como $A$ não possui subgrupos de índice finito, segue que $[B, A] \leq B^{0}$. Assim segue que

$$
[B, A, A] \leq\left[B^{0}, A\right]=1
$$

O lema está provado.

A demonstração do Lema 1.75, pode ser repetida ainda que seja retirada a hipótese de $A$ ser de Chernikov, de modo que vale o seguinte resultado mais geral.

Lema 1.76. Seja A um grupo periódico e radicável agindo sobre um grupo de Chernikov B. Então $[B, A, A]=1$. 
Observação 1.77. Mais sobre o matemático S. N. Chernikov e o desenvolvimento da teoria de grupos infinitos pode ser obtido em [8]. Nesse artigo, os autores se propõem a mostrar o desenvolvimento e a continuação dos estudos em que $S$. N. Chernikov manteve-se como autor principal e a demonstrar a extensão da influência exercida pelas ideias e resultados de Chernikov na teoria moderna de grupos infinitos.

Com essa observação encerramos o capítulo. 


\section{Um critério para um subgrupo normal ser de Chernikov}

\subsection{Resultados obtidos}

Se $\left\{H_{i}\right\}_{i \in I}$ for uma cobertura de um grupo $G$ por subgrupos, é natural indagarmos quais informações sobre $G$ podem ser deduzidas a partir de propriedades dos subgrupos $H_{i}$. No caso em que a cobertura é finita, muito pode ser dito sobre a estrutura do grupo G. O primeiro resultado nesta direção foi apresentado por Baer (veja Neumann [25]), onde ele provou que um grupo $G$ admite um cobertura por um número finito de subgrupos abelianos se, e somente se, $G$ for central-por-finito. Além disso, foi observado por Baer que, se um grupo possuir uma cobertura por um número finito de subgrupos cíclicos então esse grupo é cíclico ou finito (veja Robinson [30, p.123], Corolário do Teorema 4.33). Mais recentemente, Fernández-Alcober e Shumyatsky provaram em [10], que se um grupo $G$ é tal que o conjunto de todos os comutadores está contido em uma união de um número finito de subgrupos cíclicos então $G^{\prime}$ é finito ou cíclico. Isso sugere a questão sobre a estrutura de grupos cujo conjunto de todos os $\gamma_{k}$-comutadores (todos os $\delta_{k}$-comutadores, respectivamente) esteja contido em uma união de um número finito de subgrupos cíclicos. Em [7] Cutolo e Nicotera mostraram que se um grupo $G$ é tal que o conjunto de todos os $\gamma_{k}$-comutadores está contido em uma união de um número finito de subgrupos cíclicos então $\gamma_{k}(G)$ é finito-por-cíclico. Até o momento ainda não é conhecido um resultado similar para as palavras derivadas $\delta_{k}$.

Em [32] Rogério e Shumyatsky provaram os seguintes teoremas envolvendo subgrupos de Chernikov.

Teorema 2.1 ([32], Teorema 1). Sejam $k$ um inteiro positivo e $G$ um grupo tal que o conjunto de todos os $\boldsymbol{\delta}_{k}$-comutadores esteja contido em uma união de um número finito de subgrupos de Chernikov. Então $G^{(k)}$ é de Chernikov. 
Teorema 2.2 ([32], Teorema 2). Sejam $k$ um inteiro positivo e $G$ um grupo tal que o conjunto de todos os $\gamma_{k}$-comutadores esteja contido em uma união de um número finito de subgrupos de Chernikov. Então $\gamma_{k}(G)$ é de Chernikov.

Nesse capítulo nos propomos a generalizar os Teoremas 2.1 e 2.2, substituindo a hipótese do conjunto de todos os $\boldsymbol{\delta}_{k^{-}}$comutadores (respectivamente, $\gamma_{k^{-}}$ comutadores) de um grupo $G$ estar contido em uma união de um número finito de subgrupos de Chernikov por um subconjunto normal estar contido em uma união de um número finito de subgrupos de Chernikov. Mais precisamente, provaremos o seguinte resultado.

Teorema 2.3. Seja $X$ um subconjunto normal de um grupo G. Suponha que exista um número finito de subgrupos de Chernikov tais que $X$ esteja contido na união destes subgrupos. Então $\langle X\rangle$ é de Chernikov.

O objetivo principal deste capítulo é provar o Teorema 2.3.

\section{$2.2 \quad$ A prova do Teorema 2.3}

Iniciamos os resultados desse capítulo com o seguinte lema.

Lema 2.4. Se G for um grupo hipercentral gerado por seus subgrupos quase-cíclicos, então $G$ é abeliano.

Demonstração. Seja I um conjunto de índices e suponha que $G$ seja um grupo hipercentral tal que

$$
G=\left\langle Q_{i} ; Q_{i} \leq G \text { é quase-cíclico, } i \in I\right\rangle
$$

Seja $Q$ um subgrupo quase-cíclico de $G$. Sendo $G$ hipercentral, segue que $Q$ é ascendente (Proposição 1.39) e, portanto $\left\langle Q^{G}\right\rangle$ é abeliano e radicável (Lema 1.49). Sejam $x, y \in G$. Então $x=x_{1} \cdots x_{s}$, onde $x_{i} \in Q_{i_{x}}$ com $i_{x} \in I$ para todo $i \in\{1, \ldots, s\}$. Analogamente, $y=y_{1} \cdots y_{l}$, onde $y_{j} \in Q_{j_{y}}$ com $j_{y} \in I$ para todo $j \in\{1, \ldots, l\}$. Considere $M$ como o produto dos fechos normais de todos os subgrupos $Q_{i_{x}}$ e $Q_{j_{y}}$. Então $M$ é abeliano (Lema 1.51). Como $x, y \in M$, segue que $x$ e $y$ comutam. Uma vez que $x$ e $y$ foram escolhidos arbitrariamente em $G$, concluímos que $G$ é abeliano. O lema está provado.

Uma outra demonstração para o Lema 2.4 pode ser obtida combinando os Corolários 1 e 2 do Teorema 9.23 de [31], p.125.

Seja $X$ um subconjunto normal de um grupo $G$ satisfazendo as hipóteses do Teorema 2.3. Suponha que $C_{1}, \ldots, C_{k}$ sejam os subgrupos de Chernikov cuja união 
contenha todos os elementos de $X$. Dentre todas as escolhas possíveis para tais subgrupos, tome $C_{1}, \ldots, C_{k}$ tais que a soma de seus tamanhos, digamos $s(X)$, seja minimal. Assim,

$$
s(X)=\sum_{i=1}^{k} \operatorname{tam}\left(C_{i}\right),
$$

é o menor possível. A prova do Teorema 2.3 se dará por indução sobre $s(X)$.

Seja $G$ um contra exemplo, tal que a soma $s(X)$ é a menor possível. Dividiremos a demonstração do Teorema 2.3 em diversos lemas que se seguem.

Lema 2.5. Os subgrupos $C_{1}, \ldots, C_{k}$ são gerados por elementos de $X$. Em particular, $\langle X\rangle=\left\langle C_{1}, \ldots, C_{k}\right\rangle$.

Demonstração. Suponha que exista um índice $i \in\{1, \ldots, k\}$ tal que $C_{i}$ não seja gerado por elementos de $X$. Seja $M_{i}$ um subgrupo minimal infinito de $C_{i}$ gerado por todos elementos de $X$. Então $M_{i}<C_{i}$. Consequentemente, o tamanho de $M_{i}$ é estritamente menor do que o tamanho de $C_{i}$ (Lema 1.63 (1)). Além disso, temos que

$$
X \subseteq C_{1} \cup \cdots \cup C_{i-1} \cup M_{i} \cup C_{i+1} \cup \cdots \cup C_{k}
$$

Por simplicidade, denote por $M_{j}$ o subgrupo $C_{j}$, para cada $j \neq i$. Seja $s(M)$ a soma dos tamanhos dos subgrupos $M_{1}, \ldots, M_{k}$. Como $\operatorname{tam}\left(M_{i}\right)<\operatorname{tam}\left(C_{i}\right)$ concluímos que $s(M)<s(X)$. Portanto, por hipótese de indução, o subgrupo $\left\langle M_{1}, \ldots, M_{i}, \ldots M_{k}\right\rangle$ é de Chernikov e assim segue que $\langle X\rangle$ é de Chernikov, uma contradição. Logo para todo índice $i \in\{1, \ldots, k\}$ podemos supor que $C_{i}$ é gerado por elementos de $X$. Por fim, note que $\langle X\rangle \leq\left\langle C_{1}, \ldots, C_{k}\right\rangle$. Por outro lado, como para cada $i=1, \ldots, k$ temos que $C_{i}=\left\langle C_{i} \cap X\right\rangle$ e assim segue que $C_{i} \leq\langle X\rangle$ para todo índice $i$, donde obtemos a igualdade desejada. O lema está provado.

Sejam $C_{1}^{0}, \ldots, C_{k}^{0}$ as partes radicáveis de $C_{1}, \ldots, C_{k}$, respectivamente. Denote por $C$ o fecho normal em $G$ dos subgrupos $C_{1}^{0}, \ldots, C_{k}^{0}$.

$$
C=\left\langle\left(C_{1}^{0}, \ldots, C_{k}^{0}\right)\right\rangle
$$

Então $C$ não possui subgrupos próprios de índice finito (Corolário 1.44).

Se $C=1$ então $C_{i}^{0}=1$ para todo índice $i=1, \ldots, k$ e, consequentemente, cada subgrupo de Chernikov $C_{i}$ seria finito. Logo $X$ seria um subconjunto normal e finito, de modo que o subgrupo $\langle X\rangle$ seria finito (Lema 1.26). Assim podemos supor que $C \neq 1$. Em particular, existe $i \in\{1, \ldots, k\}$ tal que $C_{i}^{0} \neq 1$. Sem perda de generalidade, suponha que $C_{1}^{0} \neq 1$. Note que, isso significa que podemos supor que $C_{1}$ seja infinito. 
Seja $H$ um subgrupo infinito minimal de $C_{1}$, gerado por elementos de $X$. Observe que sendo $H$ infinito então $H$ é infinitamente gerado, uma vez que grupos de Chernikov são localmente finitos (Lema 1.58 (1)).

Lema 2.6. Para todo $x \in G$, existe um índice $i$ tal que $H^{x} \leq C_{i}$.

Demonstração. De fato, suponha que exista $x \in G$ tal que $H^{x} \not \leq C_{i}$, para todo índice $i=1, \ldots, k$. Seja $L \subseteq X$, infinito tal que $H=\langle L\rangle$. Então $L^{x} \subseteq X$, uma vez que $X$ é um subconjunto normal em $G$. Assim,

$$
L^{x} \subseteq \bigcup_{i=1}^{k} C_{i}
$$

Obviamente, existe um índice $j \in\{1, \ldots, k\}$ tal que $L^{x} \cap C_{j}$ seja infinito. Defina $T=H^{x} \cap C_{j}$. Consequentemente $T$ é infinito. Note que $T^{x^{-1}}$ é um subgrupo infinito contido em $C_{1}$, gerado por elementos de $X$ (pois $T$ é gerado por elementos de $X)$. Como $H$ é minimal com esta propriedade, segue que $H^{x}=T$ e portanto $H^{x} \leq C_{j}$. O lema está provado.

Lema 2.7. O subgrupo $C$ é abeliano.

Demonstração. Seja a um elemento qualquer em $H^{0}$. Dado $x \in G$ existe um índice $i$ tal que $H^{x} \leq C_{i}$ (Lema 2.6). Consequentemente, todo conjugado $a^{x}$ pertence a $C_{i}^{0}$ para algum $i \in\{1, \ldots, k\}$ (Lema 1.60). Como cada subgrupo $C_{i}^{0}$ tem camadas finitas (Lema 1.66), concluímos que a classe de conjugação $a^{G}$ é finita e que, portanto, a classe $a^{C}$ também é finita. Uma vez que $C$ não possui subgrupos próprios de índice finito, segue que $a \in Z(C)$. Portanto, mostramos que $H^{0} \leq Z(C)$. Note que $Z(C) \unlhd G$. Passando ao quociente, podemos repetir o argumento anterior substituindo $G$ por $G / Z(C)$ e, concluirmos que se $C \neq Z(C)$, então $Z_{2}(C) \neq Z(C)$. Continuando este processo, podemos ver que $C$ é hipercentral. Como $C$ é gerado por subgrupos quase-cíclicos, segue que $C$ é abeliano (Lema 2.4).

Lema 2.8. Seja $N=\left\langle\left(H^{0}\right)^{G}\right\rangle$. Então $N$ é um subgrupo de Chernikov.

Demonstração. Recorde que $C$ é abeliano (Lema 2.7). Assim, dados dois índices $i, j \in\{1, \ldots, k\}$, segue que os subgrupos $C_{i}^{0}$ e $C_{j}^{0}$ se centralizam. Se $x \in G$ então pelo Lema 2.6 existe $i \in\{1, \ldots, k\}$ tal que $\left(H^{0}\right)^{x} \leq C_{i}^{0}$. Portanto, concluímos que $N$ é um subgrupo do grupo $M=\left\langle C_{1}^{0}, \ldots, C_{k}^{0}\right\rangle$. Uma vez que $M$ é de Chernikov (Lema 1.67) concluímos que $N$ é de Chernikov (Proposição 1.61). O lema está provado. 
Agora estamos em condições de completar a prova do Teorema 2.3.

A Prova do Teorema 2.3

Seja $N=\left\langle\left(H^{0}\right)^{G}\right\rangle$. Como $N \unlhd G$, podemos considerar o quociente $G / N$. Observe que $N$ é infinito (pois $H^{0} \leq N$ ). Sendo $N$ de Chernikov (Lema 2.8) segue que a soma dos tamanhos das imagens de $C_{1}, \ldots, C_{k}$ no quociente $G / N$ é estritamente menor do que a soma dos tamanhos de $C_{1}, \ldots, C_{k}$ (Lema 1.63(2)). Portanto por indução sobre a soma dos tamanhos de $C_{1}, \ldots, C_{k}$ a imagem de $\langle X\rangle$ em $G / N$ é de Chernikov. Uma vez que $N$ é de Chernikov segue $\langle X\rangle$ é de Chernikov (Proposição 1.61). O teorema está provado.

Como citado no início do capítulo, o Teorema 2.3 generaliza os Teoremas 2.1 e 2.2. De fato, destacamos que vale o seguinte resultado mais geral.

Corolário 2.9. Sejam w uma palavra de grupo e G um grupo. Suponha que o conjunto de todos os w-valores de $G$ esteja contido em uma união de um número finito de subgrupos de Chernikov. Então o subgrupo verbal $w(G)$ é de Chernikov.

Demonstração. Seja $G_{w}$ o conjunto dos $w$-valores de $G$. Então $G_{w}$ é um subconjunto normal em $G$. O resultado agora é imediato pelo Teorema 2.3. 


\section{Grupos com classes de conjugação verbal limitadas}

\subsection{Resultados obtidos}

Recorde que se $w$ for uma palavra, então $G_{w}$ denota o conjunto dos $w$ valores de $G$ e $w(G)=\left\langle G_{w}\right\rangle$ denota o subgrupo verbal associado à palavra $w$. Em [11] Franciosi, de Giovanni e Shumyatsky denominaram grupos $G$ com a propriedade que $x^{G_{w}}$ seja finito para todo $x \in G$ de $\mathrm{FC}(w)$-grupos. Lembremos que FC-grupos são exatamente os grupos com classes de conjugação finitas. O principal resultado de [11] garante que se $w$ for uma palavra concisa então um grupo $G$ é um $\mathrm{FC}(w)$-grupo se, e somente se, $x^{w(G)}$ for finito para todo $x \in G$. Em particular, segue que se $G$ for um $\mathrm{FC}(w)$-grupo então o subgrupo verbal $w(G)$ é um FC-grupo. Posteriormente, foi mostrado em [5] que se $w$ for uma palavra concisa, tal que $x^{G_{w}}$ possua no máximo $m$ elementos para todo $x \in G$, então existe uma função $f=f(m, w)$ tal que $x^{w(G)}$ possui no máximo $f$ elementos, para todo $x \in G$. Ainda sobre o estudo de condições de finitude para classes de conjugação verbal, Muñoz-Escolano e Shumyatsky provaram em [24] o seguinte resultado.

Teorema 3.1 ([24], Teorema 1.1). Sejam n um inteiro positivo e w a n-ésima palavra central inferior $\gamma_{n}$ ou a n-ésima palavra derivada $\boldsymbol{\delta}_{n}$. Suponha que $G$ seja um grupo tal que $\left\langle g^{G_{w}}\right\rangle$ seja de Chernikov para todo $g \in G$. Então $\left\langle g^{w(G)}\right\rangle$ é de Chernikov para todo $g \in G$.

Nesse capítulo buscamos fortalecer o Teorema 3.1, provando o seguinte teorema.

Teorema 3.2. Sejam $n$ um inteiro positivo e $w$ a palavra central inferior $\gamma_{n}$ ou a palavra derivada $\boldsymbol{\delta}_{n}$. Suponha que $G$ seja um grupo tal que, para cada elemento $g \in G$ exista um número finito de subgrupos de Chernikov cuja união contenha $g^{G_{w}}$. Então $\left\langle g^{w(G)}\right\rangle$ é de Chernikov para todo $g \in G$.

O objetivo deste capítulo é provar o Teorema 3.2. 


\subsection{Resultados auxiliares}

Dedicamos esta seção à obtenção de resultados que serão importantes na demonstração do Teorema 3.2 .

Proposição 3.3. Seja $G$ um grupo gerado por um elemento $g$ e por algum subgrupo radicável $S$. Suponha que $G$ possua um número finito de subgrupos de Chernikov cuja união contenha a classe de conjugação $g^{S}$. Então o subgrupo $\left\langle g^{S}\right\rangle$ é de Chernikov.

Seja $G=\langle g, S\rangle$ um grupo satisfazendo as hipóteses da Proposição 3.3. Suponha que a proposição seja falsa e que, portanto, o subgrupo $\left\langle g^{S}\right\rangle$ não seja de Chernikov. Sejam $C_{1}, \ldots, C_{k}$ os subgrupos de Chernikov tais que

$$
g^{S} \subseteq \bigcup_{i=1}^{k} C_{i}
$$

Sem perda de generalidade, podemos assumir que os subgrupos $C_{1}, \ldots C_{k}$ sejam escolhidos de tal maneira que a soma de seus tamanhos seja o menor possível. Dividiremos a prova da Proposição 3.3 em diversos lemas que se seguem.

Lema 3.4. Para cada $i=1, \ldots, k$ o subgrupo $C_{i}$ é gerado por elementos de $C_{i} \cap g^{S}$.

Demonstração. De fato, suponha que exista um índice $i \in\{1, \ldots, k\}$ tal que $C_{i}$ não seja gerado por elementos de $C_{i} \cap g^{S}$. Seja $M_{i}$ um subgrupo infinito de $C_{i}$ gerado por todos elementos de $g^{S}$. Então $M_{i}<C_{i}$. Note que

$$
g^{S} \subseteq C_{1} \cup \cdots \cup C_{i-1} \cup M_{i} \cup C_{i+1} \cup \cdots \cup C_{k}
$$

Como $M_{i}<C_{i}$ segue que a soma dos tamanhos dos subgrupos $C_{1}, \ldots, C_{i-1}, M_{i}, C_{i+1}, \ldots C_{k}$ é estritamente menor do que a soma dos tamanhos dos subgrupos de Chernikov $C_{1}, \ldots, C_{i}, \ldots, C_{k}$ (Lema 1.63(2)). Porém isso é uma contradição uma vez que os subgrupos $C_{1}, \ldots, C_{k}$ foram tomados tais que a soma de seus tamanhos seja minimal. O lema está provado.

Seja $U=\left\langle g^{S}\right\rangle$. Como $G=\langle g, S\rangle$ concluímos que $U=\left\langle g^{G}\right\rangle$. Em particular, o subgrupo $U$ é normal em $G$. Observe entretanto que o subconjunto $g^{S}$ em geral não é normal em $G$.

Lema 3.5. Existe ao menos um indice $i \in\{1, \ldots, k\}$ tal que o subgrupo $C_{i}$ seja infinito.

Demonstração. De fato, se todos os subgrupos $C_{1}, \ldots, C_{k}$ fossem finitos, então $g^{S}$ seria finito, pois

$$
g^{S} \subseteq \bigcup_{i=1}^{k} C_{i}
$$


Como $\left|g^{S}\right|=\left|S: C_{S}(g)\right|$ (Lema $1.1(2)$ ) segue que o subgrupo $C_{S}(g)$ possui índice finito em $S$. Sendo $S$ radicável, concluímos que $S=C_{S}(g)$ (Lema 1.43) e, em particular, $g^{S}=\{g\}$. Como existe um índice $i \in\{1, \ldots, k\}$ tal que $g \in C_{i}$, concluímos que o elemento $g$ possui ordem finita e assim o subgrupo $U=\left\langle g^{S}\right\rangle$ seria finito uma contradição. O lema está provado.

Sem perda de generalidade, suponhamos que o subgrupo $C_{1}$ seja infinito. Dentre todos os subgrupos infinitos de $C_{1}$ que são gerados por elementos de $g^{S}$, tomemos um minimal com essa propriedade. Seja $K$ tal subgrupo.

Lema 3.6. Para todo $x \in S$ existe um indice $j \in\{1, \ldots, k\}$ tal que $K^{x} \leq C_{j}$.

Demonstração. Seja $Y=K \cap g^{S}$. Observe que $K=\langle Y\rangle$. Sendo $C_{1}$ de Chernikov, segue que $C_{1}$ é localmente finito (Lema 1.58 (1)). Uma vez que $K$ foi tomado um subgrupo infinito, contido em $C_{1}$, temos que $K$ não pode ser finitamente gerado. Logo podemos assumir que $Y$ seja infinito. Como $S$ normaliza o subconjunto $g^{S}$ segue que $Y^{z} \subseteq g^{S}$, para todo $z \in S$. Seja $x$ um elemento qualquer em $S$. Obviamente existe um índice $j \in\{1, \ldots, k\}$ tal que $Y^{x} \cap C_{j}$ seja infinito. Considere $L$ como sendo o subgrupo gerado por $C_{j} \cap Y^{x}$. Então $L^{x^{-1}}$ é um subgrupo infinito de $K$, gerado por algum subconjunto de $Y$. Devido à minimalidade de $K$ concluímos que $L^{x^{-1}}=K$ e, portanto, segue que $K^{x} \leq C_{j}$. O lema está provado.

Lema 3.7. Se $K^{0}$ denota a parte radicável de $K$ então $\left[K^{0}, S\right]=1$.

Demonstração. Seja $a \in K^{0}$. Para cada $x \in S$ podemos combinar os Lemas 1.60 e 3.6 para concluirmos que existe um índice $j \in\{1, \ldots, k\}$ tal que $a^{x} \in C_{j}^{0}$. Como cada subgrupo $C_{j}^{0}$ tem camadas finitas (Lema 1.66), segue que a classe de conjugação $a^{S}$ é finita e consequentemente temos que $C_{S}(a)=S$ (Lema 1.43). Assim $[a, S]=1$. Como $a$ foi escolhido arbitrariamente em $K^{0}$, segue que $\left[K^{0}, S\right]=1$. O lema está provado

Agora estamos em condições de concluirmos a demonstração da Proposição 3.3.

A prova dA Proposição 3.3

Seja $G=\langle g, S\rangle$, onde $S$ é um subgrupo radicável de $G$. Suponhamos que existam $C_{1}, \ldots, C_{k}$, subgrupos de Chernikov, tais que $g^{S} \subseteq \bigcup_{i=1}^{k} C_{i}$. Suponhamos ainda que $C_{1}$ seja infinito (Lema 3.5). Sem perda de generalidade, assuma que $g \in C_{1}$. De fato, se $g \notin C_{1}$, tome $z \in S$ tal que $g_{1}=g^{z} \in C_{1}$ (tal elemento $z$ existe, pois $g^{S} \subseteq \cup C_{i}$ ). Note que $G=\left\langle g_{1}, S\right\rangle$. Assim, poderíamos repetir todos os argumentos dos lemas anteriores substituindo o elemento $g$ por $g_{1} \in C_{1}$. Seja $K$ um subgrupo minimal de $C_{1}$ gerado por elementos de $g^{S}$. Como descrito na demonstração do Lema 3.6, seja $Y=K \cap g^{S}$. Note que $g \in Y$, pois claramente $g \in g^{S}$ e uma vez que estamos supondo 
$g \in C_{1}$ segue que $g \in K$. Portanto, concluímos que $G=\langle Y, S\rangle$. Uma vez que $K=\langle Y\rangle$ e como $K^{0}$ é normal em $K$ concluímos que $Y$ normaliza $K^{0}$. Além disso, $\left[K^{0}, S\right]=1$ (Lema 3.7). Logo $K^{0}$ é normal em $G$. Sendo $K$ infinito, segue que $K^{0}$ é infinito (Lema 1.42). Assim o tamanho da imagem de $C_{1}$ em $G / K^{0}$ é estritamente menor do que o tamanho de $C_{1}$ (Lema 1.63(2)). Portanto por indução sobre a soma dos tamanhos do subgrupos $C_{1}, \ldots, C_{k}$ concluímos que $\left\langle g^{S}\right\rangle K^{0} / K^{0}$ é de Chernikov. Sendo $K^{0}$ de Chernikov obtemos que $\left\langle g^{S}\right\rangle$ é de Chernikov (Proposição 1.61). A proposição está provada.

\subsection{A prova do Teorema 3.2}

A partir de agora assumiremos as hipóteses do Teorema 3.2. Primeiramente, provaremos o Teorema 3.2 considerando o caso $w=\delta_{n}$. Posteriormente, na subseção 3.3.2, apresentaremos a demonstração do Teorema 3.2 para o caso $w=\gamma_{n}$.

\subsubsection{O caso $w=\delta_{n}$}

Sejam $n$ um inteiro positivo, $w=\delta_{n}$ e $X=G_{w}$ o conjunto de todos os $\delta_{n^{-}}$ valores de $G$. Denote por $H$ o subgrupo gerado por $X$. Portanto,

$$
H=G^{(n)} .
$$

Suponha que $G$ seja um grupo satisfazendo as hipóteses do Teorema 3.2, isto é, suponha que para todo elemento $g \in G$ exista uma quantidade finita de subgrupos de Chernikov cuja união contenha $g^{G_{w}}$. Com estas notações, mostraremos que $\left\langle g^{H}\right\rangle$ é de Chernikov para todo $g \in G$.

Seja $B$ o subgrupo de $G$ gerado por todos os subgrupos da forma $[T, x]$ onde $T$ é um subgrupo abeliano e radicável contido em $G$ e $x$ um elemento de $X$ que normalize $T$.

Lema 3.8. O subgrupo B é abeliano.

Demonstração. Seja $S=[T, x]$, onde $T$ é um subgrupo abeliano e radicável, e $x$ um elemento de $X$ que normalize $T$. Observe que $G$ é um grupo periódico, pois para cada $g \in G$, existe um subgrupo de Chernikov $C$ tal que $g \in C$. O Lema 1.54 garante que o subgrupo $S$ é radicável. Decorre do Lema 1.53 que

$$
S=[S, x]=[S, \underbrace{x, \ldots, x}_{n}]
$$


Pelo Lema 1.16 concluímos que todo elemento de $S$ é um $\delta_{n}$-comutador. Consequentemente, $S$ é um grupo abeliano e radicável contido em $X$. Seja $a \in G$ um elemento qualquer. Decorre da Proposição 3.3 que o subgrupo $\left\langle a^{S}\right\rangle$ é de Chernikov. Claramente o subgrupo $S$ (radicável) age sobre o subgrupo de Chernikov $\left\langle a^{S}\right\rangle$ e assim pelo Lema 1.76 concluímos que

$$
\left[\left\langle a^{S}\right\rangle, S, S\right]=1
$$

Em particular, segue que $[a, S, S]=1$. Consequentemente concluímos que os subgrupos $S$ e $S^{a}$ comutam. Como $a$ foi escolhido arbitrariamente em $G$, segue que os subgrupos $S$ e $S^{g}$ comutam para todo $g \in G$. Portanto, o fecho normal $\left\langle S^{G}\right\rangle$ é abeliano. O Lema 1.51 garante que um produto de subgrupos normais, abelianos, radicáveis e periódicos é abeliano. Sendo $B$ um produto de tais grupos, concluímos que $B$ é abeliano. O lema está provado.

Claramente $B$ é um subgrupo normal de $G$. Observe entretanto que $B \leq H$. De fato, $B$ é gerado por subgrupos da forma $[T, x]$, com $x \in X$ agindo sobre o subgrupo abeliano e radicável $T$. Como observado na demonstração do Lema 3.8, temos que $[T, x]=[T, \underbrace{x, \ldots, x}_{n}]$, de modo que, todo elemento em $[T, x]$ é um $\delta_{n}$-comutador. Logo $[T, x] \subseteq X$ donde concluímos que $[T, x] \leq H$. Sendo $B$ gerado por tais subgrupos segue que $B \leq H$. Assim, podemos considerar o grupo quociente $H / B$. O próximo resultado garante que esse quociente é um FC-grupo.

Lema 3.9. O grupo quociente $H / B$ é um FC-grupo.

Demonstração. Sob a hipótese adicional de que $B=1$, é suficiente provarmos que $H$ seja um FC-grupo. Provaremos primeiramente que o índice $\left|H: C_{H}(x)\right|$ é finito para todo $x \in X$. Portanto, a partir de agora assuma que $B=1$. Suponha o lema falso e escolha $x \in X$ tal que $\left|H: C_{H}(x)\right|$ seja infinito. Sejam $Y=x^{X}$ e $C_{1}, \ldots, C_{k}$ os subgrupos de Chernikov tais que

$$
Y \subseteq \bigcup_{i=1}^{k} C_{i} .
$$

Sem perda de generalidade podemos assumir que os subgrupos $C_{1}, \ldots, C_{k}$ foram escolhidos de tal maneira que a soma dos seus tamanhos seja a menor possível. Neste caso, é claro que cada subgrupo $C_{i}$ é gerado por elementos de $C_{i} \cap Y$. Se os subgrupos $C_{1}, \ldots, C_{k}$ fossem todos finitos então $Y$ seria finito e portanto pelo Teorema 1.33 a classe de conjugação $x^{H}$ seria finita também. Porém como $\left|x^{H}\right|=\left|H: C_{H}(x)\right|$ (Lema $1.1(2))$ segue que ao menos um dos subgrupos $C_{1}, \ldots, C_{k}$ é infinito. Assuma que $C_{1}$ seja infinito e seja $Y_{1}=Y \cap C_{1}$. Note que $C_{1}=\left\langle Y_{1}\right\rangle$ (pois estamos assumindo que $C_{1}$ seja gerado por elementos de $\left.Y \cap C_{1}\right)$. Seja $C_{1}^{0}$ a parte radicável de $C_{1}$. Para todo $y \in Y_{1}$ temos que $\left[C_{1}^{0}, y\right] \leq B$. Como $B=1$ segue que $Y_{1}$ centraliza $C_{1}^{0}$ e assim concluímos que 
$C_{1}^{0} \leq Z\left(C_{1}\right)$. Logo pelo Lema 1.68 segue que $C_{1}$ é finito, uma contradição. O lema está provado.

O próximo resultado garante que o grupo $G$ é localmente finito.

Lema 3.10. O grupo $G$ é localmente finito.

Demonstração. Pelo Lema 3.9 temos que o grupo quociente $H / B$ é um FC-grupo. Uma vez que $G$ seja um grupo periódico, concluímos pelo Lema 1.29 que $H / B$ é localmente finito. Como $B$ é um grupo periódico abeliano (Lema 3.8) segue que $B$ é localmente finito. Consequentemente, pelo Teorema 1.20 concluímos que $H$ é um subgrupo localmente finito. Observe agora que o quociente $G / H$ é solúvel e periódico. Decorre do Lema 1.21 que $G / H$ é localmente finito. Novamente, utilizando o Teorema 1.20 concluímos que $G$ é localmente finito. O lema está provado.

Lema 3.11. Para todo $g \in G$, então a imagem de $C=\left\langle g^{H}\right\rangle$ em $G / B$ é de Chernikov.

Demonstração. Sem perda de generalidade podemos assumir que $B=1$ e assim segue que $H$ é um FC-grupo (Lema 3.9). Como $G$ é um grupo localmente finito (Lema 3.10) segue que $\left\langle x^{H}\right\rangle$ é finito para todo $x \in H$. Denote por $Q$ o subgrupo gerado por todos os subgrupos abelianos e radicáveis contidos em $H$. Pelo Lema 1.69 concluímos que $Q$ é abeliano e radicável. Sendo $H$ periódico segue que $Q$ é um produto direto de grupos quase-cíclicos (Teorema 1.40). Porém pelo Teorema 1.45 temos que cada um desses subgrupos quase-cíclicos é central em $H$. Desse modo, concluímos que todos os subgrupos abelianos e radicáveis de $H$ são centrais.

Sejam $g \in G$ e $C_{1}, \ldots, C_{k}$ o número finito de subgrupos de Chernikov tais que,

$$
g^{X} \subseteq \bigcup_{i=1}^{k} C_{i} .
$$

Denote por $C_{i}^{0}$ a parte radicável de $C_{i}$. Uma vez que $H$ é FC-grupo, concluímos que o subgrupo $J=\left\langle C_{1}^{0}, \ldots, C_{k}^{0}\right\rangle$ é de Chernikov, visto que é gerado por um número finito de subgrupos de Chernikov que se centralizam (Lema 1.67). Seja $n$ a ordem do elemento $g$ e seja

$$
J_{1}=\prod_{i=0}^{n-1} J^{g^{i}} .
$$

Note que $J_{1}$ é um subgrupo de Chernikov. Seja $M=H\langle g\rangle$ e observe que $M$ normaliza $J_{1}$. Para ver isso note que para todo $i=1, \ldots, k$ o subgrupo $C_{i}^{0}$ está contido no centralizador de $H$ em $G$. De fato, dado $x \in X$, para cada índice $j=1, \ldots, k$, denote por $M_{j}$ o subgrupo $\left[C_{j}^{0}, x\right]$. Seja $i \in\{1, \ldots, k\}$. Assim, $M_{i}$ é abeliano e radicável (Lema 
1.54). Além disso,

$$
M_{i}=\left[M_{i}, x\right]=[M_{i}, \underbrace{x, \ldots, x}_{n}] \quad(\text { Lema 1.53). }
$$

Consequentemente, $M_{i} \subseteq X$. Como estamos supondo $B=1$, segue que $M_{i}=1$. Logo concluímos que $C_{i}^{0} \leq C_{G}(H)$. Portanto $H$ centraliza $J$ e uma vez que $H \unlhd G$ segue que $H$ centraliza $J^{g^{i}}$ para todo $i=0,1, \ldots$ Consequentemente concluímos que $\left[M, J_{1}\right]=\left[H\langle g\rangle, J_{1}\right] \leq J_{1}$.

Observe que os subgrupos $C_{1}, \ldots, C_{k}$ possuem imagens finitas no quociente $M J_{1} / J_{1}$. Consequentemente, a imagem da classe de conjugação verbal $g^{X}$ em $M J_{1} / J_{1}$ é finita e portanto obtemos que a imagem da classe de conjugação $g^{H}$ em $M J_{1} / J_{1}$ é finita (Lema 1.22). Como $g$ possui ordem finita, segue que a imagem de $\left\langle g^{H}\right\rangle$ em $M J_{1} / J_{1}$ é finita (Lema 1.26). Por fim, sendo $J_{1}$ de Chernikov, concluímos que $\left\langle g^{H}\right\rangle$ é de Chernikov (Proposição 1.61). O lema está provado.

Lema 3.12. Para todo $h \in H$ o subgrupo $[B, h]$ é de Chernikov.

Demonstração. Suponha primeiramente que $h \in X$. Por um argumento já repetido diversas vezes nesse capítulo, temos que $[B, h] \subseteq X$. Além disso, $[B, h]$ é abeliano e radicável (Lema 1.54). Consequentemente, o subgrupo $\left\langle h^{[B, h]}\right\rangle$ é de Chernikov (Proposição 3.3). Porém $[B, h]=[B, h, h]$ (Lema 1.53) e como $[B, h, h] \leq\left\langle h^{[B, h]}\right\rangle$ (Lema $1.5(1))$, concluímos que $[B, h]$ é de Chernikov para todo $h \in X$.

Agora podemos deixar de lado a hipótese de que $h \in X$ e assumirmos que $h \in H$. Uma vez que $h \in H$ segue que $h$ pode ser escrito como um produto de um número finito de elementos em $X$. Sejam $x_{1}, \ldots, x_{l} \in X$ tais que $h=x_{1} \ldots x_{l}$. Então

$$
[B, h] \leq \prod_{i=1}^{l}\left[B, x_{i}\right] .
$$

Como mostrado anteriormente $\left[B, x_{i}\right]$ é de Chernikov para todo $i=1, \ldots, l$. Além disso $\left[B, x_{i}\right] \leq B$ para todo $i \in\{1, \ldots, l\}$ e assim segue que os subgrupos $\left[B, x_{i}\right]$ e $\left[B, x_{j}\right]$ comutam para quaisquer $i, j \in\{1, \ldots, l\}$. Consequentemente, o produto

$$
\prod_{i=1}^{l}\left[B, x_{i}\right]
$$

é de Chernikov (Lema 1.67) e disso segue que $[B, h]$ é de Chernikov. O lema está provado.

Lema 3.13. Seja A um subgrupo de $H$ cuja imagem em $G / B$ seja abeliana e radicável. Então $[B, A]=1$. 
Demonstração. Seja $a \in A$ e denote por $\bar{A}$ a imagem de $A$ em $G / B$. Como $B$ é abeliano (Lema 3.8 ) segue que $\bar{A}$ age naturalmente sobre $[B, a]$ e claramente $[B, a, \bar{A}]=[B, a, A]$. Pelo Lema 3.12 o subgrupo $[B, a]$ é de Chernikov. Segue do Lema 1.76 que $[B, a, \bar{A}, \bar{A}]=1$. Logo concluímos que $[B, a, A, A]=1$. Em particular, $[B, a, a, a]=1$. Pelo Lema 1.53 temos que $[B, a]=[B, a, a]$. Consequentemente segue que $[B, a]=1$. Como $a$ foi escolhido de maneira arbitrária no subgrupo $A$ concluímos que $[B, A]=1$. O lema está provado.

Lema 3.14. Para todo $g \in G$ o subgrupo $[B, g]$ é de Chernikov.

Demonstração. Como observado na prova do Lema 3.8, se $T$ for um subgrupo abeliano e radicável e se $x \in X$ for um elemento que normalize $T$, então $S=[T, x]$ é um subgrupo abeliano e radicável contido em $X$. Consequentemente, concluímos que $B$ é o produto de seus subgrupos abelianos e radicáveis $S_{1}, S_{2}, \ldots$, cada um dos quais, por sua vez, está contido em $X$. Sejam $g \in G$ e $C_{1}, \ldots, C_{k}$ a quantidade finita de subgrupos de Chernikov tais que

$$
g^{X} \subseteq \bigcup_{i=1}^{k} C_{i}
$$

Para cada $i=1, \ldots, k$, defina

$$
B_{i}=C_{i} \cap B
$$

Uma vez que $G$ é localmente finito (Lema 3.10), segue que $g$ possui ordem finita. Seja $|g|=n$. Para cada $i=1, \ldots, k$ e para todo $j \in\{0,1, \ldots, n-1\}$ considere os subgrupos da forma

$$
\left(B_{i}\right)^{g^{j}}=\left\{b^{g^{j}} ; b \in B_{i}\right\}
$$

Observe que, para qualquer escolha de índices $i$ e $j$, temos que $\left(B_{i}\right)^{g^{j}} \leq B$, pois $B \unlhd G$.

Seja $D$ o produto de todos os subgrupos da forma $\left(B_{i}\right)^{g^{j}}$. Assim

$$
D=\prod_{i, j}\left(B_{i}\right)^{g^{j}}
$$

Então $D$ é um subgrupo de Chernikov, uma vez que é gerado por um número finito de subgrupos de Chernikov que se centralizam (Lema 1.67). Observe que $D$ é normal em $B\langle g\rangle$.

Uma vez que cada subgrupo $S_{l}$ está contido em $X$, segue que

$$
g^{S_{l}} \subseteq \bigcup_{i=1}^{k} C_{i}
$$


Considere a classe de conjugação $g^{S_{l}}=\left\{g^{z} ; z \in S_{l}\right\}$. Como $B$ possui índice finito em $B\langle g\rangle$, concluímos que a imagem de $g^{S_{l}}$ em $B\langle g\rangle / D$ é finita.

Sejam $\bar{g}$ e $\bar{S}_{l}$, respectivamente, as imagens de $g$ e $S_{l}$ em $B\langle g\rangle / D$. Então $\bar{S}_{l}$ é radicável (Lema 1.46). Como a imagem de $g^{S_{l}}$ em $B\langle g\rangle / D$ é finita, concluímos que o índice $\left|\bar{S}_{l}: C_{\bar{S}_{l}}(\bar{g})\right|$ é finito e portanto segue que $\bar{S}_{l}=C_{\bar{S}_{l}}(\bar{g})$. Seja $x \in S_{l}$ e denote por $\bar{x}$ sua imagem em $B\langle g\rangle / D$. Então $\bar{x} \in \bar{S}_{l}$ e consequentemente $[\bar{x}, \bar{g}]=1$. Portanto, $[x, g] D \leq D$, ou seja $[x, g] \in D$. Logo

$$
\left[S_{l}, g\right] \leq D
$$

Em particular, segue que o subgrupo $\left[S_{l}, g\right]$ é de Chernikov.

Por fim, como observado anteriormente, o subgrupo $B$ coincide com o produto dos subgrupos $S_{1}, S_{2}, \ldots$ Assim, obtemos a seguinte igualdade

$$
[B, g]=\prod_{l}\left[S_{l}, g\right]
$$

Como para todo $l=1,2, \ldots$ temos que $\left[S_{l}, g\right] \leq D$, concluímos que

$$
[B, g] \leq D
$$

Consequentemente, $[B, g]$ é de Chernikov uma vez que o produto $\prod_{l}\left[S_{l}, g\right]$ é de Chernikov (Lema 1.67). O lema está provado.

Lema 3.15. Para todo $g \in G$ o subgrupo $\left[B,\left\langle g^{H}\right\rangle\right]$ é de Chernikov.

Demonstração. Sejam $g \in G, K=\left\langle g^{H}\right\rangle$ e $C=C_{K}(B)$. Então $K / C$ age naturalmente sobre $B$. Além disso, é claro que $[B, K]=[B, K / C]$. Lembremos que, a imagem de $K$ em $G / B$ é de Chernikov (Lema 3.11). Considere o subgrupo $K_{1}=K \cap H$. Como $K_{1} \leq K$ segue que a imagem de $K_{1}$ em $G / B$ também é de Chernikov. Seja $A$ o subgrupo de $K_{1}$ cuja imagem em $G / B$ coincida com a parte radicável da imagem de $K_{1}$ em $G / B$. Como $A \leq H$ segue que $[A, B]=1$ (Lema 3.13) e portanto concluímos que $A \leq C$. Note que, módulo $H$, o subgrupo $K$ é cíclico finito (gerado pela imagem de $g$ módulo $H$ ). Consequentemente, $K_{1}$ possui índice finito em $K$. Além disso, $A$ possui índice finito em $K_{1}$. De fato, sejam $\bar{K}_{1}$ e $\bar{K}_{1}^{0}$ as imagens de $K_{1}$ e da parte radicável da imagem de $K_{1}$ em $G / B$, respectivamente. Então $\left|K_{1}: A\right|=\left|\bar{K}_{1}: \bar{K}_{1}^{0}\right|$. Como o índice de $\bar{K}_{1}^{0}$ em $\bar{K}_{1}$ é finito, segue que o índice de $A$ em $K_{1}$ é também finito. Uma vez que $A$ está contido em $C$, segue que o grupo quociente $K / C$ é finito. Suponha que $|K: C|=m$. Tomemos $x_{1}, \ldots, x_{m}$ conjugados de $g$ tais que $\left\{x_{1} C, \ldots, x_{m} C\right\}$ seja um conjunto normal em $K / C$. Assim $K=\left\langle C, x_{1}, \ldots, x_{m}\right\rangle$ e como $[B, C]=1$, segue que $[B, K]$ coincide com o produto dos subgrupos $\left[B, x_{1}\right], \ldots,\left[B, x_{m}\right]$ (Lema 1.10). Uma vez que cada subgrupo da forma 
$\left[B, x_{i}\right]$ é de Chernikov (Lema 3.14), segue pelo Lema 1.67 que o produto

$$
\prod_{i=1}^{m}\left[B, x_{i}\right]
$$

é de Chernikov. Consequentemente, o subgrupo $[B, K]$ é de Chernikov. O lema está provado.

Agora estamos em posição de completar a prova do Teorema 3.2, para o caso $w=\delta_{n}$.

A PROVA DO TEOREMA 3.2, PARA O CASO $w=\delta_{n}$

Sejam $g \in G$ e $K=\left\langle g^{H}\right\rangle$. Decorre do Lema 3.15, que o subgrupo $[B, K]$ é de Chernikov. Note que $[B, K]$ é normal em $H K$. Considere o quociente $\bar{V}=H K /[B, K]$. Denotaremos a imagem de um subgrupo $T$ de $H K$ em $\bar{V}$, por $\bar{T}$.

Como $[\bar{B}, \bar{K}]=1$ concluímos que $\bar{B} \leq C_{\bar{V}}(\bar{K})$ e portanto $\bar{B} \cap \bar{K} \leq Z(\bar{K})$. Consequentemente, o quociente $\bar{K} / \bar{K} \cap \bar{B}$ é de Chernikov. De fato, como $K B / B$ é de Chernikov (Lema 3.11) segue que $K / K \cap B$ é de Chernikov, donde obtemos que $\bar{K} / \bar{K} \cap \bar{B}$ é de Chernikov. Consequentemente $\bar{K}^{\prime}$ é de Chernikov (Teorema 1.70), onde $\bar{K}^{\prime}$ denota o subgrupo derivado de $\bar{K}$.

No quociente $H K /[B, K]$ podemos supor que $B \cap K \leq Z(K)$. Assim, podemos repetir os argumentos do parágrafo anterior e concluirmos que $K^{\prime}$ é também de Chernikov. Note que $K^{\prime}$ é normal em $H K$. Passando ao quociente $H K / K^{\prime}$ podemos supor que $K$ é abeliano. Sendo $K$ gerado por elementos de mesma ordem (a saber, elementos que possuem a mesma ordem que o elemento $g$ ), concluímos que $K$ possui expoente finito. Assim, $\left\langle g^{X}\right\rangle$ é um subgrupo abeliano de expoente finito. Como $\left\langle g^{X}\right\rangle=\left\langle C_{1}, \cdots, C_{k}\right\rangle$, decorre que, para cada $i=1, \ldots, k$ o subgrupo $C_{i}$ é abeliano, de Chernikov e possui expoente finito. Logo para todo $i=1, \ldots, k$ segue que o subgrupo $C_{i}$ é finito (Lema 1.58(3)). Em particular, a classe de conjugação $g^{X}$ é finita e uma vez que $G$ é um grupo localmente finito (Lema 3.10) concluímos que $g^{H}$ é finito (Lema 1.22). Consequentemente $K=\left\langle g^{H}\right\rangle$ é finito. O teorema está provado.

Com a demonstração do Teorema $3.2\left(\operatorname{caso} w=\delta_{n}\right)$ atingimos parcialmente o objetivo deste capítulo. A seguir apresentaremos uma demonstração do Teorema 3.2, para o caso $w=\gamma_{n}$.

\subsection{2 $\mathrm{O}$ caso $w=\gamma_{n}$}

Na Seção 3.3.1 provamos o Teorema 3.2 para o caso $w=\delta_{n}$. Provaremos agora o Teorema 3.2, considerando $w$ como sendo a $n$-ésima palavra central inferior, 
$\gamma_{n}$. Essencialmente, as demonstrações feitas para o caso $w=\delta_{n}$ e $w=\gamma_{n}$ são as mesmas. Entretanto, optamos por explicitar a prova do caso $w=\gamma_{n}$ para uma melhor compreensão do texto.

Sejam $n$ um inteiro positivo, $X$ o conjunto de todos $\gamma_{n}$-valores de $G$ e $H=\langle X\rangle$. Então $H=\gamma_{n}(G)$. Denote por $\widehat{B}$ o subgrupo de $G$ gerado por todos os subgrupos abelianos, radicáveis e de Chernikov contidos em $X$. Assim

$$
\widehat{B}=\langle T ; T \subseteq X, T \text { é abeliano, radicável e de Chernikov }\rangle \text {. }
$$

Então $\widehat{B}$ é abeliano. De fato, sejam $g \in G$ e $T \subseteq X$ um subgrupo abeliano, radicável e de Chernikov. Logo $\left\langle g^{T}\right\rangle$ é de Chernikov (Proposição 3.3) e consequentemente $\left[\left\langle g^{T}\right\rangle, T, T\right]=1$ (Lema 1.75). Em particular, $[g, T, T]=1$ e portanto segue que $\left\langle T^{G}\right\rangle$ é abeliano. Observe que $\widehat{B}$ é abeliano, pois coincide com um produto de subgrupos normais, periódicos, abelianos e radicáveis (Lema 1.51). Além disso, $\widehat{B}$ é um subgrupo normal em $G$. Seguindo as ideias apresentadas no Lema 3.9 podemos concluir que o quociente $H / \widehat{B}$ é um FC-grupo e, que consequentemente, $G$ é um grupo localmente finito.

Seguindo a mesma linha de raciocínio da Seção 3.3.1 podemos então mostrar que dado $g \in G$ a imagem do subgrupo $\left\langle g^{H}\right\rangle$ em $G / \widehat{B}$ é de Chernikov. Além disso, é possível mostrar que $\left[\widehat{\boldsymbol{B}},\left\langle g^{H}\right\rangle\right]$ é de Chernikov para todo $g \in G$. Assim, estamos em posição de completar a prova do Teorema 3.2.

A prova do TeOrema 3.2, PARA O CASO $w=\gamma_{n}$

Sejam $g \in G$ e $K=\left\langle g^{H}\right\rangle$. Então o subgrupo $[\widehat{B}, K]$ é de Chernikov. Note que $[\widehat{B}, K]$ é normal em $H K$ de modo que, podemos considerar o grupo quociente, $\bar{U}=H K /[\widehat{B}, K]$. Sejam $\bar{B}$ e $\bar{K}$ as imagens de $\widehat{B}$ e $K$ em $\bar{U}$, respectivamente.

Obviamente $[\bar{B}, \bar{K}]=1$. Como a imagem de $K$ em $G / \widehat{B}$ é de Chernikov concluímos que $\bar{K} / Z(\bar{K})$ é de Chernikov e, portanto $\bar{K}^{\prime}$ é de Chernikov (Teorema 1.70) onde $\bar{K}^{\prime}$ denota o subgrupo derivado de $\bar{K}$.

Repetindo os argumentos anteriores, podemos concluir que $K^{\prime}$ é de Chernikov. Seja $L=\left\langle g^{X}\right\rangle$. Observe que $L$ é gerado por um número finito de subgrupos de Chernikov. Suponha que $L=\left\langle C_{1}, \ldots, C_{k}\right\rangle$. Uma vez que $K^{\prime}$ seja de Chernikov concluímos que $L^{\prime}$ é também de Chernikov. Assim o grupo quociente $L / L^{\prime}$ é abeliano gerado por seus subgrupos de Chernikov $C_{i} L^{\prime} / L^{\prime}$ e, portanto $L / L^{\prime}$ é de Chernikov (Lema 1.67). Em particular, obtemos que $L=\left\langle g^{X}\right\rangle$ é de Chernikov. Esse argumento pode ser repetido à todos elemento do grupo $G$, de modo que podemos utilizar o Teorema 3.1 e concluirmos que $K$ é de Chernikov. A prova do Teorema 3.2 agora está completa. 
Com a demonstração do Teorema 3.2 atingimos o objetivo desse capítulo e, com ela o encerramos. 


\section{Limitando a ordem do residual nilpotente de um grupo finito}

\subsection{Comutadores coprimos em grupos finitos}

Os comutadores coprimos $\gamma_{k}^{*}$ e $\delta_{k}^{*}$ foram introduzidos por Shumyatsky em [37], como uma ferramenta para se estudar propriedades de grupos finitos, que possam ser expressas em termos dos comutadores de elementos de ordens coprimas.

Todo elemento de um grupo finito $G$ é um $\gamma_{1}^{*}$-comutador. Sejam $k \geq 2$ e $X$ o conjunto de todos os elementos de $G$ que sejam potências de $\gamma_{k-1}^{*}$-comutadores. Um elemento $x \in G$ é chamado um $\gamma_{k}^{*}$-comutador se existirem $a \in X$ e $b \in G$ tais que $x=[a, b]$ e $(|a|,|b|)=1$. O subgrupo de $G$ gerado por todos os $\gamma_{k}^{*}$-comutadores será denotado por $\gamma_{k}^{*}(G)$.

Similarmente os $\delta_{k}^{*}$-comutadores são definidos como segue. Todo elemento de um grupo finito $G$ é um $\delta_{0}^{*}$-comutador. Sejam $k \geq 1$ e $Y$ o conjunto de todos os elementos de $G$ que sejam potências de $\delta_{k-1}^{*}$-comutadores. Um elemento $x \in G$ é chamado um $\delta_{k}^{*}$-comutador se existirem $a, b \in Y$ tais que $x=[a, b]$ e $(|a|,|b|)=1$. O subgrupo de $G$ gerado por todos os $\delta_{k}^{*}$-comutadores será denotado por $\delta_{k}^{*}(G)$.

Observação 4.1. Note que se $G$ for um grupo periódico podemos tratar de comutadores de elementos de ordens coprimas, sendo portanto, que o conceito $\gamma_{k}^{*}-$ comutadores (respectivamente, $\delta_{k}^{*}$-comutadores) introduzido anteriormente, pode ser generalizado a grupos periódicos em geral.

O seguinte resultado sobre os comutadores coprimos é imediato.

Lema 4.2 ([37]). Sejam $k$ um inteiro positivo e $G$ um grupo finito. Suponha que $x \in G$ seja um $\gamma_{k}^{*}$-comutador (respectivamente, $\delta_{k}^{*}$-comutador). Então x pode ser visto como um $\gamma_{i}^{*}$-comutador (respectivamente, $\delta_{i}^{*}$-comutador), para todo $i \leq k$.

Lema 4.3 ([37]). Seja $N$ um subgrupo normal de um grupo finito G. Seja $x \in G$ tal que sua imagem em $G / N$ seja um $\gamma_{k}^{*}$-comutador (respectivamente, um 
$\delta_{k}^{*}$-comutador). Então existe um $\gamma_{k}^{*}$-comutador $y \in G$ (respectivamente, um $\delta_{k}^{*}$ comutador) tal que $x \in y N$.

Lema 4.4 ([37]). Sejam $k>1$ um inteiro positivo e $G$ um grupo finito. Então $G$ é nilpotente se, e somente se, $\gamma_{k}^{*}(G)=1$.

Além disso, em [37] foi estudada a influência que os $\delta_{k}^{*}$-comutadores exercem sobre a estrutura de $G$. O $p^{a} q^{b}$-Teorema de Burnside diz que um grupo finito cuja ordem é divisível por somente dois primos é solúvel (veja [14, Teorema 4.3.3]). O seguinte teorema é uma generalização do Teorema de Burnside. Como usual, o $\pi$ subgrupo normal maximal de um grupo $G$ será denotado por $O_{\pi}(G)$.

Teorema 4.5 ([37], Teorema 2.4). Sejam $k$ um inteiro positivo e $\pi$ um conjunto consistindo de, no máximo, dois números primos. Suponha que $G$ seja um grupo finito tal que todos os seus $\boldsymbol{\delta}_{k}^{*}$-comutadores sejam $\pi$-elementos. Então $G$ é solúvel e $\delta_{k}^{*}(G) \leq O_{\pi}(G)$

O próximo resultado garante que se um grupo finito $G$ satisfaz $\delta_{k}^{*}(G)=1$, então $G$ é solúvel e possui altura de Fitting no máximo $k$. Relembre que a altura de Fitting $h=h(G)$ de um grupo finito solúvel $G$ é o menor número $h$ tal que $G$ possua um série normal de comprimento $h$, onde todos os quocientes sejam nilpotentes.

Teorema 4.6 ([37], Teorema 2.6). Sejam $k$ um inteiro positivo e $G$ um grupo finito. Então $\delta_{k}^{*}(G)=1$ se, e somente se, $G$ for um grupo solúvel com altura de Fitting no máximo $k$.

Corolário 4.7 ([37], Corolário 2.7). Sejam $k$ um inteiro positivo e $p$ um número primo. Suponha que $G$ seja um grupo finito tal que todos os $\delta_{k}^{*}$-comutadores sejam p-elementos. Então $G$ é solúvel e $h(G) \leq k+1$.

O último termo da série central inferior de um grupo finito $G$ é chamado o residual nilpotente de $G$ e, é usualmente denotado por $\gamma_{\infty}(G)$. Observe que

$$
\gamma_{\infty}(G)=\bigcap_{i} \gamma_{i}(G)
$$

A série inferior de Fitting de um grupo $G$ é definida recursivamente por

$$
D_{0}(G)=G \text { e } D_{i+1}(G)=\gamma_{\infty}\left(D_{i}(G)\right)
$$

para $i=0,1,2, \ldots$

Lema 4.8 ([37]). Sejam $k$ um inteiro positivo e $G$ um grupo finito. 
1. Se $k \geq 2$ então $\gamma_{k}^{*}(G)=\gamma_{\infty}(G)$.

2. Se $k \geq 1$ então $\delta_{k}^{*}(G)=D_{k}(G)$.

Ainda sobre $\delta_{k}^{*}(G)$ o seguinte resultado é verdadeiro.

Lema 4.9 ([1], Lema 2.3). Seja $k \geq 0$ um inteiro. Para um grupo finito $G$ vale a seguinte igualdade

$$
\delta_{k}^{*}\left(\delta_{1}^{*}(G)\right)=\delta_{k+1}^{*}(G) .
$$

Um grupo é dito metanilpotente se existir $N \unlhd G$ nilpotente, tal que $G / N$ seja nilpotente. Observe que todo grupo metanilpotente é solúvel e que subgrupos e quocientes de grupos metanilpotentes são metanilpotentes. O próximo resultado segue imediatamente da definição de grupos metanilpotentes.

Lema 4.10. Um grupo finito $G$ é metanilpotente se, e somente se, $\gamma_{\infty}(G)$ for nilpotente.

Lema 4.11 ([1], Lema 2.4). Sejam G um grupo metanilpotente finito, $p$ um número primo e $P$ um p-subgrupo de Sylow de $\gamma_{\infty}(G)$. Se $H$ for um $p^{\prime}$-subgrupo de Hall de $G$ então

$$
P=[P, H] .
$$

Lema 4.12 ([1], Lema 2.6). Sejam $k \geq 0$ um inteiro positivo e $G$ um grupo solúvel finito de ordem $p^{a} n$, onde $p$ é um primo e $n$ não é divisível por $p$. Se $P$ for um p-subgrupo de Sylow de $G$ então $P \cap \delta_{k}^{*}(G)$ é gerado por $n$-ésimas potências de $\boldsymbol{\delta}_{k^{-}}^{*}$ comutadores contidas em $P$.

O seguinte resultado é devido à Khukhro e Shumyatsky [20].

Proposição 4.13 ([20], Lema 2.3). Sejam p um primo, $m$ um inteiro positivo e $V$ um p-grupo abeliano elementar finito. Suponha que $H$ seja um $p^{\prime}$-grupo finito de automorfismos de $V$. Se $|[V, h]| \leq m$ para todo $h \in H$ então $|[V, H]|$ é m-limitado. Além disso, neste caso $|H|$ é m-limitado.

Observe que os comutadores coprimos $\gamma_{k}^{*}$ e $\delta_{k}^{*}$ não são palavras, porém se comportam como palavras. Recorde que no Capítulo 1, vimos que uma palavra $w$ é dita concisa se o subgrupo verbal $w(G)$ for finito sempre que o conjunto $\operatorname{dos} w$-valores $G_{w}$ for finito implicar. Entretanto, o conceito de ser "conciso" pode ser aplicado em diversos outros contextos (não apenas em palavras de grupos). Suponha que $\mathfrak{X}$ seja uma classe de grupos e para cada grupo $G \in \mathfrak{X}$, seja $\phi(G)$ um subconjunto de $G$. Podemos então indagar se uma eventual finitude do subconjunto $\phi(G)$ acarretaria na finitude do subgrupo gerado por $\phi(G)$. Conforme observado por Acciarri, Shumyatsky e Thillaisundaram em [1] os comutadores coprimos $\delta_{k}^{*}$ e $\gamma_{k}^{*}$ respeitam o fenômeno de serem concisos (no sentido definido anteriormente). 
Teorema 4.14 ([1], Teorema 1.1). Sejam $k \geq 1$ um inteiro e $G$ um grupo finito. Suponha que o conjunto dos $\gamma_{k}^{*}$-comutadores possua ordem $m$. Então $\left|\gamma_{k}^{*}(G)\right|$ é $m$ limitado.

Teorema 4.15 ([1], Teorema 1.2). Sejam $k \geq 0$ um inteiro e $G$ um grupo finito. Suponha que o conjunto dos $\delta_{k}^{*}$-comutadores possua ordem $m$. Então $\left|\delta_{k}^{*}(G)\right|$ é $m$ limitado.

Observe que a limitação para $\left|\gamma_{k}^{*}(G)\right|$ e $\left|\delta_{k}^{*}(G)\right|$ não depende de $k$, Esse fenômeno foi denominado por Fernández-Alcober e Morigi em [9] como uniformemente conciso.

\subsection{Resultados obtidos}

Em [11] Franciosi, de Giovanni e Shumyatsky provaram que se $w$ é uma palavra concisa então um grupo $G$ é um $\mathrm{FC}(w)$-grupo se, e somente se, o subgrupo verbal $w(G)$ for FC-imerso em $G$, isto é, se $x^{w(G)}$ for finito para todo $x \in G$ (Teorema 1.33). Em [5] Brazil, Krassilnikov e Shumyatsky introduziram o conceito de palavras limitadamente concisas e, mostraram que se $m$ for inteiro positivo e se $w$ for uma palavra limitadamente concisa tal que $G$ seja um grupo com a propriedade que $\left|x^{G_{w}}\right| \leq m$ para todo $x \in G$ então existe um inteiro $d,\{m, w\}$-limitado, tal que $\left|x^{w(G)}\right| \leq d$. Na seção anterior apresentamos dois resultados (Teoremas 4.14 e 4.15) que nos asseguram que, em grupos finitos, os conjuntos dos comutadores coprimos possuem a propriedade de serem uniformemente concisos.

Seguindo a forma de pensar que foi apresentada em [11], introduzimos agora a noção de $\operatorname{BFC}(X)$-grupos. Sejam $k$ um inteiro positivo, $G$ um grupo finito e, $X$ o conjunto de todos $\delta_{k}^{*}$-comutadores (ou, respectivamente $\gamma_{k}^{*}$-comutadores) de $G$. Diremos que $G$ é um $\operatorname{BFC}(X)$-grupo se o número de elementos em $g^{X}$ for limitado por uma constante que não dependa da escolha do elemento $g$. Decorre imediatamente da definição de $\operatorname{BFC}(X)$-grupo que subgrupos e quocientes de $\operatorname{BFC}(X)$-grupos são $\operatorname{BFC}(X)$-grupos.

Reunindo então estes fatos, surge naturalmente a seguinte indagação, que estende o Teorema 1.38 , proposto em [5], para o conjunto dos $\delta_{k}^{*}$-comutadores (ou, respectivamente, $\gamma_{k}^{*}$-comutadores). Sejam $G$ um grupo finito e $k$ um inteiro positivo. Denote por $X$ o conjunto de todos os $\delta_{k}^{*}$-comutadores (ou, respectivamente $\gamma_{k}^{*}$ comutadores) de $G$. Suponha que $G$ seja um $\operatorname{BFC}(X)$-grupo tal que $\left|g^{X}\right| \leq m$ para todo $g \in G$. É verdade que $g^{\langle X\rangle}$ possui ordem $(m, k)$-limitada para todo $g \in G$ ? A resposta para essa pergunta é positiva e, será respondida na forma das seguintes proposições. 
Proposição 4.16. Sejam $k \geq 2$ um inteiro e $G$ um grupo finito. Denote por $X$ o conjunto de todos os $\gamma_{k}^{*}$-comutadores de $G$. Suponha que $G$ seja um BFC(X)-grupo tal que $\left|g^{X}\right| \leq m$ para todo $g \in G$. Então $\left|g^{\gamma_{k}^{*}(G)}\right|$ é $(m, k)$-limitado, para todo $g \in G$.

Corolário 4.17 (Proposição 4.16). Sejam $k \geq 2$ um inteiro e $G$ um grupo localmente finito. Denote por $X$ o conjunto de todos os $\gamma_{k}^{*}$-comutadores de $G$ e suponha que $G$ seja um $B F C(X)$-grupo tal que $\left|g^{X}\right| \leq m$ para todo $g \in G$. Então $\left|g^{\gamma_{k}^{*}(G)}\right|$ é $(m, k)$ limitado, para todo $g \in G$.

Recorde que dado um grupo finito $G$, os subgrupos $\delta_{k}^{*}(G)$ e $D_{k}(G)$ coincidem (Lema $4.8(2))$.

Proposição 4.18. Sejam $k \geq 1$ um inteiro e $G$ um grupo finito. Denote por $X$ o conjunto de todos os $\boldsymbol{\delta}_{k}^{*}$-comutadores de $G$. Suponha que $G$ seja um BFC(X)-grupo tal que $\left|g^{X}\right| \leq m$ para todo $g \in G$. Então $\left|g^{D_{k}(G)}\right|$ é $(m, k)$-limitado, para todo $g \in G$.

Corolário 4.19 (Proposição 4.18). Sejam $k \geq 1$ um inteiro e $G$ um grupo localmente finito. Denote por $X$ o conjunto de todos os $\delta_{k}^{*}$-comutadores de $G$ e suponha que $G$ seja um BFC(X)-grupo tal que $\left|g^{X}\right| \leq m$ para todo $g \in G$. Então $\left|g^{\delta_{k}^{*}(G)}\right|$ é $(m, k)$ limitado, para todo $g \in G$.

Após provarmos as Proposições 4.16 e 4.18, dedicaremo-nos aos resultados principais deste capítulo, onde obtemos uma limitação para as ordens dos subgrupos $\gamma_{k}^{*}(G)$ e $D_{k}(G)$, em termos apenas dos parâmetros $m$ e $k$ em $\operatorname{BFC}(X)$-grupos finitos tais que $\left|g^{X}\right| \leq m$ para todo $g \in G$. Mais precisamente, provaremos os seguintes teoremas.

Teorema 4.20. Sejam $k \geq 2$ um inteiro e $G$ um grupo finito. Denote por $X$ o conjunto de todos os $\gamma_{k}^{*}$-comutadores de $G$. Suponha que $\left|g^{X}\right| \leq m$ para todo $g \in G$. Então $\left|\gamma_{k}^{*}(G)\right|$ é $(m, k)$-limitado.

Teorema 4.21. Sejam $k \geq 1$ um inteiro e $G$ um grupo finito. Denote por $X$ o conjunto de todos os $\boldsymbol{\delta}_{k}^{*}$-comutadores de $G$. Suponha que $\left|g^{X}\right| \leq m$ para todo $g \in G$. Então $\left|D_{k}(G)\right|$ é $(m, k)$-limitado.

O objetivo central deste capítulo é provar os Teoremas 4.20 e 4.21. Entretanto as demonstrações desses resultados passam pelas provas das Proposições 4.16 e 4.18 respectivamente. Observe também que uma prova para a Proposição 4.16 pode ser obtida mediante uma demonstração da Proposição 4.18, pela simples substituição do termo " $\delta_{k}^{*}$-comutador" pelo termo " $\gamma_{k}^{*}$-comutador" em toda a demonstração da Proposição 4.18. Sendo assim, concentraremos inicialmente nossos esforços em provarmos a Proposição 4.18. 


\subsection{A prova da Proposição 4.18}

O esquema geral da prova da Proposição 4.18 segue a linha dos resultados apresentados por Brazil, Krasilnikov e Shumyatsky em [5].

Dado um subconjunto $Y$ de um grupo $G$, diremos que um subgrupo $H \leq G$ possui $Y$-índice $m$, se $Y$ estiver contido em uma união de precisamente $m$ classes laterais (à direita) de $H$ em $G$.

Lema 4.22. Sejam $H_{1}$ e $H_{2}$ dois subgrupos de um grupo $G$ e suponha que $H_{1} e$ $H_{2}$ possuam $Y$-índices $m_{1}$ e $m_{2}$, respectivamente. Então a intersecção $H_{1} \cap H_{2}$ possui $Y$-índice no máximo $m_{1} m_{2}$ em $K$.

Demonstração. Por definição, existem $x_{1}, \ldots, x_{m_{1}}$ e $y_{1}, \ldots, y_{m_{2}}$ elementos de $K$ tais que

$$
X \subseteq \bigcup_{i=1}^{m_{1}} H_{1} x_{i} \quad \text { e } \quad X \subseteq \bigcup_{j=1}^{m_{2}} H_{2} y_{j}
$$

Consequentemente,

$$
X \subseteq \bigcup_{i, j}\left(H_{1} x_{i} \cap H_{2} y_{j}\right)=\bigcup_{i, j}\left(H_{1} \cap H_{2}\right) a_{i, j}
$$

onde $a_{i, j} \in H_{1} x_{i} \cap H_{2} y_{j}$. Portanto, $H_{1} \cap H_{2}$ possui $X$-índice no máximo $m_{1} m_{2}$. O lema está provado.

O seguinte resultado é um corolário imediato do Lema 4.22

Corolário 4.23. Seja $G$ um grupo e suponha que $H_{1}, H_{2}, \ldots, H_{s} \leq G$ possuem $Y$ indices $m_{1}, m_{2}, \ldots, m_{s}$, respectivamente, então a intersecção $H_{1} \cap \cdots \cap H_{s}$ possui $Y$ indice no máximo $m_{1} m_{2} \ldots m_{s}$.

Demonstração. Basta utilizar indução sobre $s$ em conjunto com Lema 4.22.

De agora em diante, nesta seção, a menos que se diga o contrário $G$ denota um grupo finito, $X$ o conjunto de todos os $\delta_{k}^{*}$-comutadores de $G$ e $K$ o subgrupo gerado por $X$. Portanto, pelo Lema 4.8(2), temos que $K=D_{k}(G)$.

Lema 4.24. Suponha que $G$ seja um $B F C(X)$-grupo tal que $\left|g^{X}\right| \leq m$ para todo $g \in G$. Então $C_{K}(g)$ possui $X$-índice no máximo $m$ em $K$ para todo $g \in G$.

Demonstração. Seja $a \in G$ um elemento qualquer e sejam $g_{1}, \ldots, g_{s}$ elementos em $X$, dois a dois distintos, tais que

$$
a^{X}=\left\{a^{g_{1}}, \ldots, a^{g_{s}}\right\}
$$


Sob nossas hipóteses, podemos então escolher os elementos $g_{1}, g_{2}, \ldots, g_{s}$ tais que $s \leq m$. Se $x \in X$ então $a^{x} \in a^{X}$ e portanto, existe um índice $i \in\{1, \ldots, s\}$ tal que $a^{x}=a^{g_{i}}$. Consequentemente $x g_{i}^{-1}$ centraliza o elemento $a$ e assim $x \in C_{K}(a) g_{i}$, donde obtemos que

$$
X \subseteq \bigcup_{i=1}^{s} C_{K}(a) g_{i}
$$

com $s \leq m$. Portanto, $C_{K}(a)$ possui $X$-índice no máximo $m$ em $K$. O lema está provado.

Observação 4.25. A seguinte definição para $\delta_{k}^{*}$-comutadores em grupos finitos é equivalente à apresentada na página 60. Para cada elemento a de um grupo G seja $\delta_{0}^{*}(a)=a$, e para $k \geq 1$ defina

$$
\delta_{k}^{*}\left(a_{1}, \ldots, a_{2^{k}}\right)=\left[\delta_{k-1}^{*}\left(a_{1}, \ldots, a_{2^{k-1}}\right)^{n}, \delta_{k-1}^{*}\left(a_{2^{k-1}+1}, \ldots, a_{2^{k}}\right)^{m}\right]
$$

se existirem inteiros positivos $m$ e $n$ tais que

$$
\left(\left|\delta_{k-1}^{*}\left(a_{1}, \ldots, a_{2^{k-1}}\right)^{m}\right|,\left|\delta_{k-1}^{*}\left(a_{2^{k-1}+1}, \ldots, a_{2^{k}}\right)^{n}\right|\right)=1
$$

Se não existirem os inteiros positivos $m$ e $n$ tais que a equação (4.1) seja satisfeita, defina $\delta_{k}^{*}\left(a_{1}, \ldots, a_{2^{k}}\right)=1$.

Note que todo elemento do tipo $\delta_{k}^{*}\left(a_{1}, \ldots, a_{2^{k}}\right)$ definido acima é um $\delta_{k^{-}}^{*}$ comutador. O próximo lema garante que a recíproca também é verdadeira, isto é, todo $\delta_{k}^{*}$-comutador de um grupo $G$ é um elemento do tipo $\delta_{k}^{*}\left(a_{1}, \ldots, a_{2^{k}}\right)$, para adequados $a_{1}, \ldots, a_{2^{k}} \in G$.

Lema 4.26. Seja y um $\delta_{k}^{*}$-comutador de um grupo $G$. Então existem $a_{1}, \ldots, a_{2^{k}}$, elementos de $G$, tais que $y=\delta_{k}^{*}\left(a_{1}, \ldots, a_{2^{k}}\right)$. Em particular,

$$
\delta_{k}^{*}(G)=\left\langle\delta_{k}^{*}\left(a_{1}, \ldots, a_{2^{k}}\right) ; a_{i} \in G\right\rangle
$$

Demonstração. A prova do lema se dará por indução sobre $k$. Se $k=0$ então $y=\delta_{0}^{*}(y)$ e não há o que se demonstrar. Por indução, suponha o resultado verdadeiro para $k-1$, isto é, se $x$ for um $\delta_{k-1}^{*}$-comutador então existem elementos $g_{1}, \ldots, g_{2^{k-1}}$ em $G$ tais que

$$
x=\delta_{k-1}^{*}\left(g_{1}, \ldots, g_{2^{k-1}}\right) .
$$

Como $y$ é um $\delta_{k}^{*}$-comutador, por definição (página 60) existem $x_{1}, x_{2}$ potências de $\delta_{k-1}^{*}$-comutadores tais que $y=\left[x_{1}, x_{2}\right]$, com $\left(\left|x_{1}\right|,\left|x_{2}\right|\right)=1$. Assim, existe um inteiro positivo $m$ e existem $a_{1}, \ldots, a_{2^{k-1}}$ elementos de $G$ tais que $x_{1}=\delta_{k-1}^{*}\left(a_{1}, \ldots, a_{2^{k-1}}\right)^{m}$. 
Analogamente, existe um inteiro positivo $n$ e existem $a_{2^{k-1}+1}, \ldots, a_{2^{k}} \in G$ tais que $x_{2}=\delta_{k-1}^{*}\left(a_{2^{k-1}+1}, \ldots, a_{2^{k}}\right)^{n} . \operatorname{Logo}$,

$$
y=\left[\delta_{k-1}^{*}\left(a_{1}, \ldots, a_{2^{k-1}}\right)^{m}, \delta_{k-1}^{*}\left(a_{2^{k-1}+1}, \ldots, a_{2^{k}}\right)^{n}\right]=\delta_{k}^{*}\left(a_{1}, \ldots, a_{2^{k}}\right) .
$$

O lema está provado.

Lema 4.27. Suponha que $G$ seja um $B F C(X)$-grupo tal que $\left|g^{X}\right| \leq m$ para todo $g \in G$. Se $y \in X$ então existe um inteiro positivo $(m, k)$-limitado, digamos $n$, tal que $y^{n} \in Z(G)$.

Demonstração. Seja $a_{0}$ um elemento qualquer de $G$. Pelo Lema 4.26 existem $a_{1}, \ldots, a_{2^{k}}$ elementos em $G$ tais que $y=\delta_{k}^{*}\left(a_{1}, \ldots, a_{2^{k}}\right)$.

Denote por $E$ o subgrupo gerado por $a_{0}, a_{1}, \ldots, a_{2^{k}}$. Observe que $y$ é um $\delta_{k^{-}}^{*}$ comutador em $E$. Seja $Y$ o conjunto de todos os $\delta_{k}^{*}$-comutadores de $E$. Claramente $Y \subseteq X$. Por hipótese $\left|a_{i}^{X}\right| \leq m$, para cada $i=0,1, \ldots, 2^{k}$. Em particular, segue que $\left|a_{i}^{Y}\right| \leq m$, para todo $i=0,1, \ldots, 2^{k}$. Assim, temos que $E$ é um $\operatorname{BFC}(Y)$-grupo. Portanto, segue que para cada $i=0,1, \ldots, 2^{k}$ o subgrupo $C_{\delta_{k}^{*}(E)}\left(a_{i}\right)$ possui $Y$-índice $\leq m$ em $\delta_{k}^{*}(E)$ (Lema 4.24). Como $Z(E)=\bigcap_{i=0}^{2^{k}} C_{E}\left(a_{i}\right)$, concluímos que o subgrupo $Z(E) \cap \delta_{k}^{*}(E)$ possui $Y$-índice $\leq m^{2^{k}+1}$ em $\delta_{k}^{*}(E)$ (Corolário 4.23). Consequentemente, o número de $\delta_{k}^{*}$-comutadores no quociente $E / Z(E)$ é no máximo $m^{2^{k+1}}$. Decorre, portanto, do Teorema 4.15 que a ordem do subgrupo $\delta_{k}^{*}(E / Z(E))$ é $(m, k)$-limitada.

Sendo $y$ um $\delta_{k}^{*}$-comutador de $E$, segue que sua imagem no quociente $\delta_{k}^{*}(E) / \delta_{k}^{*}(E) \cap Z(E)$, possui ordem $(m, k)$-limitada. Assim, existe um inteiro, digamos $n=n(m, k)$, tal que $y^{n} \in \delta_{k}^{*}(E) \cap Z(E)$. Em particular, $y^{n} \in Z(E)$. Como $a_{0} \in E$, concluímos que $y^{n}$ e $a_{0}$ comutam. Por fim, como o elemento $a_{0}$ foi escolhido arbitrariamente em $G$ podemos então garantir que esse processo se repete a qualquer outro elemento deste grupo. Logo, dado $y \in X$ existe $n=n(m, k)$ tal que $y^{n} \in Z(G)$. O lema está provado.

Seja $a$ um elemento qualquer do grupo $G$ e, suponha que $G$ seja um $\operatorname{BFC}(X)$ grupo tal que $\left|g^{X}\right| \leq m$ para todo $g \in G$. Sejam $u_{1}, \ldots, u_{s-1}, u_{s}=1$ elementos de $X$ tais que

$$
a^{X}=\left\{a^{u_{1}}, \ldots, a^{u_{s-1}}, a\right\} .
$$

Nossa hipótese implica que os elementos $u_{1}, \ldots, u_{s-1}, u_{s}=1$, podem ser escolhidos de maneira que $s \leq m$. Seja $h \in K$ um elemento qualquer. Note que $h$ pode ser escrito como um produto de um número finito de elementos de $X$ e, assim o seguinte resultado, cuja demonstração segue passo a passo a demonstração do Lema 2.3 de [5], é verdadeiro. 
Lema 4.28. Seja $h=x_{1} \cdots x_{l}$, onde $x_{1}, \ldots, x_{l} \in X$. Então

$$
a^{h}=a^{u_{i_{1}} u_{i_{2}} \cdots u_{i_{l}}}
$$

para adequados $i_{1}, \ldots, i_{l}$ tais que $1 \leq i_{1}, i_{2}, \ldots, i_{l} \leq s$.

Demonstração. A prova que apresentaremos será por indução sobre $l$. Se $l=1$ então $h=x_{1}$ e $a^{h}=a^{x_{1}}=a^{u_{i_{1}}}$, para $1 \leq i_{1} \leq s$. Suponha que o lema seja verdadeiro para todos os elementos de $K$ que possam ser escritos como um produto de no máximo $l-1$ elementos de $X$. Observe que $a^{x_{1}}=a^{u_{i}}$, para algum $1 \leq i \leq s$. Consequentemente, segue que

$$
\begin{aligned}
a^{h} & =a^{x_{1} \cdots x_{l}} \\
& =a^{u_{i} x_{2} \cdots x_{l}} \\
& =a^{c_{2} \cdots c_{l} u_{i}},
\end{aligned}
$$

onde $c_{j}=u_{i} x_{j} u_{i}^{-1}$, para $j=2, \ldots, l$.

Note que, $c_{j} \in X$ pois $X$ é um subconjunto normal em $G$. Por hipótese de indução, segue que,

$$
a^{c_{2} \cdots c_{l}}=a^{u_{i_{1}} u_{i_{2}} \cdots u_{i_{l-1}}}
$$

para adequados $i_{1}, \ldots, i_{l-1}$ tais que $1 \leq i_{1}, \ldots, i_{l-1} \leq s$. Portanto,

$$
\begin{aligned}
a^{h} & =\left(a^{c_{2} \cdots c_{l}}\right)^{u_{i}} \\
& =a^{c_{2} \cdots c_{l} u_{i}} \\
& =a^{u_{i_{1}} u_{i_{2}} \cdots u_{i_{l-1}} u_{i_{l}}}
\end{aligned}
$$

onde consideramos $i_{l}=i$ e $1 \leq i_{1}, \ldots, i_{l-1}, i_{l} \leq s$. O lema está provado.

Observação 4.29. Uma relação de ordem < sobre um conjunto A é dita uma relação de ordem total se:

(a) < for antissimétrica, reflexiva e transitiva.

(b) Para quaisquer $a, b \in A$, com $a \neq b$, temos que $a<b$ ou $b<a$.

Seja $A$ um conjunto e seja $<$ uma relação de ordem sobre $A$. Diremos que $A=(A,<)$ é um conjunto bem ordenado se todo subconjunto não vazio de $A$ tiver um elemento minimal, isto é, se $\varnothing \neq B \subseteq A$ então existe $b_{0} \in B$ tal que $b_{0}<b$ para todo $b \in B \backslash\left\{b_{0}\right\}$.

É um fato bem conhecido que $\mathbb{N}$, o conjunto dos números naturais, é um conjunto bem ordenado. 
Seja $a \in G$ e suponha que $G$ seja um $\operatorname{BFC}(X)$-grupo tal que $\left|g^{X}\right| \leq m$ para todo $g \in G$. Sejam $u_{1}, \ldots, u_{s-1}, u_{s}=1$ elementos de $X$ escolhidos como na equação (4.2), tais que $a^{X}=\left\{a^{u_{1}}, \ldots, a^{u_{s-1}}, a^{u_{s}}=a\right\}$, com $s \leq m$.

Defina uma relação de ordem $<$, sobre o conjunto de todos os produtos (formais) da forma $u_{i_{1}} u_{i_{2}} \cdots u_{i_{l}}$, onde $1 \leq i_{j} \leq s$ para cada $j=1, \ldots, l$ como segue:

$$
u_{i_{1}} u_{i_{2}} \cdots u_{i_{l}}<u_{j_{1}} u_{j_{2}} \cdots u_{j_{l^{\prime}}}
$$

se, e somente se, as seguintes condições são satisfeitas:

(i) $l<l^{\prime}$ ou;

(ii) $l=l^{\prime}$ e existe um índice $t \leq l$ tal que $i_{t}<j_{t}$ e $i_{v}=j_{v}$ para todo $v>t$.

Note que a relação de ordem < definida anteriormente é uma relação de boa ordem para o conjunto dos produtos da forma $u_{i_{1}} u_{i_{2}} \cdots u_{i_{l}}$. De fato, a ordenação, nesse caso é feita pelos índices e, estes possuem entradas em $\mathbb{N}$. Como observado anteriormente, $\mathbb{N}$ é bem ordenado. Resumimos isso no seguinte lema.

Lema 4.30. A relação de ordem < definida anteriormente é uma boa ordenação para o conjunto constituído por todos os produtos da forma $u_{i_{1}} u_{i_{2}} \cdots u_{i_{l}}$, com $l \geq 1$, onde $1 \leq i_{j} \leq s$, para cada $j=1, \ldots, l$.

Suponha que $G$ seja um $\operatorname{BFC}(X)$-grupo tal que $\left|g^{X}\right| \leq m$ para todo $g \in G$. Sejam $a \in G$ e $h \in K$. Então $h=x_{1} \ldots x_{l}$, onde $x_{i} \in X$ para todo $i=1,2, \ldots, l$. Suponha que $a^{X}=\left\{a^{u_{1}}, \ldots, a^{u_{s-1}}, a^{u_{s}}=a\right\}$, para adequados $u_{i} \in X$, com $s \leq m$ (como na equação (4.2)). A relação < definida anteriormente é uma relação de boa ordem sobre o conjunto de todos os produtos da forma $u_{i_{1}} u_{i_{2}} \cdots u_{i_{l}}$, com $l \geq 1$, onde $1 \leq i_{j} \leq s$, para cada $j=1, \ldots, l$ (Lema 4.30). Seja $u_{i_{1}} u_{i_{2}} \ldots u_{i_{l}}$ o menor produto destes elementos tais que

$$
a^{h}=a^{u_{i_{1}} u_{i_{2}} \cdots u_{i_{l}}}
$$

Lema 4.31. Seja $u_{i_{1}} u_{i_{2}} \ldots u_{i_{l}}$ o menor produto descrito anteriormente. Então $i_{1} \geq$ $i_{2} \geq \cdots \geq i_{l}$.

Demonstração. De fato, suponha que exista um índice $n$ tal que $i_{n}<i_{n+1}$. Assim, temos que

$$
\begin{aligned}
a^{h} & =a^{u_{i_{1}} \cdots u_{i_{n-1}} u_{i_{n}} u_{i_{n+1}} u_{i_{n+2}} \cdots u_{i_{l}}} \\
& =a^{u_{i_{1}} \cdots u_{i_{n-1}} u^{\prime} u_{i_{n}} u_{i_{n+2}} \cdots u_{i_{l}}}
\end{aligned}
$$

onde $u^{\prime}=u_{i_{n}} u_{i_{n+1}} u_{i_{n}}^{-1} \in X$. Pelo Lema 4.28, temos que

$$
a^{u_{i_{1}} \ldots u_{i_{n-1}} u^{\prime}}=a^{u_{j_{1}} \ldots u_{j_{n-1}} u_{j \prime}}
$$




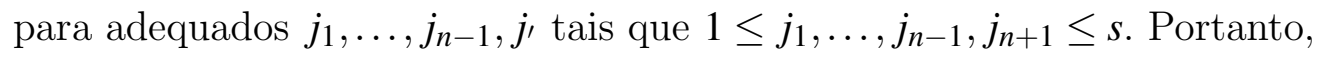

$$
a^{h}=a^{u_{j_{1}} \ldots u_{j_{n-1}} u_{j l} u_{i_{n}} u_{i_{n+2}} \ldots u_{i_{l}}} .
$$

Porém isso é uma contradição com a escolha do menor produto $u_{i_{1}} u_{i_{2}} \ldots u_{i_{l}}$, uma vez que, por definição, temos :

$$
u_{j_{1}} \ldots u_{j_{n-1}} u_{j^{\prime}} u_{i_{n}} u_{i_{n+2}} \ldots u_{i_{l}}<u_{i_{1}} \ldots u_{i_{n-1}} u_{i_{n}} u_{i_{n+1}} u_{i_{n+2}} \ldots u_{i_{l}}
$$

pois estamos supondo que $i_{n}<i_{n+1}$.

Agora estamos em posição de concluirmos a prova da Proposição 4.18.

A prova da Proposição 4.18

Recorde que $G$ é um $\operatorname{BFC}(X)$-grupo finito tal que $\left|g^{X}\right| \leq m$ para todo $g \in G$. Sejam $a \in G$ e $h$ um elemento arbitrário de $K=D_{k}(G)$. Combinando os Lemas 4.28 e 4.31, concluímos que

$$
a^{h}=a^{u_{i_{1}} u_{i_{2}} \ldots u_{i_{l}}}
$$

com $i_{1} \geq i_{2} \geq \cdots \geq i_{l}$. Equivalentemente, temos que

$$
a^{h}=a^{u_{s-1}^{m_{s-1}} \ldots u_{2}^{m_{2}} u_{1}^{m_{1}}}
$$

para adequados inteiros não negativos $m_{1}, m_{2}, \ldots, m_{s-1}$, onde $s \leq m$. Sabemos que existe um inteiro não negativo $n=n(m, k)$, tal que $y^{n} \in Z(G)$, para cada $y \in X$ (Lema $4.27)$ e, assim podemos então supor que $m_{i} \leq n$, para cada $i=1,2, \ldots, s-1$. Logo segue que

$$
a^{h}=a^{u_{s-1}^{m_{s-1}} \ldots u_{2}^{m_{2}} u_{1}^{m_{1}}}
$$

com $m_{i} \leq n$ e $s \leq m$. Como $h \in K$ foi tomado arbitrariamente segue que $\left|a^{K}\right| \leq(n+1)^{m}$, ou seja, $\left|a^{K}\right|$ é $(m, k)$-limitado. A Proposição 4.18 está provada.

Destacamos na Observação 4.1 que a noção de $\delta_{k}^{*}$-comutadores (respectivamente, $\gamma_{k}^{*}$-comutadores) pode ser estendida naturalmente para grupos periódicos em geral. A demonstração da Proposição 4.18 depende do Lema 4.27. Porém tal demonstração pode ser reproduzida (literalmente) no caso onde o grupo em questão seja localmente finito. De fato, note no Lema 4.27 que o subgrupo $E$ é um $\operatorname{BFC}(X)$ grupo finitamente gerado e, portanto, é finito (estamos supondo $G$ localmente finito nesse caso). Assim, podemos usar o Teorema 4.15 (válido para grupos finitos) e concluirmos que se $G$ for um $\operatorname{BFC}(X)$-grupo localmente finito, tal que $\left|g^{X}\right| \leq m$ para todo $g \in G$, então para cada $y \in X$ existe um inteiro $(m, k)$-limitado, digamos $n$, tal 
que $y^{n} \in Z(G)$. Dessa maneira podemos repetir a demonstração da Proposição 4.18 para $\operatorname{BFC}(X)$-grupos localmente finitos, de modo que vale o seguinte resultado.

Corolário 4.19 Sejam $k \geq 1$ um inteiro e $G$ um grupo localmente finito. Denote por $X$ o conjunto de todos os $\delta_{k}^{*}$-comutadores de $G$ e suponha que $G$ seja um $B F C(X)$ grupo tal que $\left|g^{X}\right| \leq m$ para todo $g \in G$. Então $\left|g^{\delta_{k}^{*}(G)}\right|$ é $(m, k)$-limitado, para todo $g \in G$.

Com a demonstração da Proposição 4.18, atingimos o primeiro objetivo proposto nesse capítulo. Na próxima seção, apresentaremos uma noção da demonstração da Proposição 4.16, inteiramente análoga à demonstração da Proposição 4.18 feita nessa seção.

\subsection{A prova da Proposição 4.16}

Nesta seção $G$ denota um grupo finito, $X$ o conjunto de todos os $\gamma_{k}^{*}$ comutadores de $G$ e $K$ o subgrupo gerado por $X$. Assim, pelo Lema 4.8(1), se $k \geq 2$, temos que $K=\gamma_{\infty}(G)$.

Obviamente é claro que vale um análogo do Lema 4.24, para o conjunto de todos os $\gamma_{k}^{*}$-comutadores de $G$.

Seguindo a linha de raciocínio da seção anterior, apresentaremos uma definição equivalente à apresentada na página 60 , para $\gamma_{k}^{*}$-comutadores em grupos finitos. Para todo elemento $a \in G$, defina $\gamma_{1}^{*}(a)=a$, e recursivamente defina para $k \geq 2$

$$
\gamma_{k}^{*}\left(a_{1}, \ldots, a_{k}\right)=\left[\gamma_{k-1}^{*}\left(a_{1}, \ldots, a_{k-1}\right)^{n}, a_{k}\right]
$$

se existir um inteiro positivo $n$ tal que

$$
\left(\left|\gamma_{k-1}^{*}\left(a_{1}, \ldots, a_{k-1}\right)^{n}\right|,\left|a_{k}\right|\right)=1
$$

ou, $\gamma_{k}^{*}\left(a_{1}, \ldots, a_{k}\right)=1$, se não existir um inteiro positivo $n$ que satisfaça à equação (4.3).

É claro que todo elemento do tipo $\gamma_{k}^{*}\left(a_{1}, \ldots, a_{k}\right)$ definido acima é um $\gamma_{k}^{*}$ comutador. O próximo lema (análogo ao Lema 4.26) garante que a recíproca também é verdadeira, isto é, todo $\gamma_{k}^{*}$-comutador de $G$ é um elemento do tipo $\gamma_{k}^{*}\left(a_{1}, \ldots, a_{k}\right)$, para adequados $a_{1}, \ldots, a_{k} \in G$.

Lema 4.32. Seja y um $\gamma_{k}^{*}$-comutador de $G$. Então existem $a_{1}, \ldots, a_{k}$, elementos em $G$, tais que $y=\gamma_{k}^{*}\left(a_{1}, \ldots, a_{k}\right)$. Em particular,

$$
\gamma_{k}^{*}(G)=\left\langle\gamma_{k}^{*}\left(a_{1}, \ldots, a_{k}\right) ; a_{i} \in G\right\rangle .
$$


O próximo resultado é análogo ao Lema 4.27, agora para $\gamma_{k}^{*}$-comutadores.

Lema 4.33. Suponha que $G$ seja um $B F C(X)$-grupo tal que $\left|g^{X}\right| \leq m$ para todo $g \in G$. Se $x \in X$, então existe um inteiro positivo $(m, k)$-limitado, digamos $n_{0}$, tal que $x^{n_{0}} \in Z(G)$.

Demonstração. Seja $a_{0}$ um elemento qualquer de $G$. Para cada $x \in X$ o Lema 4.32 garante a existência de $k$ elementos em $G$ tais que $x=\gamma_{k}^{*}\left(a_{1}, \ldots, a_{k}\right)$.

Denote por $E$ o subgrupo gerado por $a_{0}, a_{1}, \ldots, a_{k}$. Então $x$ é um $\gamma_{k}^{*}$ comutador em $E$. Seja $Z$ o conjunto de todos os $\gamma_{k}^{*}$-comutadores de $E$. Claramente $Z \subseteq X$. Assim temos que $\left|a_{i}^{Z}\right| \leq m$, para todo $i=0,1, \ldots, k$. Logo $E$ é um $\operatorname{BFC}(Z)$ grupo e, consequentemente, para cada $i=0,1, \ldots, k$, o subgrupo $C_{\gamma_{k}^{*}(E)}\left(a_{i}\right)$ possui $Z$-índice $\leq m$ em $\gamma_{k}^{*}(E)$ (Lema 4.24). Assim, o subgrupo $Z(E) \cap \gamma_{k}^{*}(E)$ possui $Z$-índice $\leq m^{k+1}$ em $\gamma_{k}^{*}(E)$ (Lema 4.23). Passando ao quociente $E / Z(E)$ e usando o fato do conjunto de todos os $\gamma_{k}^{*}$-comutadores de $E$ ser uniformemente conciso (Teorema 4.14) concluímos que o índice de $\left|\gamma_{k}^{*}(E): Z(E) \cap \gamma_{k}^{*}(E)\right|$ é $(m, k)$-limitado.

Sendo $x$ um $\gamma_{k}^{*}$-comutador de $E$ segue então que sua imagem no quociente $\gamma_{k}^{*}(E) / \gamma_{k}^{*}(E) \cap Z(E)$, possui ordem $(m, k)$-limitada. Consequentemente, existe um inteiro, digamos $n_{0}=n_{0}(m, k)$, tal que $x^{n_{0}} \in \gamma_{k}^{*}(E) \cap Z(E)$. Em particular, $x^{n_{0}} \in Z(E)$. Como $a_{0} \in E$ segue que $x^{n_{0}}$ e $a_{0}$ comutam. Por fim, como o elemento $a_{0}$ foi escolhido arbitrariamente em $G$ podemos então garantir que esse processo se repete a qualquer outro elemento de $G$. O lema está provado.

Agora estamos em posição de concluirmos a prova da Proposição 4.16.

A Prova da Proposição 4.16

Recorde que $G$ é um $\operatorname{BFC}(X)$-grupo finito tal que $\left|g^{X}\right| \leq m$ para todo $g \in G$. Sejam $a$ um elemento qualquer do grupo $G$ e $v_{1}, \ldots, v_{s-1}, v_{s}=1$, elementos de $X$, tomados tais que $s \leq m$ e com a propriedade que

$$
a^{X}=\left\{a^{v_{1}}, \ldots, a^{v_{s-1}}, a\right\}
$$

Seja $h \in K=\gamma_{\infty}(G)$ um elemento qualquer. Então $h$ pode ser escrito como um produto de um número finito de elementos de $X$, de modo que podemos assim repetir a prova do Lema 4.28 e mostrarmos que se $h=x_{1} \cdots x_{l}$, onde $x_{1}, \ldots, x_{l} \in X$ então

$$
a^{h}=a^{v_{i_{1}} v_{i_{2}} \cdots v_{i_{l}}}
$$

para adequados $i_{1}, \ldots, i_{l}$ tais que $1 \leq i_{1}, i_{2}, \ldots, i_{l} \leq s$. Considere a relação de boa ordem $<$ definida na seção anterior (página 69). Seja $v_{i_{1}} v_{i_{2}} \ldots v_{i_{l}}$ o menor produto 
dos elementos $v_{1}, \ldots, v_{s}$ tal que

$$
a^{h}=a^{v_{i_{1}} v_{i_{2}} \ldots v_{i_{l}}}
$$

Assim, segue que $i_{1} \geq i_{2} \geq \cdots \geq i_{l}$ (Lema 4.31). Equivalentemente, temos

$$
a^{h}=a^{v_{s-1}^{m_{s-1}} \ldots v_{2}^{m_{2}} v_{1}^{m_{1}}}
$$

para adequados inteiros não negativos $m_{1}, m_{2}, \ldots, m_{s-1}$, onde $s \leq m$. Como existe um inteiro positivo $n_{0}=n_{0}(m, k)$, tal que $x^{n_{0}} \in Z(G)$ para todo $x \in X$ (Lema 4.33), podemos supor que $m_{i} \leq n_{0}$ para todo $i=1,2, \ldots, s-1$. Assim, dado $a \in G$, segue que

$$
a^{h}=a^{u_{s-1}^{m_{s-1}} \ldots u_{2}^{m_{2}} u_{1}^{m_{1}}},
$$

com $m_{i} \leq n_{0}$ e $s \leq m$. Como $h \in K$, foi tomado arbitrariamente, concluímos então que $\left|a^{K}\right| \leq\left(n_{0}+1\right)^{m}$. A Proposição 4.16 está provada.

Tendo em vista as observações feitas na seção anterior, obtemos o seguinte corolário.

Corolário 4.17 Sejam $k \geq 2$ um inteiro e $G$ um grupo localmente finito. Denote por $X$ o conjunto de todos os $\gamma_{k}^{*}$-comutadores de $G$ e suponha que $G$ seja um $B F C(X)$ grupo tal que $\left|g^{X}\right| \leq m$ para todo $g \in G$. Então $\left|g^{\gamma_{k}^{*}(G)}\right|$ é $(m, k)$-limitado, para todo $g \in G$.

\subsection{A prova dos Teoremas 4.20 e 4.21}

Esta seção destina-se às demonstrações dos resultados centrais desse capítulo. O seguinte lema é uma consquência direta da Proposição 4.13.

Lema 4.34. Sejam $p$ um primo, $m$ um inteiro positivo e $V$ um p-grupo abeliano finito. Suponha que $H$ seja um $p^{\prime}$-grupo finito de automorfismos de $V$. Se $|[V, h]| \leq m$ para todo $h \in H$ então $|[V, H]|$ é m-limitado.

Demonstração. Seja $N=\Omega_{1}(V)=\left\{x \in V ; x^{p}=1\right\}$. Sendo $V$ abeliano, temos que $N$ é abeliano elementar (vide página 22). Além disso o Teorema 1.12 garante que $N$ é um subgrupo característico de $V$. Seja $h \in H$ um automorfismo tal que $x^{h}=x$, para todo $x \in N$. Denote por $A$ o subgrupo gerado por $h$. Logo $A$ age trivialmente sobre $N$ e, consequentemente, pelo Teorema 1.13 concluímos que $A=1$ e, em particular, decorre que $h=1$. Em outras palavras, $H$ age fielmente sobre $N$. Uma vez que $[N, h] \leq[V, h]$ 
para todo $h \in H$, concluímos que $|[N, h]| \leq m$ para todo $h \in H$. Consequentemente a Proposição 4.13 garante que a ordem do subgrupo $[N, H]$ é $m$-limitada. Esse mesmo resultado garante que $|H|$ é $m$-limitado. Novamente sendo $V$ abeliano temos que

$$
[V, H]=\sum_{h \in H}[V, h]
$$

Portanto $|[V, H]| \leq m|H|$. Como $|H|$ é $m$-limitado, o resultado segue. O lema está provado.

Agora estamos em condição de provar os Teoremas 4.20 e 4.21 .

A prova do Teorema 4.20

Recorde que $k \geq 2$ é um inteiro positivo e que $G$ é um grupo finito. Como de costume, denotaremos por $X$ o conjunto de todos os $\gamma_{k}^{*}$-comutadores de $G$. Suponha que $G$ seja um $\operatorname{BFC}(X)$-grupo tal que $\left|g^{X}\right| \leq m$ para todo $g \in G$. Mostraremos, sob estas condições, que o subgrupo $\gamma_{k}^{*}(G)$ possui ordem $(m, k)$-limitada.

Seja $K=\gamma_{k}^{*}(G)$. Então decorre da Proposição 4.16 que $K$ é um subgrupo BFC-imerso em $G$. Em particular, $K$ é um BFC-grupo tal que $\left|k^{K}\right| \leq n$, para todo $k \in K$, onde $n$ é um inteiro $(m, k)$-limitado. Consequentemente, $K^{\prime}$ possui ordem $(m, k)$ limitada (Teorema 1.32), onde $K^{\prime}$ denota o subgrupo derivado de $K$. Note que $K^{\prime}$ é normal em $G$, de modo que podemos considerar o quociente $G / K^{\prime}$ e, assim podemos supor que $K$ seja abeliano. Sendo $K$ um grupo finito, segue que $K$ coincide com o produto direto de seus subgrupos de Sylow. Logo, para concluirmos que $K$ possui ordem $(m, k)$-limitada é, suficiente que mostremos que cada um de seus subgrupos de Sylow possui ordem $(m, k)$-limitada. Seja $\pi(K)=\left\{p_{1}, \ldots, p_{s}\right\}$ o conjunto de todos os números primos divisores da ordem de $K$ e $P_{1}, \ldots, P_{s}$ os correspondentes subgrupos de Sylow de $K$. Tome $p_{i} \in \pi(K)$ e considere $P_{i}$ o respectivo subgrupo de Sylow de $K$. Passando ao quociente $G / O_{p_{i}^{\prime}}(G)$, onde $O_{p_{i}^{\prime}}(G)$ denota o $p_{i}^{\prime}$-subgrupo normal maximal de $G$, podemos, sem perda de generalidade, supor que $K=P_{i}$. Sendo $P_{i}$ abeliano, segue que $G$ é metanilpotente (Lema 4.10). Se $H$ for um $p_{i}^{\prime}$-subgrupo de Hall de $G$, então pelo Lema 4.11 concluímos que

$$
P_{i}=\left[P_{i}, H\right]
$$

Para cada $h \in H$ temos pelo Teorema 1.14 que

$$
P=[P, h] \times C_{P}(h) .
$$

Assim segue da Proposição 4.16 que $|[P, h]|$ é $(m, k)$-limitado. Pelo Lema 4.34 temos que $P=[P, H]$ possui ordem $(m, k)$-limitada. O teorema está provado. 


\section{A PROVA DO TEOREMA 4.21}

Sejam $k \geq 1$ um inteiro e $G$ um grupo finito. Denote por $X$ o conjunto de todos os $\delta_{k}^{*}$-comutadores de $G$. Suponha que seja $G$ um $\operatorname{BFC}(X)$-grupo tal que $\left|g^{X}\right| \leq m$ para todo $g \in G$. Mostraremos que o subgrupo $D_{k}(G)$ possui ordem $(m, k)$ limitada.

Seja $K=\langle X\rangle$. Pelo Lema 4.8(2) temos que $K=D_{k}(G)$. Decorre da Proposição 4.18 que $K$ é um subgrupo BFC-imerso em $G$. Em particular, $K$ é um BFC-grupo tal que $\left|g^{K}\right| \leq n_{0}$, para algum inteiro $n_{0}=n_{0}(m, k)$. Consequentemente, $K^{\prime}$ possui ordem $(m, k)$-limitada (Teorema 1.32). Note que $K$ é normal em $G$, de modo que podemos considerar o quociente $G / K^{\prime}$ e supor que $K$ seja abeliano. Assim, para concluirmos que a ordem de $K$ é $(m, k)$-limitada é, suficiente que mostremos que a ordem de cada um de seus subgrupos de Sylow seja $(m, k)$-limitada. Considere $\pi(K)=\left\{p_{1}, \ldots, p_{s}\right\}$, o conjunto de todos os números primos divisores da ordem de $K$, e $P_{1}, \ldots, P_{s}$ os correspondentes subgrupos de Sylow de $K$. Para cada $i=1, \ldots, s$ escolha um $p_{i}^{\prime}$-subgrupo de Hall em $Q=D_{k-1}(G)$. Se $a \in H_{i}$ então $P_{i}=\left[P_{i}, a\right] \times C_{P_{i}}(a)$ (Teorema 1.14). Portanto, pela Proposição 4.18 temos que $\left|\left[P_{i}, a\right]\right|$ é $(m, k)$-limitado para todo $a \in H_{i}$. Pelo Lema 4.34 concluímos que $\left|\left[P_{i}, H_{i}\right]\right|$ é $(m, k)$-limitado. Observe que $K=\gamma_{\infty}(Q)$ (Lema 4.8(2)) é abeliano e portanto pelo Lema 4.10 segue que $Q$ é metanilpotente. Pelo Lema 4.11 temos que $P_{i}=\left[P_{i}, H_{i}\right]$ para todo $i=1, \ldots, s$. Como a ordem de $K$ é justamente o produto da ordem de seus subgrupos de Sylow, o resultado segue. O teorema está provado.

Com a demonstração dos Teoremas 4.20 e 4.21 atingimos todos os objetivos propostos nesse capítulo e, assim o encerramos. 


\section{Referências Bibliográficas}

[1] Acciarri, C., Shumyatsky, P. and Thillaisundaram, A. Conciseness of Coprime Commutators in Finite Groups. Bulletin of the Australian Mathematical Society, 89 (2014), 252-258.

[2] Amberg, B. and Kazarin, L. On The Product of Two Chernikov Subgroups. Israel Journal of Mathematics, 175 (2010), 363-389.

[3] Andrade, A. F. and Shumyatsky, P. Bounding the order of the nilpotent residual of a finite group. Bulletin of the Australian Mathematical Society, doi.10.1017/S0004972716000150, to appear.

[4] BAER, R. Finite extensions of abelian groups with minimum condition. Trans. Amer. Math. Soc., 79 (1955), 521-540.

[5] Brazil, S., Krasilnikov, A. and Shumyatsky, P. Groups with bounded verbal conjugacy classes. J. Group Theory 9 (2006), 127-137.

[6] Casolo, C. Groups with all subgroups subnormal. Dipartimento di Matematica "Ulisse Dini", Università di Firenze, Italy, 2007.

[7] Cutolo, G. and Nicotera, C. Verbal sets and cyclic coverings. J. Algebra, 324 (2010), 1616-1624.

[8] Dixon, M. R., Kirichenko, V.V., Kurdachenko, L.A, Otal, J., Semko, N.N, Shemetkov, L.A and Subbotin I. Ya. S. N. Chernikov and the development of infinite group theory. Algebra and Discrete Mathematics (2), 13 (2012), 169-208.

[9] Fernández-Alcober, G.A and Morigi, M. Outer commutator words are uniformly concise. J. London Math. Soc. 82 (2010), 581-595.

[10] Fernández-Alcober, G.A and Shumyatsky, P. On groups in which commutators are covered by a finitely many cyclic subgroups. J. Algebra, 319 (2008), 4844-4851. 
[11] Franciosi, S., de Giovanni, F. and Shumyatsky, P. On group with finite verbal conjugacy classes. Houston J. Math. 28 (2002), 683-689.

[12] Fuchs, L. Abelian groups. Oxford: Pergamon (1960).

[13] Garcia, E.F FC-grupos e a subclasse dos FO-grupos. Dissertação de Mestrado, UnB, Brasília, (2004).

[14] Gorenstein, D. Finite Groups. Chelsea Publishing Company, New York (1980).

[15] Isaacs, I.M. Finite Group Theory. Amer. Math. Soc., vol, 92 (2008).

[16] Ivanov, S.V. P.Hall's conjecture on the finiteness of verbal subgroups. Soviet Math. 33 (1989), 59-70.

[17] Johnson, D.L. Presentations of groups. 2nd ed (London Mathematical Society student texts; 15, (1997).

[18] Kegel, O.H and Wehrfritz, B.A.F. Strong finiteness conditions in locally finite groups. Math. Z. v. 117 (1970), 309-324.

[19] Kegel, O.H and Wehrfritz, B.A.F. Locally finite groups. North-Holland, Amsterdam (1973).

[20] Khukhro, E. I. and Shumyatsky, P. Almost Engel Finite and Profinite Groups. arXiv:1512.0609 (2015).

[21] Kurosh, A. G. The Theory of Groups Vol. 1. 2nd ed (Chelsea Publishing Company, 1960).

[22] Lima, F. E. do Nascimento. Centralizadores em Grupos Localmente Finitos. Tese de Doutorado, UnB, Brasília (2013).

[23] Merzlyakov, Ju. I. Verbal and Marginal subgroups of linear groups. Dokl. Akad. Nauk SSSR 177 (1967), 1008-1011.

[24] Muñoz-Escolano, J.M and Shumyatsky, P. A finiteness condition for verbal conjugacy classes in a group. Publ. Math. Debrecen, 82/1 (2013), 97-105.

[25] Neumann, B.H. Groups covered by finitely many cosets. Publ. Math. Debrecen 3 (1954), 227-242.

[26] Neumann, B.H. Groups covered by permutable subsets. J. London Math. Soc. 29 (1954), 236-248. 
[27] Olshanskir, A.Yu. Geometry of defining relations in groups, Mathematics and its applications 70 (1991) (Soviet Series). Kluwer Academic Publishers, Dordrecht.

[28] Polovickir Ya. D. Locally extremal and layer-extremal groups. Mat. Sb. 58 (1962), 685-694.

[29] Robinson, D. J. S. A course in the Theory of Groups, 2nd ed. (SpringerVerlag, 1996).

[30] Robinson, D. J. S. Finiteness Condition and Generalized Soluble Groups, Part 1, (Springer-Verlag, 1972).

[31] Robinson, D. J. S. Finiteness Condition and Generalized Soluble Groups, Part 2, (Springer-Verlag, 1972).

[32] Rogério, J.R. and Shumyatsky, P. A finiteness condition for verbal subgroups. J. Group Theory 10 (2007), 811-815.

[33] Rose J. S. A course on Group Theory. 1st ed., (Dover, 2014).

[34] Schlette, A. Artinian, almost abelian groups and their group of automorphisms. Pacific J. Math., 29 (1969), 403-425.

[35] Schmidt, O.J. Infinite soluble groups. Mat. Sb. 17 (1945), 145-162.

[36] Shumyatsky, P. On the Exponent of a Verbal Subgroup in a Finite Group. Journal of the Australian Mathematical Society, v. 93 (2012), 325-332.

[37] Shumyatsky, P. Commutators of elements of coprime orders in finite groups. Forum Mathematicum, v. 27 (2015), 575-583.

[38] Shumyatsky, P. and Andrade, A.F. On groups with small verbal conjugacy classes. Publ. Math. Debrecen, v. 88/3-4 (2016), 477-485.

[39] Shunkov, V.P. On the minimality problem for locally finite groups. Algebra and Logic 9 (1970), 137-151.

[40] Tomkinson, M. J. FC-groups. Pitman, Boston (1984)

[41] Turner-Smith, R.F. Finiteness conditions for verbal subgroups. J. London Math. Soc. 41 (1966), 166-176.

[42] Wiegold, J. Groups with boundedly finite classes of conjugate elements. Proc. Roy. Soc. London Ser. A 328 (1957), 389-401.

[43] Wilson, J. On outer-commutator words. Can. J. Math. 26 (1974), 608-620. 


\section{Índice Remissivo}

$Y$-índice, 65

$\pi$-grupo, 23

$\pi$-subgrupo de Hall, 23

$w$-valor, 23

índice de um subgrupo, 18

ação

de grupos, 21

fiel, 21

trivial, 21

altura de Fitting, 25

automorfismo, 19

interno, 19

$\operatorname{BFC}(X)$-grupo, 63

$\operatorname{BFC}(w)$-grupo, 29

BFC-grupo, 29

centralizador

de um elemento, 19

de um subgrupo, 19

centro de um grupo, 19

classe de conjugação, 18

classe de conjugação verbal, 29

classe lateral, 18

cobertura de um grupo, 27

comutador, 19

$\delta_{k}$-comutador, 24

$\delta_{k}^{*}$-comutador, 60

$\gamma_{k}$-comutador, 24

$\gamma_{k}^{*}$-comutador, 60

condição de cadeia descendente, 36

condição minimal para subgrupos, 36 elemento minimal, 36

FC

centro, 28

elemento, 28

grupo, 28

FC(w)-grupo, 29

fecho normal, 19

grupo

p-grupo, 22

p-grupo abeliano elementar, 22

camadas finitas (finite-layer), 38

central-por-finito, 27

de Chernikov, 36

de expoente finito, 25

hipercentral, 31

localmente finito, 26

localmente- $X, 27$

metanilpotente, 62

nilpotente, 25

periódico (ou de Torção), 25

quase-cíclico (Prüfer), 32

radicável (divisível), 32

residualmente finito, 28

solúvel, 25

grupo de automorfismos, 21

grupo dos pontos fixos, 21

hipercentro de um grupo, 31

homomorfismo, 19

isomorfismo, 19 
Lema dos Três Subgrupos, 21

normalizador de um subgrupo, 19

palavra, 23

central inferior, 24

concisa, 29

derivada, 24

parte radicável, 36

residual finito, 37

residual nilpotente, 61

série inferior de Fitting, 61

série superior de Fitting, 25

subconjunto normal, 19

subgrupo

BFC-imerso, 30

de Fitting, 25

derivado, 19

FC-imerso, 30

gerado por um conjunto, 18

verbal, 24

tamanho (grupo de Chernikov), 38

transversal, 18 